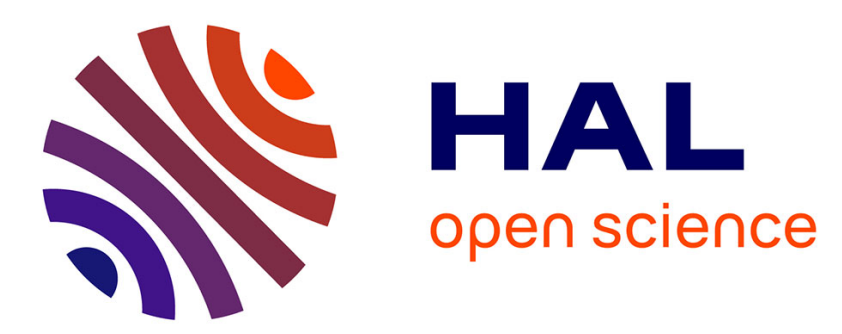

\title{
State of art and recent trends in bulk carbon nitrides synthesis
}

\author{
Graziella Goglio, Denis Foy, Gérard Demazeau
}

\section{To cite this version:}

Graziella Goglio, Denis Foy, Gérard Demazeau. State of art and recent trends in bulk carbon nitrides synthesis. Materials Science and Engineering: R: Reports, 2008, 58 (6), pp.195-227. 10.1016/j.mser.2007.10.001 . hal-00195408

\section{HAL Id: hal-00195408 \\ https://hal.science/hal-00195408}

Submitted on 8 Apr 2009

HAL is a multi-disciplinary open access archive for the deposit and dissemination of scientific research documents, whether they are published or not. The documents may come from teaching and research institutions in France or abroad, or from public or private research centers.
L'archive ouverte pluridisciplinaire HAL, est destinée au dépôt et à la diffusion de documents scientifiques de niveau recherche, publiés ou non, émanant des établissements d'enseignement et de recherche français ou étrangers, des laboratoires publics ou privés. 


\section{State of Art and Recent Trends}

\section{in Bulk Carbon Nitride Synthesis}

\section{Graziella GOGLIO*, Denis FOY and Gérard DEMAZEAU}

Institut de Chimie de la Matière Condensée de Bordeaux - CNRS

Université Bordeaux 1

87 av. Dr A. Schweitzer, 33608 PESSAC Cedex, France

*corresponding author: goglio@icmcb-bordeaux.cnrs.fr

$$
\begin{aligned}
& \text { Tel : }+33(0) 540006334 \\
& \text { Fax : }+33(0) 540002761
\end{aligned}
$$




\begin{abstract}
Light elements-based materials are of relevant interest because of their specific physicochemical properties mainly dependent on the involved strong chemical bonds. Among them, diamond and c-BN are still today the most representative materials especially concerning super hardness property. Nevertheless, since the prediction by Liu and Cohen (on the basis of ab initio calculation) of theoretical materials with $\mathrm{C}_{3} \mathrm{~N}_{4}$ composition exhibiting low compressibility, many efforts have been devoted to the synthesis of carbon nitrides.

The first part of this review deals with the brief description of the different predicted $\mathrm{C}_{3} \mathrm{~N}_{4}$ polymorphs exhibiting either a dense network or a graphitic one. In addition, predicted carbon nitrides with different stoichiometry are also described.

The second part presents the analysis of the processing routes described in the literature for the synthesis of carbon nitrides as bulk materials. If many attempts have been devoted to high-pressure processes (direct synthesis, direct conversion from the graphitic form, flux assisted conversion or solvothermal processes), some experiments performed in moderate experimental conditions have also been investigated and appear as really promising. A comparison with the different processes developed for diamond and c-BN is associated.
\end{abstract}

As a conclusion, a discussion about the promising routes related to bulk carbon nitrides synthesis is given.

Keywords $: \quad \mathrm{C}_{3} \mathrm{~N}_{4}$; carbon nitride; synthesis; hard materials; high pressure ; solvothermal synthesis 


\section{Introduction}

Light elements-based materials which associate $2 p$ and $3 p$ elements mainly from columns III to $\mathrm{V}$ are of great interest due to their various physicochemical properties: because of the chemical bond strength induced by the short atomic distance they exhibit very high hardness $(\mathrm{H})$, high chemical inertia, good thermal conductivity, optical transparency on a wide wave number range, highly refractory character (if atmosphere does not induce a chemical degradation) and electronic insulator behaviour with high band gap values.

Among all these properties, hardness is the most representative. It represents the ability of a solid to resist the penetration of a hardest material. As a consequence ultrahard materials will undergo slight deformations. On the microscopic level, for ideal solids, hardness $(\mathrm{H})$ can be evaluated by the bulk modulus (B), superhard covalent materials necessarily exhibiting high $\mathrm{B}$ values. The excessive hardness and bulk modulus in light elements-based materials as diamond are induced by two main factors: the short interatomic distances, inducing a high covalency of the chemical bonds and the threedimensional crystalline network. To date, diamond is the hardest known material which makes it particularly suitable for applications such as cutting, drilling, grinding or polishing tools. Nevertheless its chemical reactivity in presence of ferrous metals or oxygen at high temperature leads to the formation of iron carbide or carbon oxide respectively. These experimental restrictions involve that the research of new superhard materials has become a world-wide challenge [1,2].

In 1956, cubic boron nitride with blende-type structure has been synthesized under high pressure [3]. While isoelectronic and isostructural with diamond, it is nevertheless less impressive from mechanical and thermal point of view due to the heteropolar B-N bond. 
It appears however interesting because it is less chemical reactive in presence of ferrous metals.

In 1989, Liu and Cohen have proposed an empirical model to define the bulk modulus of covalent solids as a function of average coordination number $\mathrm{N}_{\mathrm{c}}$, ionicity parameter $\lambda$ and bond length $d: B=1 / 4 N_{c}(1971-220 \lambda) d^{-3.5}$ [4-5]. According to this formula and on the basis of the $\beta-\mathrm{Si}_{3} \mathrm{~N}_{4}$ structure, the authors have claimed the existence of an hypothetic material $\beta-\mathrm{C}_{3} \mathrm{~N}_{4}$ which expected mechanical properties were of relevant interest. Then, many efforts have been devoted to the study of this promising material and other derived polymorphs. Theoretical and experimental studies have been performed in order to determine and elaborate superhard carbon nitrides of general $\mathrm{CN}_{\mathrm{x}}$ formula with high mechanical performances.

Concerning the elaboration, two main preparation routes have been developed: carbon nitrides have been obtained either as thin films or as bulk materials. Many publications devoted to $\mathrm{CN}_{\mathrm{x}}$ thin film elaboration have allowed concluding that the existence of crystalline stoichiometric $\mathrm{C}_{3} \mathrm{~N}_{4}$ has not been clearly evidenced yet. To date, the soobtained deposits are generally mainly amorphous and can eventually contain nanometric $\mathrm{CN}_{\mathrm{x}}$ crystallites [6,7]. However, these amorphous thin films seem to present interesting mechanical, tribological and optical properties [8-11].

We propose here a State of Art devoted to the elaboration of bulk carbon nitrides. The first part briefly reminds the various polymorphs predicted either with $\mathrm{C}_{3} \mathrm{~N}_{4}$ stoichiometry or not. In the second one, a description of processes involved for the synthesis of diamond and cubic boron nitride is first given. We then analyze experimental results obtained concerning the elaboration of carbon nitrides according to 
different routes and in softer conditions. In this way, promising trends are finally discussed.

\section{Description of carbon nitrides}

\section{II.1. About carbon nitrides among the family of light elements-based materials}

Studies on light elements based materials date back to middle of the $\mathrm{XIX}^{\text {th }}$ century. Since Lavoisier evidenced that diamond was a structural form of carbon, much denser than graphite, many researches have been devoted to its synthesis under high pressure [12-15]. In 1939, in order to favour the graphite $\rightarrow$ diamond conversion, Leipunskii suggested to use a flux able to dissolve partially graphite as precursor [14]. Bulk diamond elaboration was first achieved in 1953 by Liander et Lundlab, from ASEA Company (Sweden) who performed High Pressure-High Temperature route (HPHT) using melt iron as flux able to dissolve graphite [16]. This result was confirmed in 1955 by Bundy et al. from General Electric (USA) [17]. In 1958 Eversole has attempted to elaborate diamond thin films by Chemical Vapor Deposition (in the thermodynamic domain where the dense diamond form is metastable). Due to the small efficiency of such a process (diamond coexisting with graphite), different authors proposed an hydrogen-rich gaseous flow for eliminating graphite (due to its higher chemical reactivity) in order to obtain only diamond grains [18-21]. Moreover because geochemical studies about diamond elaboration into the mantle of the Earth have revealed the great influence of the crustal fluids [22-23], new solvothermal synthesis routes were also studied during these last fifteen years mainly using carbon precursors in presence of water [24-32]. 
The second light elements based material to be evidenced was boron nitride ( $\mathrm{B}, \mathrm{N}$ being isoelectronic of two carbons) which, unlike carbon, is not a natural compound. It presents three different polymorphs: blende-, wurtzite- and graphitic-type structures. Cubic boron nitride (c-BN, blende type) was first elaborated in 1957 by Wentorf from General Electric (USA) performing direct conversion process of graphitic boron nitride $\left(7 \mathrm{GPa}, 1500^{\circ} \mathrm{C}\right)$ [3]. This polymorph exhibits properties competitive with those of diamond and its bulk modulus reaches $367 \mathrm{GPa}$ (see Table I). c-BN applications are devoted to cutting tools and manufacturing of ferrous alloys due to its lower chemical affinity for iron. Moreover, it can be considered as the first III-V material (others being AlN, GaN, InN...) which induces potential applications (nowadays limited by crystal growth) in optoelectronics due to laser emission at the pn junction of two single crystals [33-35].

Interest for carbon nitrides has been initiated by research on materials exhibiting mechanical properties comparable with those of diamond. The evolution of bulk modulus B as a function of interatomic distance $\mathrm{d}$ in light elements-based materials with three-dimensional structures and in predicted $\beta-\mathrm{C}_{3} \mathrm{~N}_{4}$ is presented on Table $\mathrm{I}$. Experimental hardness is also reported. The bulk modulus of diamond in comparison with those of $\mathrm{c}-\mathrm{BN}$ and $\beta-\mathrm{Si}_{3} \mathrm{~N}_{4}$ is higher because this carbon polymorph (homopolar $\mathrm{C}$ C bond) is the most covalent $(\lambda=0)$ with the highest coordination number (4 instead of 3 for c-BN and $24 / 7$ in $\beta-\mathrm{Si}_{3} \mathrm{~N}_{4}$ ) and the shortest interatomic distances (the more $\mathrm{d}$ decreases, the more B increases which is due to the enhancement of the orbital overlap). Conversely, due to its longest bond distance (Silicon being a $3 p$ element) and decreasing of covalency, $\beta-\mathrm{Si}_{3} \mathrm{~N}_{4}$ exhibits the lowest bulk modulus and consequently the lowest hardness $\mathrm{H}$. In this sense, some works have been devoted to research of the 
diamond-like $\mathrm{BC}_{2} \mathrm{~N}$ ternary system [36-37]. Recently, Solozhenko et al. have elaborated c- $\mathrm{BC}_{2} \mathrm{~N}$ by direct conversion under $18 \mathrm{GPa}$ and around $2000^{\circ} \mathrm{C}$ of graphitic $\mathrm{BC}_{2} \mathrm{~N}$ [38]. As expected this material exhibits mechanical properties (hardness and elastic modulus) intermediate between diamond and c-BN [39]. In case of theoretical $\beta-\mathrm{C}_{3} \mathrm{~N}_{4}$, as presented in Table I, the most favourable interatomic distance in comparison with diamond compensates the weak decreasing of covalency associated with a lower average coordination number. As a consequence this carbon nitride exhibits a predicted $\mathrm{B}$ higher than c-BN and close to diamond bulk modulus. Then as $\mathrm{B}$ and $\mathrm{H}$ evolve in the same way for light elements-based materials, one can then clearly consider the great interest of carbon nitrides family. Then, due to expected impressive mechanical properties not only for $\beta-\mathrm{C}_{3} \mathrm{~N}_{4}$ but also for other dense polymorphs, the research of new carbon nitrides has then aroused a world-wild interest.

\section{II.2. Structural description of predicted $C_{3} N_{4}$ polymorphs}

Several polymorphs have been proposed exhibiting either a three-dimensional (3D) structure or a two-dimensional (2D) one.

\section{II.2.1. Dense $C_{3} N_{4}$ structures}

As $\beta-\mathrm{Si}_{3} \mathrm{~N}_{4}$ was, at the beginning, used as structural model, $\beta-\mathrm{C}_{3} \mathrm{~N}_{4}$ has been the first polymorph to be predicted (Fig. 1a) [4]. The structure consists in a complex network of $\mathrm{CN}_{4}$ tetrahedra that are linked at the corners. This ordering ensures a slightly distorted tetrahedral site for carbon and a planar triply coordinated site for nitrogen. Therefore, it is in agreement with $\mathrm{sp}^{3}$ and $\mathrm{sp}^{2}$ hybridizations on carbon and nitrogen respectively. Authors have proposed either $\mathrm{P} 3$ [40-41] or $\mathrm{P}_{3} / \mathrm{m}$ [42] as space group for this structure. 
$a$ and $c$ parameters of the hexagonal unit cell $\left(2 \mathrm{C}_{3} \mathrm{~N}_{4}\right.$ formula units $)$ are claimed in the ranges 6.35-6.47 $\AA$ and 2.397-2.467 $\AA$ respectively.

In the same way, $\alpha-\mathrm{C}_{3} \mathrm{~N}_{4}$ has been deduced from $\alpha-\mathrm{Si}_{3} \mathrm{~N}_{4}$, replacing silicon by carbon (Fig. 1b). The structure, which has been first studied by Guo et Goddard in 1995 [40] then by Teter and Hemley in 1996 [41], still consists in a network of corners-linked $\left(\mathrm{CN}_{4}\right)$ tetrahedrons, carbon and nitrogen adopting $\mathrm{sp}^{3}$ and $\mathrm{sp}^{2}$ hybridizations respectively. $\alpha-C_{3} N_{4}$ can be described as $A B A B$ stacking where $A$ represents the $\beta$ $\mathrm{C}_{3} \mathrm{~N}_{4}$ unit cell and $\mathrm{B}$ is $\mathrm{A}$ mirror reflection. $c$ parameter of $\alpha-\mathrm{C}_{3} \mathrm{~N}_{4}$ structure is then twice $c$ of $\beta-\mathrm{C}_{3} \mathrm{~N}_{4}$ polymorph. $a$ and $c$ parameters of the hexagonal cell containing four $\mathrm{C}_{3} \mathrm{~N}_{4}$ formula units have been predicted in the ranges $6.35-6.47 \AA$ and $4.64-4.71 \AA$ respectively. For $\alpha-\mathrm{C}_{3} \mathrm{~N}_{4}$ structure authors have proposed $\mathrm{P} 3_{1} \mathrm{c}$ as space group.

Pseudocubic $\mathrm{C}_{3} \mathrm{~N}_{4}$ polymorph is isostructural to $\alpha-\mathrm{CdIn}_{2} \mathrm{Se}_{4}[45]$ and has been firstly proposed by Liu and Wentzcovitch [42] (Fig. 1c). It is also called zinc blende-type as it can be described from c-BN structure taking into account carbon vacancies $\left(\left(C_{3} \square\right) \mathrm{N}_{4}\right)$. The network consists of corners-linked $\mathrm{CN}_{4}$ tetrahedrons in such a way that the $C N C$ angle is close to $109^{\circ}$, which ensures $\mathrm{sp}^{3}$ hybridization for nitrogen (carbon hybridization being the same). Authors have proposed either P-43m [42] or P-42m [41] as space group for this structure. The unit cell is cubic and contains one $\mathrm{C}_{3} \mathrm{~N}_{4}$ formula unit. $a$ parameter is estimated in the range $3.41-3.44 \AA$.

Cubic $\mathrm{C}_{3} \mathrm{~N}_{4}$ is a polymorph isostructural to $\mathrm{Zn}_{2} \mathrm{SiO}_{4}$ high pressure structure which has been proposed by Teter and Hemley (Fig. 1d) [41]. The network consists of cornerslinked $\mathrm{CN}_{4}$ tetrahedrons, the $\mathrm{CNC}$ angle close to $109^{\circ}$ still ensuring in this case $\mathrm{sp}^{3}$ hybridization for nitrogen (carbon hybridization being the same). Two space groups 
have been proposed : I-43d [41] and F43m [46]. Here $a$ parameter is claimed in the range 5.395-5.444 $\AA$.

Finally, Mo et al. [47] and later Kroll [48] have proposed cubic $\gamma-\mathrm{C}_{3} \mathrm{~N}_{4}$ polymorph derivated from $\gamma-\mathrm{Si}_{3} \mathrm{~N}_{4}$ spinel high pressure structure. The predicted space group is Fd$3 \mathrm{~m}$ with $a$ parameter equal to $6,872 \AA$ [47] or $6,782 \AA$ [48]. Here nitrogen atoms are localized by their average position on anionic sites in spinel structure and $\mathrm{x}_{\mathrm{sp}} \mathrm{a}$ corrective factor associated to the small size of $\mathrm{N}$. The localization of carbon can be described from the following formula $\left(\mathrm{C}_{2}\right)_{\mathrm{Oh}}(\mathrm{C})_{\mathrm{Td}} \mathrm{N}_{4}$ where $\mathrm{C}$ atoms occupy both octahedral and tetrahedral sites of the CCF nitrogen network. Due to the difficulty to stabilize carbon in octahedral coordination such a structural form would be elaborated in the highest pressure conditions.

The most relevant difference between these structures deals with the hybridization of nitrogen and carbon. In case of $\beta$ - and $\alpha-\mathrm{C}_{3} \mathrm{~N}_{4}$, carbon adopts $\mathrm{sp}^{3}$ hybridization while nitrogen one is $\mathrm{sp}^{2}$. In pseudocubic or cubic $\mathrm{C}_{3} \mathrm{~N}_{4}$, both carbon and nitrogen exhibit $\mathrm{sp}^{3}$ hybridization.

Theoretical values of bulk modulus B for these four polymorphs are reported in Table II. For a given structure, B values are quite homogeneous apart those corresponding to MSFF [40] and DFT-LDDA [43] calculation methods which seem to be under and over estimated respectively. Concerning $\beta-\mathrm{C}_{3} \mathrm{~N}_{4}$, the $\mathrm{B}$ calculated values are very high (the LDA values are in the range 421-451 GPa) and close to that of diamond (443 GPa). Values predicted for $\alpha-\mathrm{C}_{3} \mathrm{~N}_{4}$ bulk modulus are scattered however the value obtained by LDA calculations $(425 \mathrm{GPa})$ is really close to $\mathrm{B}$ calculated with the same ab initio method for $\beta-\mathrm{C}_{3} \mathrm{~N}_{4}$ which sounds logical considering the structural similarities between these two structures. Same tendency is also observed in case of $\alpha$ - and $\beta-\mathrm{Si}_{3} \mathrm{~N}_{4}$ 
polymorphs which bulk modulus are close (228 and 219 GPa respectively) [49]. The calculated bulk modulus for pseudocubic $\mathrm{C}_{3} \mathrm{~N}_{4}$ are still very high in the range 430$448 \mathrm{GPa}$ according to LDA calculation. These expected values are comparable with those predicted for $\alpha$ - and $\beta$ - forms despite the fact that the planar surrounding of nitrogen is less isotropic than in tetrahedral coordination. Nevertheless, the close densities of these three structures can explain the same compressibility behaviour. Finally, cubic polymorph is expected the hardest one with bulk modulus higher than diamond. In this case, the structure is slightly denser than others, which can explain this weak B increased value.

\section{II.2.2. Graphitic $C_{3} N_{4}\left(g-C_{3} N_{4}\right)$}

This polymorph consists of the stacking along $c$ axis of graphitic planes. In the hexagonal graphitic $\mathrm{C}_{3} \mathrm{~N}_{4}$, Teter and Hemley have first described this graphitic planes as hexagonal organization of $\left(\mathrm{C}_{3} \mathrm{~N}_{3}\right)$ triazine cycles (Fig. 2a) [41]. The bonding between cycles is ensured by supplementary nitrogen that is linked to three cycles. In this structure, while carbon is only present with $\mathrm{sp}^{2}$ hybridization, $\mathrm{N}$ exhibits $\mathrm{sp}^{2}$ and $\mathrm{sp}^{3}$ hybridizations into and between the cycles respectively.

On the basis of transmission electronic microscopy characterization of graphitic carbon nitride synthesized under high pressure, Alves et al. have proposed another $\left(\mathrm{C}_{3} \mathrm{~N}_{3}\right)$ linking into the planes (Fig. 2b) [50]. Here, the $\left(\mathrm{C}_{3} \mathrm{~N}_{3}\right)$ cycles can be bonded one to another by two different ways: (i) direct $\mathrm{sp}^{2} \mathrm{~N}-\mathrm{sp}^{3} \mathrm{~N}$ bonding between two nitrogen atoms belonging to two adjacent cycles and (ii) bonding via $\mathrm{sp}^{2} \mathrm{~N}$ which does not belong to the cycles. 
Moreover, many stacking ways have been considered. The ABCABC stacking has been proposed by Liu and Wentzcovitch and is compatible with R3m space group [42]. Teter and Hemley have proposed the $\mathrm{AB}$ stacking which is in agreement with $\mathrm{P} 6 \mathrm{~m} 2$ space group [41]. AA stacking has also been suggested [51]. Interplanar distance is expected to vary as $3.45 \AA, 3.36 \AA$ and $3.06 \AA$ according to the $\mathrm{AA}, \mathrm{AB}$ and $\mathrm{ABC}$ stacking modes respectively.

As expected for graphitic polymorph, the bulk modulus is very low which is consistent with lamellar structure (Table II).

\section{II.3. Carbon nitrides predicted with a stoichiometry different from $C_{3} N_{4}$}

While many predicted carbon nitrides exhibit the $\mathrm{C}_{3} \mathrm{~N}_{4}$ stoichiometry, first synthesis mainly devoted to thin films elaboration have early evidenced the great difficulty to obtain a $\mathrm{C}: \mathrm{N}$ ratio equal to 0.75 . Côté and Cohen [52], on the basis of ab initio calculations, have then thought of new structural models for 1:1 C:N stoichiometry. Eight structural types have been selected: two cubic ones (rock salt- and blende- types), one rhombohedral (buckled carbon nitride sheets with interplanar covalent bonds), one orthorhombic based on $\beta-\operatorname{InS}$ structure, one tetragonal based on high pressure GeP polymorph and three hexagonal forms, two of them called bct- 4 and H- 6 being three dimensional networks of pure $\mathrm{sp}^{2}$ bonded solids and the last one being isostructural of GaSe. Calculations have evidenced that (i) all cubic phases are unstable and relax to the rhombohedral structure, (ii) the most stable phase is of GaSe-type and consists in layers linked one to another by $\mathrm{C}-\mathrm{C}$ bonds which are perpendicular to the planes (the calculated bulk modulus is $199 \mathrm{GPa}$ ), (iii) finally, bulk modulus calculated for bct- 4 and 
H-6 are high (375 and $345 \mathrm{GPa}$ respectively) and comparable with same polymorphs consisting of pure carbon or with cubic boron nitride.

In the purpose to explain nitrogen departure during the synthesis of carbon nitride thin films by CVD process, Betranhandy has suggested - on the basis of $\mathrm{FeS}_{2}$ pyrite as structural model - two hypothetical materials with different $\mathrm{C}: \mathrm{N}$ stoichiometries : $\mathrm{CN}_{2}$ and $\mathrm{C}_{2} \mathrm{~N}$ [53-54]. $\mathrm{AX}_{2}$ compounds with the pyrite structure contain $\mathrm{X}_{2}$ diatomic entities $\left(\mathrm{N}_{2}\right.$ in case of $\mathrm{CN}_{2}$ and $\mathrm{C}_{2}$ in case of $\left.\mathrm{C}_{2} \mathrm{~N}\right)$ in the octahedral holes of an FCC sublattice of $\mathrm{A}$ atom $\left(\mathrm{C}\right.$ in $\mathrm{CN}_{2}$ and $\mathrm{N}$ in $\left.\mathrm{C}_{2} \mathrm{~N}\right)$. He has then studied the consequences of cell distorsions under stress. Concerning $\mathrm{CN}_{2}, \mathrm{~N}_{2}$ molecule is formed while $\mathrm{C}_{2} \mathrm{~N}_{2}$ cyanogens groups departure has been evidenced for $\mathrm{C}_{2} \mathrm{~N}$ which allows to explain carbon and nitrogen rearrangement as $\mathrm{CN} \bullet$ radicals.

As many reported studies claimed nitrogen under stoichiometry induced by the great stability of $\mathrm{N}_{2}$ molecule, Sandré et al. [55] have proposed many structural models for the composition $\mathrm{C}_{3} \mathrm{~N}$ making the substitution of one quarter of carbon atom by nitrogen in the carbon graphite structure. Optimized ab initio calculations have then led to two 2D structures (called graphitic 1 and graphitic 2) and two $3 \mathrm{D}$ ones (called poly- $\mathrm{C}_{3} \mathrm{~N}-\mathrm{a}$ and poly- $\mathrm{C}_{3} \mathrm{~N}-\mathrm{b}$ ) with orthorhombic symmetry. Authors mainly insist on the fact that dynamic structural transformations from one polymorph to another are favoured which makes very difficult structural characterizations.

\section{The different routes for the synthesis of carbon nitrides as bulk materials}

For materials synthesis the use of temperature is the classical way to improve both diffusion processes and the reactivity of precursors. Nevertheless, in case of carbon 
nitrides, the strong stability of the $\mathrm{N}_{2}$ molecule competes with the formation of the chemical bonds $\mathrm{C}-\mathrm{N}$ that damages the elaboration of the required material. In this sense, pressure parameter could improve such a chemical reactivity, which consequently allows to lower processes temperatures then favouring the formation of carbon nitrides.

\section{III.1. The role of pressure in Materials Chemistry}

Pressure parameter has been taken into account only at the middle of the XVII ${ }^{\text {th }}$ century. The development either of basic researches or applied ones have allowed to understand its effects in Materials Chemistry under some few bar at the beginning of the XVIII ${ }^{\text {th }}$ century and up to 400 GPa nowadays (diamond anvils cell technology).

Compared to temperature, the energy associated to high pressures is small Consequently pressure plays an important role for materials synthesis through different specific phenomena: densification effect, stabilization of thermally unstable precursors or improvement of the chemical reactivity.

(i) The densification effect implies that the volume variation $\Delta \mathrm{V}$ between the final products and the precursors is only characterized by a negative value, $\Delta \mathrm{V}$ being defined as: $\Delta \mathrm{V}=\Sigma$ (volumes per formula for products) $-\Sigma$ (volumes per formula for precursors). This effect is a key factor for the understanding and definition of phases diagrams. Thus under high pressures novel phases can be stabilized in comparison with that elaborated only under temperature. As an illustration, in the system $\mathrm{Al}_{2} \mathrm{O}_{3}-\mathrm{B}_{2} \mathrm{O}_{3}$ at ambient pressure and $900^{\circ} \mathrm{C}$, two different compositions can be prepared: $9 \mathrm{Al}_{2} \mathrm{O}_{3}$ $2 \mathrm{~B}_{2} \mathrm{O}_{3}$ and $2 \mathrm{Al}_{2} \mathrm{O}_{3}-\mathrm{B}_{2} \mathrm{O}_{3}$. On the contrary using the same temperature $\left(900^{\circ} \mathrm{C}\right)$ but under a high pressure close to $5 \mathrm{GPa}$ the previous compositions are not observed and two new ones corresponding to $\mathrm{Al}_{2} \mathrm{BO}_{6}$ and $\mathrm{AlBO}_{3}$ can be prepared [56]. 
(ii) Temperature applied for activation of chemical processes can lead to the formation of a gaseous phase (due to sublimation or decomposition of some precursors). Consequently the resulting stoichiometry of the final products can be modified. With respect to Le Chatelier law, the impliement of pressure can impede such phenomena through a consecutive increase of the temperature necessary to induce the sublimation or decomposition of the reagents and consequently favours the stoichiometry of the resulting material.

Such a stabilization of thermally unstable precursors under high pressures have been used either for the synthesis of new oxides (as for example $\mathrm{PbCrO}_{3}$ resulting of a chemical reaction between $\mathrm{PbO}$ and $\mathrm{CrO}_{2}$ - both thermally unstable [57]) but also for preparing nitrides (as metallic nitridophosphates from $\mathrm{P}_{3} \mathrm{~N}_{5}[58]$ ).

(iii) The chemical reactivity is an important parameter for the formation of chemical bonds and consequently for the synthesis of novel materials. With high pressures, the reaction temperature and the reaction time are considerably reduced compared to the same reaction carried out at normal pressure [59]. The synthesis of $\mathrm{LaFeO}_{3}$ can be given as an illustration : using the same precursors $\mathrm{La}_{2} \mathrm{O}_{3}$ and $\mathrm{Fe}_{2} \mathrm{O}_{3}$ and the same reaction temperature $\left(1100^{\circ} \mathrm{C}\right)$ the reaction time at normal pressure is close to 30 hours whereas 15 minutes are sufficient at $5 \mathrm{GPa}$ for obtaining pure $\mathrm{LaFeO}_{3}$.

Reactivity is also improved under high pressure conditions for chemical reactions involving a solid and a liquid phase as different mechanisms can be involved : dissolution-recrystallisation, physico-chemical phenomena at the interface [60]... Such reactions performed in a close system are called solvothermal reactions.

Then, in order to favour $\mathrm{C}_{3} \mathrm{~N}_{4}$ stoichiometry and the formation of dense polymorphs, pressure seems to be a powerful tool. 


\section{III.2. Analysis of the different chemical reactions involved for the synthesis of}

\section{light elements-based materials under pressure}

The following analysis will be mainly based on the synthesis routes developed for preparing the two superhard materials considered as references: diamond and cubic boron nitride.

Both materials can exist on two main structural forms: 2D as the graphitic structures and $3 \mathrm{D}$ as the zinc blende-type structure or wurtzite-type structure. The considered reactions involve the stabilization of the dense structures that are preferably researched due to their potential physico-chemical properties [31]. Two main ways can be considered : either one should think about the direct synthesis of the dense phase or the conversion process which will involve a phase transition from $2 \mathrm{D}$ towards $3 \mathrm{D}$ polymorph.

In this last case, due to the strong densification effect occurring during the $2 \mathrm{D} \rightarrow 3 \mathrm{D}$ transition (for example $\Delta \mathrm{V} / \mathrm{V} \approx-40 \%$ in the case of the transition graphite $\rightarrow$ diamond) high pressures have played an important role for stabilizing either diamond or c-BN [61].

\section{III.2.1. Direct synthesis of the dense form}

This synthesis route consists of the direct elaboration of diamond or c-BN involving a reaction between chemical reagents under high static pressures. Such a direct synthesis has been not yet widely investigated due to the weak chemical reactivity of the starting chemicals and/or their high cost for a future industrial development. In the case of diamond synthesis, the chemical reaction between fluorinated carbon $\left(\mathrm{CF}_{\mathrm{x}}\right)$ and 
magnesium according to equation 1 performed at a pressure close to $6 \mathrm{GPa}$ and a temperature slightly higher than that of the melting point of $\mathrm{Mg}$ can be given as illustration [62]: 2/x $\mathrm{CF}_{\mathrm{x}}+\mathrm{Mg} \rightarrow \mathrm{MgF}_{2}+\mathrm{C}_{\text {diam }}$ (equation 1).

\section{III.2.2. Direct conversion under static or dynamic high pressure}

The direct conversion is described as the structural transformation of a $2 \mathrm{D}$ phase towards a 3D one under pressure and temperature conditions without modification of the chemical composition. Apparatus that are commonly used such as belt type, multi anvils press or diamond anvils cell generate static high pressure.

Due to the absence of structural relations between layered and dense polymorphs, it is necessary to break chemical bonds in order to reconstruct the 3D lattice. Consequently the required static pressure and temperature conditions are severe $(\mathrm{P} \approx 12 \mathrm{GPa}$ and $\mathrm{T} \approx 2000^{\circ} \mathrm{C}$ for the direct transformation graphite $\rightarrow$ diamond [63-65]; $\mathrm{P} \approx 10 \mathrm{GPa}$, $\mathrm{T} \approx 1800^{\circ} \mathrm{C}$ in the case of $\mathrm{h}-\mathrm{BN} \rightarrow \mathrm{c}-\mathrm{BN}[66]$.

Moreover due to kinetics characterizing the phase transitions when dynamic pressures are applied, such processes have been recently tried out because they appear particularly appropriated for industrial applications.

In such a way, the formation of diamond microcrystallites by the detonation of condensed explosive has attracted a considerable attention during the eighties (19851995) [67-70]. The direct conversion process through dynamic pressure was also developed for producing small c-BN crystallites [71-74]. 


\section{III.2.3. Flux assisted conversion}

The flux assisted conversion process can be described as a structural transformation $2 \mathrm{D} \rightarrow 3 \mathrm{D}$ in presence of a flux under high pressure and temperature conditions. Such a process is based on the difference of the $2 \mathrm{D}$ and $3 \mathrm{D}$ phases solubility into the flux. For graphite $\rightarrow$ diamond conversion, in order to reduce the required pressure and temperature, different metallic flux compositions able to improve the graphite solubility have been developed (Ni, $\mathrm{Co}, \mathrm{Fe}, \mathrm{NiMnCo....)} \mathrm{[75-76].} \mathrm{In} \mathrm{the} \mathrm{case} \mathrm{of} \mathrm{h-BN} \rightarrow \mathrm{c}-\mathrm{BN}$ conversion, the flux is generally an eutectic composition between h-BN and a boron nitride as for example $\mathrm{Ca}_{3} \mathrm{~B}_{2} \mathrm{~N}_{4}$ [77]. In order to improve h-BN solubility, development of fluxes characterized by a high ionicity (as nitrofluorides [78-79]) has led to a better conversion yield.

Nevertheless works about diamond and cubic boron nitride have evidenced the difficulty to reduce the conversion temperature due to that required for the flux formation and the high melting point of alloys, nitrides and derived materials.

\section{III.2.4. Solvothermal route}

Reagents used for the synthesis of light elements-based materials being very often unreactive due to the covalency of their chemical bonds, many works have been focused on the enhancement of the chemical reactivity in order to reduce the required experimental temperature and pressure. In this way, solvothermal processes have been greatly developed. 
Solvothermal synthesis can be described as a reaction between reagents in presence of a solvent (aqueous or non aqueous) in a close system at a temperature higher than the boiling temperature of the solvent. This process can involve sub- or supercritical conditions and homogeneous or heterogeneous conditions [80]. Historically, the ancestor of the solvothermal route was the hydrothermal reaction with water as solvent [81-82]. Solvothermal process involving the use of non aqueous solvents was developed as soon as 1990 in ICMCB (Bordeaux) for the synthesis of novel materials or the elaboration of composite microcrystallites :

(i) On the basis of geomimetism approach layered oxides (phyllosiloxides) isostructural of natural phyllosilicates have been elaborated using alkools as solvents [83-85],

(ii) the synthesis of nitrides (as GaN, AlN for example) with $\mathrm{NH}_{3}$ as solvent has been successfully performed through this route [86-89],

(iii) $\mathrm{Fe}_{3} \mathrm{O}_{4} / \mathrm{KFe}_{11} \mathrm{O}_{17}$ composite microcrystallites have been elaborated to be used as catalysts for the deshydrogenation of ethylbenzene leading to styrene, solvent being a mixed one (ethanol-water) [90].

First of all, it has been evidenced that the growth conditions of natural diamond involve the mantle fluids $(\mathrm{C}, \mathrm{H}, \mathrm{O}, \mathrm{S}, \mathrm{N})$ as diamond can precipitate through a displacement of the equilibrium between $\mathrm{CH}_{4}$ and $\mathrm{CO}_{2}$ [91]. Some authors have also proposed that diamond grows from a fluid $\left(\mathrm{CO}_{2}-\mathrm{H}_{2} \mathrm{O}\right)$ phase with varying composition [92-93]. Consequently the role of water in diamond nucleation and growth was studied during these last twenty years, different groups being involved in works about this hydrothermal process $[26,94-$ 95]. More recently the dechlorination of trichloroethane in alkaline-hydrothermal 
solution has allowed the polymerization of an intermediate activated carbon species on the surface of diamond seeds in mild conditions $\left(200^{\circ} \mathrm{C}, 1 \mathrm{GPa}\right)[96]$.

Solvothermal reactions have also been recently investigated for c-BN synthesis. The great interest for c-BN was due to thermodynamical calculations which have suggested that - contrary to diamond- such a 3D structure could be thermodynamically stable at normal pressure and mild temperature conditions [97-98].

In order to improve the chemical reactivity induced by reactions at the interface solvent/precursors, three different steps have been investigated :

(i) the use of reactions based on reactive precursors as melamine and cyanuric chloride and an organic solvent (ethyl di-isopropylamine) [99],

(ii) the development of conventional inorganic precursors as h-BN and a nitriding solvent as $\mathrm{NH}_{2} \mathrm{NH}_{2}[100]$,

(iii) the development of metathesis reactions as $\mathrm{BX}_{3}+\mathrm{Li}_{3} \mathrm{~N} \rightarrow 3 \mathrm{LiX}+\mathrm{BN}(\mathrm{X}$ being an halogen) with non polar solvents. For example c-BN has been obtained in mild temperature $\left(480^{\circ} \mathrm{C}\right.$ ) and pressure (autogenous) conditions using $\mathrm{BBr}_{3}$ and $\mathrm{Li}_{3} \mathrm{~N}$ as precursors and $\mathrm{C}_{6} \mathrm{H}_{6}$ as solvent [101].

\section{III.2.5. Contribution of these different synthesis routes for the elaboration of} carbon nitrides

From a chemical point of view, the synthesis of carbon nitrides is comparable to that of c-BN because in both cases main encountered problems are due to the stabilization of $\mathrm{N}_{2}$ molecule that drastically damages the stoichiometry of elaborated materials. 
Taking into account thermodynamical considerations, the stability of $3 \mathrm{D}-\mathrm{C}_{3} \mathrm{~N}_{4}$ varieties still remains questionable.

\section{III.3. Analysis of the significant results relative to the elaboration of bulk carbon nitrides}

\section{III.3.1. Direct synthesis under high pressure}

Taking into account the duration of the high pressure treatment and/or the coexistence of super-high pressures and high temperatures three different elaboration routes can be distinguished:

(i) the development of static pressures involving specific equipments belt-type [102], multi-anvils press [103], diamond-anvils cell [104],

(ii) the use of dynamic pressures in particular with shock-waves [105],

(iii) ball milling synthesis based upon local shock and friction phenomena [106].

\section{III.3.1.1. Development of static pressures}

Main results related to direct synthesis under static high pressure are reported in Table III. First of all, it is noticeable that static pressures allow to elaborate either twodimensional or three-dimensional carbon nitrides.

Still far from the theoretical graphitic $\mathrm{C}_{3} \mathrm{~N}_{4}$, the resulting $2 \mathrm{D}$ carbon nitrides are mainly characterized by a different composition (either with an excess or with a deficit in nitrogen), the presence of hydrogen and a medium or poor crystallinity. 
Zhang et al. [107] have prepared from $\mathrm{C}_{3} \mathrm{~N}_{6} \mathrm{H}_{6}$ and $\mathrm{C}_{3} \mathrm{~N}_{3} \mathrm{Cl}_{3}$ in a temperature range 500$550^{\circ} \mathrm{C}$ and under a pressure of 1-1.5 GPa (piston cylinder-type apparatus) a well crystallized carbon nitride with the composition $\mathrm{C}_{6} \mathrm{~N}_{9} \mathrm{H}_{3} \cdot \mathrm{HCl}$. The yellowish compound adopts a graphitic hexagonal structure (space group P63/m, $a=8.44 \AA, c=6.43 \AA$ ) which is structurally related to the hypothetical hexagonal graphitic $\mathrm{C}_{3} \mathrm{~N}_{4}$ unit with ordered arrangement of $\mathrm{C}_{3} \mathrm{~N}_{3}$ voids. Due to their large size, these voids are occupied by chloride ions, the charge balance of the material being ensured by an equivalent protonation of nitrogen. RMN and IR studies have underlined that the protonation occurs preferentially at the nitrogen centres belonging $\mathrm{C}_{3} \mathrm{~N}_{3}$ heterocycles. This experiment is of relevant interest because of the high quality of the graphitic carbon nitride crystallinity. Moreover, it is obvious that the $\mathrm{C}_{3} \mathrm{~N}_{3}$ skeleton of the reagent favours the condensation towards hexagonal graphitic $\mathrm{C}_{3} \mathrm{~N}_{4}$.

Ma et al. [108] have also submitted melamine to a pressure close to 5 GPa during 15 minutes in the temperature range $400-900^{\circ} \mathrm{C}$ (cubic anvils high pressure apparatus). For lowest temperatures up to $500^{\circ} \mathrm{C}$, the decomposition of melamine is really slight: the obtained materials are still white and the $\mathrm{C}: \mathrm{N}$ ratio has very weakly increased (1:1.91 instead of 1:2 in the starting reagent). At highest temperature $\left(900^{\circ} \mathrm{C}\right)$, the obtained black product is structurally related to disordered amorphous carbon but still contains nitrogen $(\mathrm{C}: \mathrm{N}=1: 0.17)$ and hydrogen $(1.03 \mathrm{wt} \%)$. At intermediate temperature $\left(650^{\circ} \mathrm{C}\right)$, authors observed the formation of a well-crystallized graphitic phase. In this brownish material, the presence of $\mathrm{CN}$ heterocycles has been evidenced and the X-Ray Diffraction (XRD) pattern is consistent with that proposed by Teter and Hemley for hexagonal graphitic $\mathrm{C}_{3} \mathrm{~N}_{4}$ [41]. The analyzed 0.75:1 C:N ratio, due to the combustion analysis technique, is representative of the whole synthesized material and can not be 
strictly attributed to this two-dimensional carbon nitride because the decomposition of melamine is not complete (the reagent is still present on XRD patterns) and the presence of an unknown third phase has been noticed. Nevertheless, it is obvious that this graphitic phase presents a $\mathrm{C}: \mathrm{N}$ ratio higher than in melamine. When comparing Zhang [107] and $\mathrm{Ma}$ [108] works performed at $500^{\circ} \mathrm{C}$, one should observe that despite higher pressure involved, Ma et al. do not observe the formation of a graphitic phase, which underlines here that the polycondensation process of $\left(\mathrm{C}_{3} \mathrm{~N}_{3}\right)$ skeleton is mainly influenced by the choice of reagents.

Still focusing on reagents with skeleton based on triazine cycles, Yu et al. $[109,110]$ have treated $\mathrm{C}_{3} \mathrm{~N}_{4} \mathrm{H}_{4}$ under $6 \mathrm{GPa}$ (six anvils apparatus) and $1500^{\circ} \mathrm{C}$ during 2.5 minutes in presence of Ni-based alloy as catalyst. The authors claim that, after decomposition of the reagent, nitrogen does not remain in the reaction product as EELS (Electron Energy Loss Spectroscopy) measurements have not detected its presence. This high pressurehigh temperature (HP-HT) treatment of the 2-amino,1,3,5-triazine leads to the coexistence of three phases. The major one is very well crystallized hexagonal graphite. The two minority phases are diamond (which is proposed to be formed by the action of Ni-based alloy on carbon issued from decomposition of reagent) and amorphous carbon. Authors then consider that HP-HT treatment has caused the destruction of C-N and C-H bonds that were previously present in the starting reagent. Consequently, different hypothesis can be proposed:

(i) During the synthesis process, all nitrogen atoms have been transformed to non reactive $\mathrm{N}_{2}$ due to the developed high temperature which leads to the formation of materials containing only carbon ; in this case, one should then notice that HP-HT treatment destroys $\left(\mathrm{C}_{3} \mathrm{~N}_{3}\right)$ skeleton. 
(ii) Under HRTEM (High Resolution Transmission Electron Microscopy) the beam energy leads to the graphitization and/or the amorphization of an unstable carbon nitride phase with loss of nitrogen. Amorphization has ever been observed under a focused electron beam during TEM analysis in nanosized crystallized clusters embedded in $\mathrm{CN}_{\mathrm{x}}$ thin films but no detail is given about the evolution of composition and possible loss of nitrogen during amorphization [111-112].

Then low temperature TEM experiments could be of relevant interest to conclude about the origin of nitrogen loss. Nevertheless, when comparing Ma's experiments [108] on melamine above $900^{\circ} \mathrm{C}$ which have also led to a loss of nitrogen from the system, it seems reasonable to admit that HP-HT treatment induces the destruction of C-N bonds in the triazine cycles, leading then to the formation of carbon species and $\mathrm{N}_{2}$. The use of triazine-based precursors is then interesting for $2 \mathrm{D}$ carbon nitride elaboration for temperatures below $800^{\circ} \mathrm{C}$ for pressures equivalent to several $\mathrm{GPa}$.

With the strategy to induce the nitridation of carbon source and on the basis of the following chemical metathesis reaction : $\mathrm{C}_{6} \mathrm{Cl}_{6}+6 \mathrm{NaN}_{3} \rightarrow 6 \mathrm{NaCl}+2 \mathrm{C}_{3} \mathrm{~N}_{4}+5 \mathrm{~N}_{2}$ (equation 2), Andreyev et al. [113] have focused on experiments under high pressure (7.7 GPa, belt-type apparatus) and moderate temperature $\left(400-500^{\circ} \mathrm{C}\right)$ during $50-70 \mathrm{~h}$ with hexachlorobenzene and sodium azide as reagents. First of all, the absence of oxygen and hydrogen in the so-obtained sample is remarkable as these elements (and particularly hydrogen) are commonly reported by many authors in thin films and bulk carbon nitrides. In this material the $\mathrm{C}: \mathrm{N}$ atomic ratio (about 1:1.24) is consistent with a slightly nitrogen-deficient $\mathrm{C}_{3} \mathrm{~N}_{4}$. Moreover, the material is predominantly amorphous but contains nanosized crystallites (smaller than 10nm) with possible graphitic hexagonal arrangement. Here carbon and nitrogen exhibit $\mathrm{sp}^{2}$ hybridization, nitrogen atoms being 
likely to substitute carbon in certain lattice sites. The interplane $\left(\begin{array}{lll}0 & 0 & 2\end{array}\right)$ distance is around $3.26 \AA$ then smaller than interlayer distance in graphite $(3.34 \AA)$. In this process $\mathrm{NaN}_{3}$ - which has to be introduced in great excess - plays a key role: it acts both as a sodium flux and nitriding agent as its decomposition under pressure and temperature leads to the formation of liquid sodium and purified $\mathrm{N}_{2}$. The mechanism involving sodium is not really understood nevertheless its action as a catalyst is envisaged. Previous works of same authors with same reagents have also been reported with different experimental conditions: while pressure and temperature were the same, the duration of P-T treatment was much shorter (30 min) and sodium azide was introduced in stoichiometric conditions according to equation 2 [114]. In this case, the nitrogen deficit is more important $(\mathrm{C}: \mathrm{N}$ equal to $1: 0.85)$, some $\mathrm{sp}^{3}$ carbon are detected $(10 \%)$, the $\left(\begin{array}{lll}0 & 0 & 2\end{array}\right)$ reticular distance $(3.36-3.40 \AA)$ is close to that of carbon and the size of graphitic nanodomains is about $1 \mathrm{~nm}$. Then, it is obvious that $\mathrm{NaN}_{3}$ has a major action reinforcing its great interest for III-V nitrides or $\mathrm{C}_{3} \mathrm{~N}_{4}$ elaboration.

The main results relative to the attempts for the elaboration of three-dimensional carbon nitrides are far from expected in the sense that no dense carbon nitride could be isolated. Nevertheless, they can be considered promising because, despite the problems associated to their characterizations, dense $\mathrm{CN}_{\mathrm{x}}$ structures have been observed.

The first high pressure synthesis leading to $3 \mathrm{D} \mathrm{C}_{3} \mathrm{~N}_{4}$ phases have been investigated by NGuyen et al. [115], using as $\mathrm{N}$ and $\mathrm{C}$ sources nitrogen and $\mathrm{C}_{60}$ buckminsterfullerene respectively and laser-heated diamond anvil cell as high pressure equipment ( $\mathrm{P}=30 \mathrm{GPa}$, $\left.\mathrm{T}=1700-2200^{\circ} \mathrm{C}\right) . \mathrm{X}$-Ray diffraction pattern of the quenched sample is consistent with a dense crystalline cubic system. The possible cell parameters $(a=7.699 \AA, 11.538 \AA$ or 
$5.442 \AA$ as proposed by the crystallographic program TREOR) and reticular distances are not compatible with any theoretical structure predicted for $\mathrm{C}_{3} \mathrm{~N}_{4}$ which suggests the formation of an unpredicted carbon nitride. Nevertheless, in spite of the obvious interest related to the discovery of a new structure, further characterizations are necessary in order to prove the presence of nitrogen in the material and to determine the accurate structure. For example X-Ray diffraction pattern recorded under pressure (30 GPa) after leaser heating could have prove unambiguously the presence or not of nitrogen. Moreover, this experiment could be particularly useful to understand the phase transition mechanism and/or the decomposition into carbon-rich species and nitrogen.

Dymont et al. have elaborated an amorphous precursor via an electrochemical route with the general composition $\mathrm{C}_{\mathrm{x}} \mathrm{N}_{\mathrm{y}} \mathrm{H}_{\mathrm{z}}$ and mainly characterized by $\mathrm{N}-\mathrm{H}, \mathrm{C}-\mathrm{H}, \mathrm{C}=\mathrm{N}$ and $\mathrm{C}=\mathrm{C}$ bonds [116]. This non-crystalline material has been treated under $7 \mathrm{GPa}$ (toroid type apparatus) at different temperatures in the range $25-330^{\circ} \mathrm{C}$ [117]. Three different phases have been simultaneously obtained: graphite, a disordered material (linear chainlike carbon allotrope) and a crystalline carbon nitride with hexagonal structure ( $a$ $=6.65 \AA, c=4.82 \AA$ ). Although such parameters are in quite good agreement with those predicted for $\alpha-C_{3} N_{4}$, due to the significant nitrogen deficit revealed by the semiquantitative Auger analysis, the authors have proposed in a first time, a composition $\mathrm{C}_{4} \mathrm{~N}_{3}$ and its associated structure (deduced from $\beta-\mathrm{C}_{3} \mathrm{~N}_{4}$ ) as previously predicted by Hughbanks and Tian [118] and confirmed by Badding [119]. Further studies have led to other conclusions concerning this material [120]: based on XRD, IR and Auger electron spectroscopy, same authors then propose a model of crystalline carbon nitride with hexagonal $\beta-\mathrm{C}_{4} \mathrm{~N}$ structure. Here, a part of nitrogen atoms of theoretical $\mathrm{C}_{3} \mathrm{~N}_{4}$ are replaced by carbon atoms which form $\mathrm{C}-\mathrm{C}$ bonded pairs as they occupy adjacent sites. 
This study of the different attempts for direct synthesis of carbon nitrides either with a 2D- or with a 3D-structure underlines different problems:

(i) High temperatures seem to lead to a loss of nitrogen, the effect of high (or very high) pressure being then not sufficient to impede $\mathrm{N}_{2}$ departure. In this sense, works performed at high pressure under moderate temperature could be a more appropriate route.

(ii) The precursors characterized by the presence of $\left(\mathrm{C}_{3} \mathrm{~N}_{3}\right)$ cycles seem suitable for the synthesis of $\mathrm{C}_{3} \mathrm{~N}_{4}$, especially graphitic phases. Efforts to optimize polycondensation phenomena should then be done by an appropriate choice of precursors. Moreover, as drastic experimental conditions lead to the destruction of the C-N bonds [108], other strategy to improve reactivity will have to be considered.

(iii) The difficulty to get crystallized and single phases whatever the developed experimental conditions has been underlined. However, experimental results concerning synthesis under high static pressure are of relevant interest because some new phases that structures were not predicted by ab initio calculations have been evidenced, their composition being probably different from $\mathrm{C}_{3} \mathrm{~N}_{4}$. Therefore, the theoretical approach seems to be still an inescapable way to have a better understanding of carbon-nitrogen system concerning all stable compositions and their associated structures. We believe that efforts should be devoted to ab initio calculations concerning the potential stability of carbon nitride with $\mathrm{C}: \mathrm{N}$ ratio higher than 1:1. Moreover, special care should be particularly given too subsequent properties such as bulk modulus. 


\section{III.3.1.2. Use of dynamic pressures}

As ever mentioned, the kinetics of diamond formation is compatible with the use of dynamic pressures. This process is characterized by the application of very high pressure $(\mathrm{P} \geq 100 \mathrm{GPa})$ and high temperature $\left(\mathrm{T}>1000{ }^{\circ} \mathrm{C}\right)$ during a short time $(\leq 1 \mu \mathrm{s})$. Then it is interesting to study if such conditions are appropriated to carbon nitride synthesis.

Main results related to direct synthesis under dynamic pressure are reported in Table IV. In 1990, by analogy with the commercial shock synthesis of diamond and wurtzite boron nitride (wBN), Wixom [121] has tried to elaborate by the same process dense carbon nitride. Due to the unavailability of crystalline graphitic $\mathrm{C}_{3} \mathrm{~N}_{4}$ to be used as precursors, the author has devoted many efforts for the elaboration of amorphous precursors characterized by $\mathrm{C}: \mathrm{N}$ suitable atomic ratio and a good spatial distribution of both elements at the submicrometer scale. The first precursor, obtained by a low temperature combustion reaction of tetrazole and its sodium salt, showed the molar composition $\mathrm{C}_{3} \mathrm{~N}_{4.5} \mathrm{H}_{1.0}$ (40\% of the mass originating from other elements, probably oxygen and sodium). The second one, which is a residue of the pyrolysis of melamineformaldehyde resin, exhibits the composition $\mathrm{C}_{3} \mathrm{~N}_{3.6} \mathrm{H}_{2.5}$. These molecular materials contain heterocyclic aromatic rings. The experimental conditions for shockwave process are close to that used for diamond : copper was added to the precursor in order to quench the heat generated during the shock compression and the exothermic chemical reaction and pressure was estimated in the range 60-250 GPa for a very short reaction time. The resulting product was well-crystallized diamond as fine microcrystallites, the absence of $\mathrm{C}-\mathrm{N}$ chemical bond being confirmed by different spectroscopic studies. Here 
is underlined the major difficulty for carbon nitride synthesis linked with the formation of the highly stable $\mathrm{N}_{2}$ molecule which competes with retention of nitrogen into the solid lattice. Another remarkable point concerns the fact that so-obtained diamond is extraordinarily well ordered in comparison with that elaborated with the same process and comparable experimental conditions but using only carbonaceous precursors.

In 2001, Collins et al. [122] have attempted the elaboration of dense carbon nitride according to the following chemical equation: $\mathrm{NaN}(\mathrm{CN})_{2}+\mathrm{CI}_{4}+\mathrm{NaN}_{3} \rightarrow \mathrm{C}_{3} \mathrm{~N}_{4}+2 \mathrm{NaI}$ $+\mathrm{N}_{2}+\mathrm{I}_{2}$ (equation 3). The precursor mixture was blended with copper. Pressure was estimated in the range $20-25 \mathrm{GPa}$ and shock pulse duration in the range $1.8 \mu \mathrm{s}-3.6 \mu \mathrm{s}$. Here the experimental conditions are softened in comparison with those used by Wixom [122] because authors suppose that the energy required for the chemical reaction between products of decomposing organic precursors is expected lower to that expected for phase transformation. After removing copper and salts, a fine black powder remains, this material being insoluble in boiling concentrated nitric acid. For highest pulse duration, carbon nitride nanocrystallites (around $40 \mathrm{~nm}, \mathrm{~N}$ content of 8-13 at.\%) embedded in amorphous matrix have been observed : TEM/PEELS (Parallel-detection Electron Energy Loss Spectroscopy) analysis has evidenced in these crystallites the $\mathrm{sp}^{3}$ type atomic bonding between carbon and nitrogen. Moreover, considering IR spectra, authors claim the existence of $\beta-\mathrm{C}_{3} \mathrm{~N}_{4}$ material which amount increases with the duration experiment. The cubic symmetry observed by electron diffraction is not compatible with hexagonal cell of this predicted material but authors precise the highly unstable character under the electron beam of the nanoparticles. Regardless of the structural considerations and nitrogen deficiency, one can then notice that, contrary to works of Wixom (performed at much higher synthesis and with lower previous nitrogen 
amount in the starting reagents) [121], the synthesized material still contains nitrogen. As shock temperature in both papers is not estimate (probably because Hugoniot and thermodynamic data are unavailable), it is then not possible to determine the parameter that is predominant to explain these different results.

Based on the expected following chemical reaction: $t \mathrm{CX}_{4}+4 \mathrm{t} \mathrm{NaN}(\mathrm{CN})_{2} \rightarrow\left[\mathrm{C}_{3} \mathrm{~N}_{4}\right]_{3 \mathrm{t}}+$ 4t $\mathrm{NaX}$ (equation 4, $\mathrm{X}$ being an halogen), shock reactions were also investigated in 2006 by Shibata and Sekine [123]. Here, the selected precursors were either $\mathrm{CBr}_{4}$ or $\mathrm{CI}_{4}$ carbon tetrahalide in stoichiometric amount with sodium dicyanoamide. Pressure and impact velocity are varied in the ranges $13-45 \mathrm{GPa}$ and $0.652-1.90 \mathrm{~km} . \mathrm{s}^{-1}$ respectively. After removing the impurities and secondary products, with $\mathrm{CBr}_{4}$ as carbon precursor, a broad peak corresponding to the 002 basal plane diffraction in poorly crystallized graphitic carbon nitride is observed on the XRD pattern. On the one hand, the associated interplanar distance $\mathrm{d}$ increases with the impact velocity while $\mathrm{C}: \mathrm{N}$ atomic ratio increases (from 1:1.26 to 1:0.427 at lowest and highest impact velocity respectively) which indicates that the more experimental conditions are drastic (highest dynamic temperature and pressure), the more nitrogen deficiency will be important. At the same time the 002 peak gets wider which is consistent with an increasing disorder due to nitrogen escapement from the material that progressively tends towards turbostratic graphite composition. On the other hand, authors also evidence the unexplained presence of hydrogen which content is all the more important since the impact velocity is low which tends to underline the great affinity of carbon nitride for this element. The differences observed between Shibata and Sekine [123] and Collins et al. [122] experiments mainly deal with the structural form (either 2D or 3D crystallites) of the obtained materials. In this sense, it is then possible that the use of $\mathrm{NaN}_{3}$ (then the 
formation of sodium flux) could be of relevant interest for the synthesis of carbon nitrides dense structures.

Komatsu [124] has submitted to shock compression a graphitic precursor with $\mathrm{C}_{3} \mathrm{~N}_{2}$ composition (prepared by pyrolysis at $800^{\circ} \mathrm{C}$ of $2,5,8$-tricarbodiimide-tris-s-triazine copper salt under a stream of $\mathrm{N}_{2}$ [125]) with the following pressure and temperature shock conditions: $30 \mathrm{GPa}$ and $2700^{\circ} \mathrm{C}$. After purification of the resulting product, the author has obtained a dark grey fine powder (yield of $8 \%$ ) which consists in a polycrystalline structure of nanocrystals (with a size of 4-5 nm). Komatsu then claims the existence of a new diamond-like carbon nitride ( $\mathrm{C}-\mathrm{N}$ heterodiamond) with the composition $\mathrm{C}_{2} \mathrm{~N}$ and $\mathrm{sp}^{3} \mathrm{C}-\mathrm{N}$ bonding.. The parameter of the cubic cell $(a=3.51 \AA)$ is 1.6-1.9\% smaller than that of diamond (the $\mathrm{C}-\mathrm{N}$ bond distance $\mathrm{d}$ is then expected shorter) which suggests (as bulk modulus varies inversely proportional to $\mathrm{d}^{3.5}$ ), highest mechanical properties than diamond. Some friction tests have evidenced that this new material is no less hard then diamond. Moreover, the lone pair of $\mathrm{N}$ atom could be interesting in the prospect of wide bandgap semiconductivity. These results are mainly significant in the sense that a dense carbon nitride has been unambiguously isolated and characterized from structural, chemical and mechanical points of view. According to the mechanism in which shock-waves compress the precursor along the $c$-axis to close the layers until the covalent bonding occurs, Komatsu proposes that the use of $\alpha-C_{3} \mathrm{~N}_{4}$ as precursor would be more appropriate for the shock compression elaboration of $\mathrm{C}_{3} \mathrm{~N}_{4}$ heterodiamond because of its higher compressibility along the $a$-axis in comparison with the $\beta$-polymorph.

Liu et al. [126] have tested different precursors for shock-waves experiments : 
(i) A graphitic carbon nitride (prepared through the thermal decomposition of thiosemicarbazide in $\mathrm{N}_{2}$ atmosphere at $630^{\circ} \mathrm{C}$ and exhibiting a poor crystallinity) characterized by $\mathrm{C}: \mathrm{N}$ atomic ratio equal to 0.783 and oxygen content of $11.8 \%$ (some residual sulphur being detected) has been submitted to shock waves. The peak pressure and shock temperature are $42-44 \mathrm{GPa}$ and $2200-2400^{\circ} \mathrm{C}$ respectively.

(ii) The dicyanodiamide $\mathrm{C}_{2} \mathrm{~N}_{4} \mathrm{H}_{4}$ has been used as precursor according to the following expected equation: $3 \mathrm{C}_{2} \mathrm{~N}_{4} \mathrm{H}_{4} \rightarrow \mathrm{C}_{3} \mathrm{~N}_{4}+4 \mathrm{NH}_{3}$ (equation 4). The peak pressure has been varied between 24 and 32 GPa (associated shock temperature in the range 240$\left.330^{\circ} \mathrm{C}\right)$.

Authors claim that both precursors have led in optimized conditions to the formation of a multiphasic system containing a material isostructural of $\beta-\mathrm{C}_{3} \mathrm{~N}_{4}$ and another phase with undetermined composition and a monoclinic structure $(a=9.81 \AA, b=7.23 \AA$, $\left.c=5.61 \AA, \beta=95.2^{\circ}\right)$. Nevertheless, chemical characterizations to quantify the content of nitrogen in both phases appear necessary to prove nitrogen presence in the system. Liu et al. have also performed shock compression on melamine (here metastable until 37 GPa) and have clearly evidenced when comparing with melamine behaviour under high static pressure or by thermal treatment that the reaction time is a key factor for carbon nitride elaboration.

These shock waves experiments allow to evidence that ultra high shock pressures seem to be not favourable to nitrogen-rich (especially $\mathrm{C}_{3} \mathrm{~N}_{4}$ ) carbon nitrides synthesis due to the fact that the high associated shock temperature induces the escapement of nitrogen from the material. Nevertheless, interesting results are obtained for either graphitic or molecular reagents containing $\left(\mathrm{C}_{3} \mathrm{~N}_{3}\right)$ heterocycles, then strong pre-existing $\mathrm{C}-\mathrm{N}$ bonds. Such precursors have to be considered for further studies. 


\section{III.3.1.3. Mechanosynthesis processes}

Another route for carbon nitrides synthesis has been recently developed. This process was previously used by INCO Company for stabilizing super alloys containing dispersed oxides [127-130] or for elaborating metastable phases [131-135]. The involved mechanisms are related to the high intergranular pressure associated with high temperature due to collisions and frictions phenomena during the grinding process. In this sense, despite of the fact that experimental pressure and temperature conditions are moderate, the local pressure and temperature are very high which allows classifying this process as high pressure-like.

Main results related to direct synthesis via ball milling process are reported in Table V. Fahmy et al. [136] have carried out at ambient temperature the first high-energy reactive ball milling process for carbon nitrides elaboration using graphite and either liquid nitrogen or liquefied anhydrous ammonia in excess as precursors. Some attempts have also been performed using $\beta-\mathrm{Si}_{3} \mathrm{~N}_{4}$ for both nucleation inducer and solid nitrogen source. Authors precise that most of the 50 trials have led to the formation of nanocrystalline graphite. Nevertheless, in ammonia environment, a few of them have allowed to evidence the formation of $\beta-\mathrm{C}_{3} \mathrm{~N}_{4}$ small crystallites (5 to $10 \%$ in volume) embedded in an amorphous carbon matrix. Here the hypothesis relative to mechanism leads to consider both pressure and temperature effects : schematically, pressure is expected to drive the evolution of graphite towards defected state which then enhances chemical reaction with nitrogen liberated from ammonia atmosphere activated by temperature.

Another ball-milled reaction using graphite under $\mathrm{N}_{2}$ atmosphere was developed by Alcala et al. at room temperature [137]. Here the mechanical treatment induces a high 
amorphization of graphite. Nevertheless, chemical analysis evidences that a weak nitridation of the reagent has occurred, $\mathrm{C}-\mathrm{N}$ bonds being created. The amorphous $\mathrm{CN}_{\mathrm{x}}$ is nitrogen poor, $\mathrm{C}: \mathrm{N}$ maximal ratio being 1:0.12. This study confirms the poor nitriding effect of $\mathrm{N}_{2}$ in ball milling conditions as ever mentioned by Fahmy [136].

On the basis of Fahmy's conclusion, Yin et al. [138] have more recently performed at room temperature the synthesis of nanosized $\beta-\mathrm{C}_{3} \mathrm{~N}_{4}$ embedded in amorphous carbon matrix still using graphite (previously milled under argon atmosphere to induce nanoscale morphology and defects) under $\mathrm{NH}_{3}$ atmosphere. The obtained material is quite stable as thermal annealing under nitrogen flow only induces changes of morphology from flake-like to sphere-like. Such a result not only confirms the research work of Fahmy et al. [136] but also underlines, due to the better yield obtained, that the reduction of the size of carbon particles favours an increasing of the chemical reactivity for nitridation probably attributed to an increase of physico-chemical defects in nanoparticles. This hypothesis has been confirmed by works carried out by same authors that have consisted in the previous ball milling treatment of graphite, so obtained carbon being then submitted to another ball milling treatment in presence of $\mathrm{NH}_{3}$ [139]. Here, $\beta-\mathrm{C}_{3} \mathrm{~N}_{4}$ is obtained as a single phase which clearly underlines the key role of defects created by ball milling that contribute to a great enhancement of reactivity. Finally, when so obtained $\beta-\mathrm{C}_{3} \mathrm{~N}_{4}$ is annealed at $350-450^{\circ} \mathrm{C}$ under a streaming flow of $\mathrm{NH}_{3}$ gas, morphology as nanorods of the same structure and composition is observed [140].

The analysis of the different results issued from ball-milling synthesis underlines that ammonia $\left(\mathrm{NH}_{3}\right)$ is much more efficient than nitrogen $\left(\mathrm{N}_{2}\right)$ as nitriding agent. Such a difference can be easily explained by the better chemical reactivity of $\mathrm{NH}_{3}$ compared to 
that of the very stable $N_{2}$ molecule. This process has allowed to access to the $\beta-C_{3} N_{4}$ structural form either embedded in amorphous carbon matrix or even as single phase when graphite is submitted previously to ball milling. Considering that high-energy ball milling, by creation of many structural imperfections and increasing of surface area, improves the reactivity of the treated reagent, Fei et al. [141] have developed an original synthesis. Graphite powder was previously ball milled to a nanoscale state under argon atmosphere. The obtained powder was then submitted to thermal annealing at $1100^{\circ} \mathrm{C}$ under $\mathrm{NH}_{3}$ flow. Then, because of the highly improvement of the chemical reactivity of carbon reagent and high concentration of atomic nitrogen (activated by high temperature), a graphitic carbon nitride exhibiting an excellent crystallinity has been obtained. Moreover, in this case $\mathrm{C}: \mathrm{N}$ ratio is very close to theoretical value. Gong et al. [142] have also performed a study in the same was. Here graphitic carbon nitride (g$\mathrm{C}_{3} \mathrm{~N}_{4}$ ) is obtained by thermal treatment at $1050^{\circ} \mathrm{C}$ under $\mathrm{NH}_{3}$ flow of ball milled amorphous nanostructured graphite. Then, when $\mathrm{g}-\mathrm{C}_{3} \mathrm{~N}_{4}$ is treated at $1350^{\circ} \mathrm{C}$ under $\mathrm{NH}_{3}$ a phase transition is claimed to occur, leading to the formation of pseudocubic $\mathrm{C}_{3} \mathrm{~N}_{4}$. Then, if such results are confirmed by further trials, they can appear as a key step in carbon nitride elaboration history. Great efforts should be carried out to understand the mechanisms leading to such differences, $\mathrm{NH}_{3}$ nitridation treatment leading to either $\beta$ $\mathrm{C}_{3} \mathrm{~N}_{4}$ or pseudocubic polymorph if it is performed during ball milling or after respectively. Another questionable point deals with the stability of the graphitic carbon nitride. It has been evidenced that graphitic carbon nitrides were thermally robust classically up to $600^{\circ} \mathrm{C}$ [143-145] and eventually $700^{\circ} \mathrm{C}$ [146]. The elaboration at ambient pressure and above $1000^{\circ} \mathrm{C}$ of $2 \mathrm{D} \mathrm{C}_{3} \mathrm{~N}_{4}$ leads then to propose some possible explanations: 
(i) Fei and Gong claim a $\mathrm{C}: \mathrm{N}$ ratio equal to the theoretical value while many carbon nitrides obtained by other routes exhibit a deviation from stoichiometry. Then, in this way, the presence of $\left(\mathrm{C}_{3} \mathrm{~N}_{3}\right)$ voids could drastically affect the thermal stability. The presence or not of hydrogen in the materials should also be taken into account.

(ii) It has been evidenced during direct conversion attempts that increase of temperature favours the decomposition into nitrogen and carbon species even under pressure [147]. In this way, one should then wonder about any potential stabilizing factors in the graphitic phases proposed by Fei or Gong. It is then possible that impurities introduced during ball milling or oxygen could help to enhance the thermal stability.

Then in order to determine if highest thermal stability observed by Fei or Gong can be attributed either to consideration about stoichiometry (nitrogen content, hydrogen) or to other stabilizing agents, further characterizations (such as chemical analysis at the nanoscale in order to look for example for the presence of metallic species and/or oxygen) should be of relevant interest.

Despite ball milling appears as an interesting process, to date, reproducibility seems hard to reach, nitridation depending on many parameters such as type of mill, ball/powder weight ratio, spinning rate, milling time, gaseous atmosphere pressure... When comparing results obtained under static high pressure or shock-waves with ball milling, it then appears that kinetics and thermodynamics aspects will have to be carefully considered to control carbon nitride elaboration and especially nitrogen content. Nevertheless, one should also take into account the high-energy ball milling experiment performed by Zhao et al. [148] using $\mathrm{C}_{3} \mathrm{~N}_{3} \mathrm{Cl}_{3}$ and $\mathrm{Li}_{3} \mathrm{~N}$ as reagents. In this case, graphitic carbon nitrides are obtained, $\left(\mathrm{C}_{3} \mathrm{~N}_{3}\right)$ skeleton of the reagent perhaps favouring the planar network. In this case, the nitrogen content of obtained material 
decreases with reaction time while crystallinity is enhanced. These works indicate that mechanosynthesis process should also be attempted with highly reactive organic molecules containing both carbon and nitrogen. Ball milling processes could be used in a first step for improving the chemical reactivity of reagents (in particular carbon or carbon precursors) and the development of moderate temperatures processes in presence of nitriding agents able to maintain or even enhance such a reactivity would be appropriate to induce nitridation.

\section{III.3.2. Direct conversion of $2 D$ carbon nitrides}

Due to the severe pressure conditions required for the direct conversion graphite $\rightarrow$ diamond or h-BN - c-BN, diamond anvil cell (DAC) was the most developed pressure equipment for investigating the $2 \mathrm{D} \rightarrow 3 \mathrm{D}$ phase transition of carbon nitrides. Main results related to direct conversion are reported in table VI.

Synchrotron X-Ray diffraction is a suitable method to study phase transformation of materials under pressure and eventually temperature (when for example DAC experiments are combined with laser heating). Nevertheless on the basis that electronic properties are strongly related to the structure of the material, Han et al. [149] have chosen to evidence the structural transformations of two-dimensional $\mathrm{C}_{3} \mathrm{~N}_{4}$ by studying in situ the induced changes of the electron transport behaviour as a function of pressure. The graphitic carbon nitride $\mathrm{C}_{3} \mathrm{~N}_{4}$ precursor was firstly prepared by $\mathrm{Ma}$ et al. by high pressure - high temperature decomposition of melamine as mentioned before [108]. After a drastic purification, the sample was charged in diamond anvil cell and submitted to in situ electrical resistance measurement as pressure increases up to $30 \mathrm{GPa}$. 
Experiments were performed at room temperature and $77 \mathrm{~K}$. At $20^{\circ} \mathrm{C}$, three different abnormal changes have been detected versus pressure: (i) $5 \mathrm{GPa}$, (ii) $11<\mathrm{P}<14 \mathrm{GPa}$, (iii) $17<\mathrm{P}<22 \mathrm{GPa}$. At liquid nitrogen temperature, only the two last transitions remain. First, one should notice that, taking into account the decreasing of resistance when temperature increases whatever pressure, the carbon nitride either graphitic or with any induced potential structural changes exhibits semiconductor transportation characteristics. Moreover although structural changes cannot be unambiguously evidenced by such experiments it is interesting to notice that the pressure events are close to that predicted by Lowther [150] or Teter and Hemley [41]. On the basis of ab initio calculations, Lowther has claimed that a pressure lower than $5 \mathrm{GPa}$ should be sufficient to ensure the phase transition from one graphitic form (low energy, P-6m2 polymorph) towards another graphitic form (high energy, $p$ type) which only differ in planar stacking and character of $\mathrm{C}-\mathrm{N}$ planar bonds. While this author ensures that very high pressure (about $80 \mathrm{GPa}$ ) would be necessary to induce phase transition from graphitic form towards $\beta$-structure, Teter and Hemley claimed that $12 \mathrm{GPa}$ should be sufficient for the transition from graphitic $\mathrm{C}_{3} \mathrm{~N}_{4}$ towards cubic polymorph. Nevertheless, it is obvious that these three changes have to be studied by X-Ray diffraction to prove unambiguously structural changes.

The first trials for carbon nitride direct conversion have been performed by Solozhenko et al. [147] submitting turbostratic $\mathrm{CN}_{\mathrm{x}}$ with 1:1.1 C:N atomic ratio to high pressure and temperature in multi-anvil apparatus (pressure and temperature varying in the ranges 4.7-17.8 $\mathrm{GPa}$ and $720-1580^{\circ} \mathrm{C}$ respectively). For a pressure of $4.7 \mathrm{GPa}$, the decomposition of the material occurs at about $720^{\circ} \mathrm{C}$ leading to disordered graphite and nitrogen. This temperature of decomposition increases with pressure, diamond being 
obtained instead of graphite for highest pressures. These works underlined the necessity to reach pressure and temperature above $20 \mathrm{GPa}$ and $1800^{\circ} \mathrm{C}$ respectively to avoid the decomposition of compressible carbon nitrides.

Ming et al. have focused their attention on the conversion of a graphitic nanocrystallized precursor (called $\mathrm{g}-\mathrm{C}_{3} \mathrm{~N}_{4}$ ) with an atomic ratio $\mathrm{C}: \mathrm{N}$ equal to 1:1.39 [151]. The structural transitions have been evidenced by X-Ray diffraction using monochromatic synchrotron radiation source under pressure and temperature conditions up to $38 \mathrm{GPa}$ and $2700^{\circ} \mathrm{C}$ respectively (apparatus being laser-heated diamond anvil cell). First of all, applying pressure at room temperature induces a broadening of the 002 reflection associated with a decreasing of its intensity which is consistent with a progressive increasing disorder in the material. At $17.6 \mathrm{GPa}$, the complete amorphization of $\mathrm{g}-\mathrm{C}_{3} \mathrm{~N}_{4}$ is evidenced by the total disappearance of the diffraction peak. When laser heated under $23 \mathrm{GPa}$, the sample then undergoes a phase transition leading to a well-crystallized high-pressure phase which structure has not be solved as the diffraction pattern is not consistent with those expected for theoretical dense $\mathrm{C}_{3} \mathrm{~N}_{4}$ polymorphs. Nevertheless, as authors do not give any details about the position of the XRD reflections, it is then difficult to ensure that the system is a single phase or to evidence a potential decomposition (a discussion about the presence or not of nitrogen would have been of relevant interest). After releasing pressure, the XRD pattern is very different indicating that this high-pressure phase is not quenchable. The indexation of the whole diffraction pattern suggests a mixture of different phases: a cubic phase $(a=3.878 \AA)$, diamond and a graphitic phase. The cubic phase does not correspond to any structural type predicted for $\mathrm{C}_{3} \mathrm{~N}_{4}$ and appears $12 \%$ denser than the graphitic phase nevertheless its density is smaller than values expected for three-dimensional $\mathrm{C}_{3} \mathrm{~N}_{4}$ polymorphs. This cubic phase is neither 
isostructural of the spinel structure as observed recently for $\mathrm{Si}_{3} \mathrm{~N}_{4}$ [152] nor the $\mathrm{C}_{2} \mathrm{~N}$ cubic phase $(a=3.51 \AA)$ evidenced by shock waves treatment [124]. Concerning graphitic phase and diamond which are present on X-Ray diffraction patterns recorded at room temperature and released pressure, authors indicated that when samples are submitted to very high pressure $(>30 \mathrm{GPa})$ and temperature $(>2500 \mathrm{~K})$, the graphitic phase is totally replaced by diamond; but in lower $\mathrm{P}$ and $\mathrm{T}$ conditions, both phases coexist. Authors discussed the origin of the diamond and graphitic phase in the quenched samples:

(i) the presence of organic residues in the graphitic $\mathrm{C}_{3} \mathrm{~N}_{4}$ precursor would lead to the formation of carbon (either graphite or diamond) after pressure and temperature treatment,

(ii) the cubic phase could exhibit a non stoichiometry resulting from the in situ decomposition of $\mathrm{g}-\mathrm{C}_{3} \mathrm{~N}_{4}$ according to the following equation : $\mathrm{g}-\mathrm{C}_{3} \mathrm{~N}_{4} \rightarrow \mathrm{c} \mathrm{C}_{3-\mathrm{x}} \mathrm{N}_{4}+\mathrm{xC}$ (equation 6).

Because diamond content is not homogeneous in the whole sample, authors claim that the second hypothesis is not available. Nevertheless, it is obvious that if carbon (either graphite or diamond) was originated from decomposition of organic residues, its polymorphs should be clearly detected on the X-Ray diffraction patterns before releasing pressure. We strongly believe that the simultaneous appearance of diamond, graphitic phase and cubic one evidences that their formations are linked one to another. Moreover, the chemical EDS analysis performed by authors on quenched samples only prove that the system has not loose significantly nitrogen but does not evidence that the cubic phase adopts the good stoichiometry. Authors claim that the high-pressure phase transforms into the metastable cubic one but the mechanism seems to be more 
complicated. One should take into account a potential decomposition of the high pressure phase which is obviously a carbon nitride which composition is close to precursor one (due to the fact that after quenching the system still exhibits quite the same nitrogen content). When releasing pressure, phase segregation is conceivable leading to an unpredicted carbon nitride cubic phase, a graphitic one that could be either graphite or graphitic $\mathrm{CN}_{\mathrm{x}}$ and diamond. Further TEM characterizations coupled with chemical quantitative analysis focused on the different phases would be necessary to understand clearly these phase transitions.

Probably due to apparatus necessary for these very high pressure experiments (diamond anvil cell generally associated with synchrotron radiation), some few works are devoted to the direct conversion of graphitic carbon nitride precursors. Nevertheless, the screening of the corresponding experimental data underlines that:

(i) Graphitic precursors may undergo structural transition. Nevertheless, the experimental pressure and eventually temperature involved are severe and do not really correspond to values expected from ab initio calculations. Moreover, in case of Ming et al. [151], it is interesting to notice that when pressure is applied at room temperature, the graphitic precursor becomes amorphous, temperature then being necessary to induce phase transition towards a crystallized system.

(ii) Some dense phases have been evidenced but characterizations remain incomplete mainly because samples are multiphasic. In addition, potential dense carbon nitride obtained after pressure and temperature treatment still do not correspond to any polymorph predicted for $\mathrm{C}_{3} \mathrm{~N}_{4}$. We then should wonder about other unpredicted compositions in carbon-nitrogen system. The obtained results are very promising as they tend to indicate that the elaboration of dense carbon nitride is possible nevertheless 
they also traduce the great intricacy of the carbon-nitrogen chemical system. Moreover, the influence of hydrogen is never discussed in the papers while we strongly believe that it could play an important role on the conversion process mechanisms and on the stabilization of new hydrogenated carbon nitride compositions.

(iii) Finally, it should be underlined that high pressure and temperature applied on the samples in adequate apparatus are often non-homogeneous over the whole sample. This fact associated to the narrow domain of stability (in pressure and temperature) of the different $\mathrm{C}_{3} \mathrm{~N}_{4}$ varieties could also explain the formation of multiphasic samples.

\section{III.3.3. Flux assisted conversion}

This synthesis route has not been widely developed in comparison with the different research works involving flux assisted conversion for diamond or c-BN [153].

Such a situation could be attributable to different factors:

(i) the difficulty to optimize fluxes chemically compatible either with carbon a nitrogen ; in this way, the strategy could be equivalent to that developed for c-BN for same reasons,

(ii) a lack of data concerning the formation of the $\mathrm{C}-\mathrm{N}$ chemical bond by comparison with C-C or B-N,

(iii) the difficulty to control the exact composition and crystallinity of the starting $2 \mathrm{D}$ phases as $\mathrm{g}-\mathrm{C}_{3} \mathrm{~N}_{4}$ (in particular the presence of hydrogen and an adequate $\mathrm{C}: \mathrm{N}$ ratio). Main results related to flux assisted conversion of 2D phases are reported in Table VII. The flux-assisted conversion has been performed by He et al. [154]. Authors used $\mathrm{C}_{3} \mathrm{~N}_{4} \mathrm{H}_{4}$ 3-amino,1,2,4-triazine [with $\left(\mathrm{C}_{3} \mathrm{~N}_{3}\right)$ molecular skeleton] as a precursor and 
NiMnCo $(70 / 25 / 5)$ as a catalyst in the following experimental conditions: $\mathrm{P}=7 \mathrm{GPa}$, $\mathrm{T}=1400^{\circ} \mathrm{C}$ during 10 minutes. The alloy NiMnCo $(70 / 25 / 5)$ has been also recently used by Zhang et al. as a metallic flux for the successful nucleation and growth of diamond (type Ib) using graphite as carbon source [155]. Considering the melting curve of NiMn $(60 / 40)$ versus pressure which evidences a melting point close to $1150^{\circ} \mathrm{C}$ at $5.5 \mathrm{GPa}$ [156], it is then likely that NiMnCo $(70 / 25 / 5)$ was liquid in the pressure and temperature conditions. Therefore that leads to the conclusion that in this case the alloy acts as a flux. He et al. [154] then observed the formation of micrometric rod-like crystals only composed of carbon and nitrogen (the presence of hydrogen being not accessible by EDS analysis). X-Ray diffraction pattern was consistent with the unambiguous and simultaneous presence of $\alpha$ - and $\beta-\mathrm{C}_{3} \mathrm{~N}_{4}$ polymorphs, diamond and graphite being not detected. On the basis of experimental results and taking into account the bond energy of $\mathrm{C}-\mathrm{X}$ ( $\mathrm{X}$ being $\mathrm{B}, \mathrm{O}, \mathrm{F}$ or $\mathrm{Cl}$ ) higher than $\mathrm{C}-\mathrm{N}$ one, authors have concluded that the presence of any X element in the precursor will prevent the elaboration of dense carbon nitride under high pressure and high temperature. Nevertheless, it is of relevant interest that, despite their high stability, N-H and C-H bonds are destroyed under pressure and temperature. Such breaking of the $\mathrm{C}-\mathrm{H}$ chemical bonds has ever been evidenced during diamond synthesis with paraffin $\left[\mathrm{C}_{2} \mathrm{H}_{6}\left(\mathrm{CH}_{2}\right)\right.$ n] as precursor in presence of same metallic alloy under high pressure and temperature (5GPa, $1200^{\circ} \mathrm{C}, 20$ minutes) [157]. Considering the high stability of the $\mathrm{C}-\mathrm{H}$ bond $(\mathrm{E}=413 \mathrm{~kJ} / \mathrm{mol})$ and the weak energy conveyed by high pressures in solid phases (correlated to the compressibility of the solid medium), the formation of C-N chemical bonds to the detriment of $\mathrm{C}-\mathrm{H}$ and $\mathrm{N}-\mathrm{H}$ ones could be attributed to the metallic hydrides formation. In this way, Baranowski et 
al. have ever underlined the affinity under high pressure of nickel-based alloys for hydrogen [158].

Nevertheless, Liang et al. [159] have also shown that the presence of high contents of nitrogen and hydrogen in the precursor could impede the nucleation of the dense form. Their work consisted of the conversion in presence of $\mathrm{Ni}_{70} \mathrm{Mn}_{25} \mathrm{Co}_{5}$ of hydrogenated carbon nitrides (elaborated by treatment under pressure and temperature of melamine) in order to get diamond. They have shown that the metallic alloy strongly reacts in order to form metallic nitrides and hydrides. The consequence is then the absence of nucleation of diamond or any dense phase in nitrogen- and hydrogen-rich regions (the nucleation being all the more disturbed or even prevented since $\mathrm{N}$ and $\mathrm{H}$ contents increase) as the characteristics of the alloy have been affected (melting point, glutinosity...).

In the same way, $\mathrm{Yu}$ et al. [110] using $\mathrm{C}_{3} \mathrm{~N}_{4} \mathrm{H}_{4}$ as precursor in presence of nickel-based alloy with the following experimental conditions $\left(\mathrm{P}=6 \mathrm{GPa}, \mathrm{T} \approx 1500^{\circ} \mathrm{C}, \mathrm{t}=2.5 \mathrm{~min}\right)$ have obtained as resulting material a mixture of different carbon forms (diamond, graphite and amorphous carbon). The EELS measurements underlined the absence of nitrogen in such final products. Here, the precursor was an allotrope of that used by He et al. [154]. Then $\mathrm{Yu}$ et al. proposed that the great differences observed in their experimental results were mainly due to the structure of the starting reagent. Nevertheless, it is also possible to take into account the slight differences concerning pressure $(6 \mathrm{GPa}[110]$ instead of $7 \mathrm{GPa}[154])$, temperature $\left(1500^{\circ} \mathrm{C}\right.$ [110] instead of $\left.1400^{\circ} \mathrm{C}[154]\right)$ and duration (2.5 min [110] instead of $10 \mathrm{~min}$ [154]) which could also induce a modulation of the stability of secondary metallic nitrides. 
The first conclusion is that the conversion in presence of such an alloy is probably based on flux-assisted process rather than on catalytic action. Moreover it is obvious that $\mathrm{C}-\mathrm{H}$ and $\mathrm{N}-\mathrm{H}$ bonds can be broken in such a process nevertheless it then appears that the elaboration of dense carbon nitride would result on a compromise between the stability of the material and the formation of metallic nitrides with the flux. The results claimed by $\mathrm{He}$ et al. are however promising and evidence the close stability of $\alpha$ - and $\beta-\mathrm{C}_{3} \mathrm{~N}_{4}$ polymorphs.

\section{III.3.4. Carbon nitrides synthesis through solvothermal route}

Considering the synthesis of carbon nitrides, solvothermal processes are of major interest since (i) the softened temperature conditions are able to prevent the loss of nitrogen and (ii) the chemical reactivity of the precursors at the interface between solid and liquid phases or between solvated species can be strongly improved.

As a consequence, during these last fifteen years, solvothermal processes were developed in different research domains involving both Materials Chemistry and Materials Sciences: synthesis of c-BN [100, 160-161], preparation of hybrid materials [162], crystal growth ( $\alpha$-quartz [163], ZnO [164-165], GaN [166-169], elaboration of micro- or nanocrystallites [170-173], stabilization of materials at the interface between Inorganic Chemistry and Bioscience [174].

Main results related to solvothermal synthesis of carbon nitrides are reported in Table VIII.

Melamine due to its specific skeleton of $\left(\mathrm{C}_{3} \mathrm{~N}_{3}\right)$ heterocycles was firstly considered as precursor. One of the first solvothermal synthesis of carbon nitride through the condensation of melamine and cyanuric chloride as precursors with ethyl-di- 
isopropylamine as solvent (in order to trap chlorine anions) in supercritical conditions $\left(\mathrm{P}=140 \mathrm{MPa}, \mathrm{T}=250^{\circ} \mathrm{C}\right)$ has been performed by Montigaud et al. [99]. It has led to the synthesis of a poorly crystallized graphitic phase with $\mathrm{C}: \mathrm{N}$ atomic ratio of 0.78 . Authors underlined the great instability of the material under electron beam (TEM analysis) and assumed that it is due to the high content of hydrogen. Recently same reagents have been used in presence of nickel with supercritical benzene as solvent (temperature being $400^{\circ} \mathrm{C}$ and pressure being autogenous) [175]. Here Li et al. observed in both cases the formation of nitrogen-rich carbon nitrides hollow spheres (10-40 nm in size) with $C: N$ equal to 0.68 . In this case, nickel is claimed to be necessary to induce polycondensation mechanism and to be responsible for this particular morphology. They have also carried out the polycondensation between melamine and cyanuric chloride in presence of nickel without solvent (temperature still being $400^{\circ} \mathrm{C}$ ) [175]. They still obtained carbon nitride hollow spheres with quite good crystallinity. When comparing this last experiment with that of Zhang et al. [107] performed at higher pressure and temperature one should then notice the key role of nickel that favours the polycondensation mechanism in much softened conditions. Nevertheless, it is obvious that crystallinity obtained by Zhang et al. is better and can be favoured not only by experimental pressure and temperature but also by the presence of chlorine ions in the obtained material. Montigaud et al. have also studied the solvothermal condensation of melamine without secondary reagent at higher pressure and temperature conditions $\left(\mathrm{P}=3 \mathrm{GPa}, \mathrm{T}=800-850^{\circ} \mathrm{C}\right)$ with pure hydrazine $\left(\mathrm{NH}_{2} \mathrm{NH}_{2}\right)$ as solvent $[176,177]$. The resulting material was a carbon nitride with a graphitic structure and a composition close to $\mathrm{C}_{3} \mathrm{~N}_{3.36} \mathrm{O}_{0.14} \mathrm{H}_{1.24}$. In this case, hydrogen content is lower and crystallinity has been clearly improved. The sample has been characterized by X-Ray diffraction under synchrotron radiation and High Resolution 
Electronic Microscopy [50]. Then an unpredicted graphitic structure has been evidenced: in this orthorhombic cell, $\left(\mathrm{C}_{3} \mathrm{~N}_{3}\right)$ heterocycles are bridged one to another by $\mathrm{sp}^{2} \mathrm{~N}-\mathrm{sp}^{3} \mathrm{~N}$ belonging to adjacent cycles and by $\mathrm{sp}^{2}$ nitrogen outside cycles. This sample still exhibits unstable character under electron beam nevertheless it is less pronounced than with the first synthesis route. Stability of these carbon nitrides is probably linked not only to hydrogen content but also to crystallinity and C:N ratio. Here one should observe that treatment of melamine under pressure and temperature performed by Ma et al. [108] without solvent has led to a mixture containing a graphitic phase which crystallinity seems not so good. Then solvothermal experiments performed by Montigaud et al. have revealed that specific mechanisms involved during solvothermal processes not only help to soften experimental conditions but also seem to be promising to get well-crystallized nitrogen-rich carbon nitrides.

Roughly two different types of precursors have then been developed to carry out solvothermal synthesis of carbon nitrides:

(i) $\mathrm{CCl}_{4}$ (with or without $\mathrm{NH}_{4} \mathrm{Cl}$ ) in presence of a nitriding polar solvent $\left(\mathrm{NH}_{3}\right.$ ), carbon and nitrogen being provided by two different sources,

(ii) $\mathrm{C}_{3} \mathrm{~N}_{3} \mathrm{Cl}_{3}$ (source of both carbon and nitrogen) with different additives able to trap chloride anions (as alcalin metals) or/and to bring additive nitrogen (as $\mathrm{NaNH}_{2}$ or $\mathrm{NaN}_{3}$ ) using a non-polar solvent $\left(\mathrm{C}_{6} \mathrm{H}_{6}\right.$ or $\left.\mathrm{C}_{6} \mathrm{H}_{12}\right)$.

In these experiments, moderate pressure and temperature conditions have been developed in solvothermal (involving either supercritical or subcritical) conditions.

Cao et al. have attempted the following chemical reaction: $\mathrm{CCl}_{4}+\mathrm{NH}_{3} \rightarrow \mathrm{C}_{\mathrm{x}} \mathrm{N}_{\mathrm{y}}+$ $\mathrm{NH}_{4} \mathrm{Cl}$ (equation 7) performing ammonothermal process with $\mathrm{CCl}_{4}$ as reagent and iron as catalyst [178]. Temperature has been varied in the range $300-500^{\circ} \mathrm{C}$ and pressure has 
been estimated to be above MPa. The obtained materials are poorly crystallized. For temperatures above $350^{\circ} \mathrm{C}$, they only contain nitrogen and carbon (the presence of hydrogen being not evidenced by IR spectroscopy), the $\mathrm{N}$ content increasing with the treatment temperature $\left(30 \%\right.$ of nitrogen for synthesis performed at $\left.500^{\circ} \mathrm{C}\right)$. Moreover, $\mathrm{C}-\mathrm{N}$ bonds have been evidenced in the nitrided materials, which proves the chemical reaction between $\mathrm{CCl}_{4}$ and ammonia in quite soft conditions.

In the same purpose, Bai et al. have treated a mixture of $\mathrm{CCl}_{4}$ and $\mathrm{NH}_{4} \mathrm{Cl}$ into an autoclave at $400^{\circ} \mathrm{C}$ during $20 \mathrm{~h}$ [179]. First ammonium chloride was decomposed in situ into $\mathrm{HCl}$ and $\mathrm{NH}_{3}\left(\mathrm{~T}_{\mathrm{c}}=132.4^{\circ} \mathrm{C}, \mathrm{P}_{\mathrm{c}}=11.28 \mathrm{MPa}\right)$ becoming both supercritical solvent and nitriding agent. Carbon nitride was then synthesized according to the expected following equation: $3 \mathrm{CCl}_{4}+4 \mathrm{NH}_{3} \rightarrow \mathrm{C}_{3} \mathrm{~N}_{4}+12 \mathrm{HCl}$ (equation 8). The as-obtained material exhibited very good crystallinity and its X-Ray diffraction pattern is consistent with graphite-like $\mathrm{C}_{3} \mathrm{~N}_{4}$. The coherence length deduced from XRD experiments was equivalent to the crystallites size observed by TEM and is about $11 \mathrm{~nm}$. Infra-Red spectroscopy not only confirmed the presence of $\mathrm{C}=\mathrm{N}$ and $\mathrm{C}-\mathrm{N}$ bonds but also evidenced the presence of hydrogen bonded to nitrogen. This work is interesting in the sense that despite the moderate experimental conditions, a well-crystallized carbon nitride has been synthesized using the in situ formation of a nitriding agent in supercritical conditions. When comparing with Cao et al. experiment [178], it is obvious that both crystallinity and chemical composition have been improved (while experimental pressure and temperature are close) which is due to an increase of nitriding power. This can be explained by the in situ formation of nitriding agent. In both cases, it is really interesting to notice that soft pressure and temperature conditions 
have been sufficient to destroy polarized bonds in order to favour the formation of more covalent $\mathrm{C}-\mathrm{N}$ ones.

Other experiments have been carried out using $\mathrm{C}_{3} \mathrm{~N}_{3} \mathrm{Cl}_{3}$ as carbon and nitrogen source, the amount of nitrogen in the final material being adjusted using additive nitriding agents.

According to the following chemical equation: $\mathrm{C}_{3} \mathrm{~N}_{3} \mathrm{Cl}_{3}+\mathrm{Li}_{3} \mathrm{~N} \rightarrow \mathrm{C}_{3} \mathrm{~N}_{4}+3 \mathrm{LiCl}$ (equation 9), Fu et al. [180] have performed the metathesis reaction between $\mathrm{Li}_{3} \mathrm{~N}$ and $\mathrm{C}_{3} \mathrm{~N}_{3} \mathrm{Cl}_{3}$ with benzene as solvent, the experimental conditions being: $\mathrm{P}=5 \mathrm{MPa}$, $\mathrm{T}=350^{\circ} \mathrm{C}$ and the duration $\mathrm{t}=12 \mathrm{~h}$. After removal of unreacted precursors and $\mathrm{LiCl}$ (which presence confirms the equation 9), the observed product was claimed to be an amorphous powder containing some polycrystalline grains indexed with the $\beta-C_{3} \mathrm{~N}_{4}$ structure. The whole C:N ratio has strongly increased (1:0.39) in comparison with starting value (1:1.33) and hydrogen has been detected by infrared experiments. This loss of nitrogen indicates that $\mathrm{C}-\mathrm{N}$ bonds have been destroyed during benzene-thermal process. In 2003, the same group has still performed the same experiment, the only difference being the amount of benzene added in the autoclave $(70 \%$ of total volume instead of $25 \%$ ) $[178,181]$. Temperature has been varied from 200 to $500^{\circ} \mathrm{C}$ and pressure from 3 to $15 \mathrm{MPa}$. The first interesting conclusion dealed with the crucial role of pressure and temperature. Authors explained that crystalline phases could only be obtained in a very narrow temperature and pressure domain, respectively in the ranges $300-400^{\circ} \mathrm{C}$ and $5-7 \mathrm{MPa}$, lowest temperatures leading to the formation of amorphous system while highest ones induced the decomposition of benzene. Best results are then obtained in supercritical benzene $\left(\mathrm{T}_{\mathrm{c}}=288.9^{\circ} \mathrm{C}\right.$ and $\left.\mathrm{P}_{\mathrm{c}}=4.86 \mathrm{MPa}\right)$ which helps the dissolution and activation of reagents. Authors claimed that the optimized powder 
obtained in such conditions mainly consisted in a mixture of $\alpha$ - and $\beta-\mathrm{C}_{3} \mathrm{~N}_{4}$. At $355^{\circ} \mathrm{C}$, the $\alpha$-form was clearly predominant which was consistent with thermodynamical considerations as it is more stable than $\beta-\mathrm{C}_{3} \mathrm{~N}_{4}$. Nevertheless, one should notice the high average $\mathrm{C}: \mathrm{N}$ ratio in comparison with theoretical value (1:0.76-1:0.66 instead of 1:1.33) and the non-indexed peaks on the X-Ray diffraction pattern indicative of the presence of one or several unknown crystallized phase. The stoichiometry of the $\alpha$ - and $\beta$-polytypes was then far from obvious. Authors assumed that the crystalline carbon nitrides are distributed in an amorphous matrix that is nitrogen-poor. Moreover they suggested that the $\mathrm{C}: \mathrm{N}$ ratio in $\beta-\mathrm{C}_{3} \mathrm{~N}_{4}$ could be slightly higher than $1: 1.33$ as ever proposed in literature due to repulsion between non bonded $\mathrm{N}$ atoms which could be replaced by $\mathrm{C}$ C bonded dimers [118]. Here further characterizations appear necessary to precise the chemical nature of the dense phases observed. To underline the role played by the nitriding agent, Guo et al. have studied the benzene-thermal reaction between $\mathrm{C}_{3} \mathrm{~N}_{3} \mathrm{Cl}_{3}$ and $\mathrm{NH}_{4} \mathrm{Cl}$ in presence of iron at $300^{\circ} \mathrm{C}$ [182]. Here graphitic polymeric $\left[\left(\mathrm{C}_{3} \mathrm{~N}_{3}\right)_{2}\left(\mathrm{NH}_{3}\right)\right]_{\mathrm{n}}$ network is obtained ( $\mathrm{C}: \mathrm{N}$ ratio equal to 0.66$)$. When comparing this experiment with those of Cao $[178,181]$, one can then conclude about the key role played by the nitriding agent. It seems obvious that the chemical reaction is different with $\mathrm{N}^{3-}$ (in case of $\mathrm{Li}_{3} \mathrm{~N}$ ) which tends to favour 3D-structures and to break some preexisting $\mathrm{C}-\mathrm{N}$ bonds while the use of $\mathrm{NH}_{4} \mathrm{Cl}$ does not affect $\mathrm{C}_{3} \mathrm{~N}_{3}$ heterocycles and favours polycondensation mechanism.

In order to precise nitridation mechanisms, others experiments have been performed still using $\mathrm{C}_{3} \mathrm{~N}_{3} \mathrm{Cl}_{3}$ as carbon and nitrogen source in presence of other nitriding agents. Guo et al. [183] have used $\mathrm{NaN}_{3}$ instead of $\mathrm{Li}_{3} \mathrm{~N}$ according to the chemical equation: $\mathrm{C}_{3} \mathrm{~N}_{3} \mathrm{Cl}_{3}+3 \mathrm{NaN}_{3} \rightarrow \mathrm{C}_{3} \mathrm{~N}_{4}+3 \mathrm{NaCl}+4 \mathrm{~N}_{2}$ (equation 10 ). The reaction has been carried 
out in presence of benzene as solvent at $220^{\circ} \mathrm{C}$ (under the critical temperature of benzene) during $15 \mathrm{~h}$. The obtained material is composed of high quality carbon nitride nanotubes (yield of $40 \%$ ) with inner diameter of $50-100 \mathrm{~nm}$, wall thickness of $20-50 \mathrm{~nm}$ and length ranges from hundreds of nanometers to about $2 \mu \mathrm{m}$. The graphite like $\mathrm{sp}^{2}$ bonded structure has been evidenced by XPS experiments. Concerning the chemical composition, the atomic $\mathrm{C}: \mathrm{N}$ ratio has been characterized by elemental analysis and is equal to 0.8 which is really close to the theoretical value for $\mathrm{C}_{3} \mathrm{~N}_{4}(0.75)$. Moreover, the presence of hydrogen bonded to nitrogen still has been detected. With the above experimental conditions, Guo et al. have succeeded in the elaboration of graphitic carbon nitride with nanotube organization. The same group has then attempted an equivalent benzene-thermal synthesis replacing $\mathrm{NaN}_{3}$ by $\mathrm{NaNH}_{2}$ with comparable moderate temperature $\left(180-220^{\circ} \mathrm{C}\right)$ [184]. The expected chemical reaction is the following: $\mathrm{C}_{3} \mathrm{~N}_{3} \mathrm{Cl}_{3}+3 \mathrm{NaNH}_{2} \rightarrow \mathrm{C}_{3} \mathrm{~N}_{4}+3 \mathrm{NaCl}+2 \mathrm{NH}_{3}$ (equation 11). However, in this case, authors have precised that the mechanism of decomposition of $\mathrm{NaNH}_{2}$ was leading to the formation of $\mathrm{NaN}_{3}$ and $\mathrm{NH}_{3}$. Here, the obtained material mainly consisted of graphitic carbon nitride nanocrystallites, the atomic $\mathrm{C}: \mathrm{N}$ ratio being 0.72 , still close to the expected value for $\mathrm{C}_{3} \mathrm{~N}_{4}$, and N-H bonds being still present. When comparing these two last experiments, we can confirm the key role of the additive nitriding agent: in both cases, the $\mathrm{C}: \mathrm{N}$ ratio is quite the same, graphitic carbon nitride planes are formed but the structural arrangement is different as the graphene planes are organized in nanotubes when $\mathrm{NaN}_{3}$ is directly used. We can then wonder about the influence of $\mathrm{NH}_{3}$ generated in situ according to the decomposition process of sodium amide into $\mathrm{NaN}_{3}$ and $\mathrm{NH}_{3}$. It seems that the formation of this polar cosolvent impedes the nanotube organization. Another hypothesis could consist of another nitriding process, $\mathrm{NaNH}_{2}$ 
decomposition then leading to $\mathrm{Na}^{+}$and $\mathrm{NH}_{2}{ }^{-}$ions. When comparing the same approach using $\mathrm{Li}_{3} \mathrm{~N}$ for temperatures below critical temperature of benzene which has only led to amorphous system with lower nitrogen content $[178,181]$, we can then conclude that $\mathrm{NaN}_{3}$ (then $\mathrm{N}_{3}^{-}$anions) is much more efficient as nitriding agent than $\mathrm{Li}_{3} \mathrm{~N}\left(\mathrm{~N}^{3-}\right.$ anions) at these low temperatures. Moreover, taking into account the fact that $\alpha$ - and $\beta-C_{3} \mathrm{~N}_{4}$ have been obtained in supercritical benzene with $\mathrm{Li}_{3} \mathrm{~N}$ as nitriding agent, it would be probably of great interest to use the system $\mathrm{C}_{3} \mathrm{~N}_{3} \mathrm{Cl}_{3}+\mathrm{NaN}_{3}$ (or $\mathrm{NaNH}_{2}$ ) above benzene critical point to verify if the elaboration of dense carbon nitride is favoured by such thermodynamical condition.

$\mathrm{Mu}$ et al. [185] have performed the wurtz-like reaction of cyanuric chloride with sodium metal in presence of cyclohexane as solvent, via a solvothermal process. Sodium acts as reducing metal that will induce the formation of $\mathrm{C}_{3} \mathrm{~N}_{3}$ clusters and $\mathrm{NaCl}$. These clusters then connect together to form extended graphitic arrangements. No catalyst has been used, temperature has been maintained to $250^{\circ} \mathrm{C}$ during $10 \mathrm{~h}$. In this case, the obtained graphitic material is a polymeric carbon nitride powder with $\mathrm{C}: \mathrm{N}$ stoichiometry equal to 1:1 as expected. The $\left(\mathrm{C}_{3} \mathrm{~N}_{3}\right)$ clusters are bridged by carbon-carbon atoms in the extended material. From a morphological point of view, the material consists in spherical nanoparticles with an average diameter of 50nm.

In the same way, Li et al. [186] have recently performed this same original synthesis for temperature and pressure in the ranges $230-290^{\circ} \mathrm{C}$ and $1.8-4.5 \mathrm{MPa}$ respectively. Two kinds of experiments were performed depending on the use or not of $\mathrm{NiCl}_{2}$ as a catalyst. Nickel chloride favours the formation of carbon nitride nanotube bundles $\left(230^{\circ} \mathrm{C}, 1.8\right.$ $\mathrm{MPa}$ ) while without catalyst only carbon nitride nanoribbons are observed. In both cases, the $\mathrm{C}: \mathrm{N}$ ratio is maintained in obtained materials. The mechanism of catalysis is 
assumed to be due to a previous reduction of $\mathrm{NiCl}_{2}$ by $\mathrm{Na}$, which leads to the deposition of nickel particles on sodium surface. Then, after reduction of the carbon nitride precursor, the $\left(\mathrm{C}_{3} \mathrm{~N}_{3}\right)$ clusters first connect by rolling at the Ni particles then assemble in nanotube bundles, the growth being then ensured in the axial direction. Without catalyst, it appeared difficult for ribbons to form tubular morphologies. In this configuration, authors have observed that the slight increase in temperature $\left(260^{\circ} \mathrm{C}\right.$ instead of $230^{\circ} \mathrm{C}$ ) much favours the dissolution and dispersion of $\mathrm{C}_{3} \mathrm{~N}_{3} \mathrm{Cl}_{3}$ in solvent, the main consequence being a clear change of the reaction rate and drastic consequences on assembly mechanisms.

When comparing results obtained by $\mathrm{Li}$ et al. [186] with those of $\mathrm{Mu}$ et al. [185] without catalyst at the same temperature we can notice that the obtained morphologies are different (microspheres of nanoribbons [186] or nanospheres [185]) while the only difference deals with the concentration of reagents and a slight modification in the ratio $\mathrm{C}_{3} \mathrm{~N}_{3} \mathrm{Cl}_{3} / \mathrm{Na}$. Then the mechanisms responsible for all these morphologies are very sensitive to all experimental parameters (concentration, temperature, reducing agent amount, catalyst presence, pressure) which underlines the great complexity of the phenomena involved in the solvothermal route.

Through a first analysis of the results obtained by solvothermal process, only a metathesis reaction $\left(\mathrm{C}_{3} \mathrm{~N}_{3} \mathrm{Cl}_{3}+\mathrm{Li}_{3} \mathrm{~N} \rightarrow \mathrm{C}_{3} \mathrm{~N}_{4}+3 \mathrm{LiCl}\right.$, equation 9) using a non polar solvent at the highest temperature (between 300 and $400^{\circ} \mathrm{C}$, above critical point) has led to the formation of carbon nitride with a three-dimensional structure ( $\alpha$ and $\beta$ forms). The other attempts have allowed the formation of graphitic structures (with original morphologies of particles in presence of reducing metal). It is interesting to underline that, in the case of the solvothermal synthesis of c-BN, also metathesis reactions (with 
benzene as solvent) were able to generate the cubic form [187]. Moreover, in this case it has been evidenced that the chlorine anions concentration strongly influenced the morphology of the c-BN particles (nanorods being obtained for highest $\mathrm{Cl}^{-}$ concentration). Such a reaction-type would be able to favour a 3D structural network if the solvent is carefully selected for dispersing the chemical reactants. Moreover, due to the drastic influence of any temperature modulation on the structural polytype obtained, careful scans in pressure and temperature will have to be undertaken and supercritical domain will have to be particularly studied. It has been evidenced that solvothermal conditions are appropriate to conserve $\mathrm{C}: \mathrm{N}$ ratio of the precursors (for example triazines) or to increase it in presence of an additive nitriding agent. In this way we strongly believe that a detailed study of the system $" \mathrm{C}_{3} \mathrm{~N}_{3} \mathrm{Cl}_{3}+\mathrm{NaN}_{3}$ " in supercritical benzene will be of relevant interest.

\section{III.3.5. Other carbon nitrides synthesis using moderate experimental conditions}

Various processes still involving mainly mild temperature conditions for preventing the formation of $\mathrm{N}_{2}$ but different from solvothermal ones have been investigated.

Significant results are reported in Table IX.

As underlined by Gillan [143], main synthetic routes for $\mathrm{C}_{3} \mathrm{~N}_{4}$ elaboration from molecular compounds usually require high temperature $\left(>700^{\circ} \mathrm{C}\right)$, the direct consequence being the poor nitrogen content in as-obtained materials. Then different authors have investigated the decomposition of organic precursor in a moderate temperature domain. Concerning the choice of the precursor, it is mainly influenced by nitriding effect: as $\mathrm{N}_{2}$ or $\mathrm{NH}_{3}$ are too stable, it is then necessary to involve nitrogen sources such as azides $\left(\mathrm{N}_{3}{ }^{-}\right)$. For example, as ever discussed in case of carbon nitrides or 
other materials such as $\mathrm{GaN}$ [169], $\mathrm{NaN}_{3}$ is particularly appropriate. Nevertheless, one should then take into account the high instability of such reagents.

During these last years several works based on thermal decomposition of organic precursors have been developed for explaining the mechanism governing the formation of a graphitic structure containing carbon and nitrogen. Thermal treatment (up to $450^{\circ} \mathrm{C}$ in a sealed glass ampoule) of $\mathrm{C}-\mathrm{N}-\mathrm{H}$ compounds such as melamine $\mathrm{C}_{3} \mathrm{~N}_{3}\left(\mathrm{NH}_{2}\right)_{3}$, dicyandiamide $\mathrm{H}_{4} \mathrm{C}_{2} \mathrm{~N}_{4}$, ammonium dicyanamide $\mathrm{NH}_{4}\left[\mathrm{~N}(\mathrm{CN})_{2}\right]$ or cyanamide $\mathrm{H}_{2} \mathrm{CN}_{2}$ has led via a polycondensation process and loss of ammonia to the formation of a nitrogen-rich condensed molecular structure so-called melem (2,5,8 triamino-tri-striazine) underlining the interest of such compounds as intermediate towards a $(\mathrm{C}, \mathrm{N}, \mathrm{H})$ graphitic structure [188]. Melem compound consists in nearly planar $\mathrm{C}_{6} \mathrm{~N}_{7}\left(\mathrm{NH}_{2}\right)_{3}$ molecules which are organized into parallel layers with an interplanar distance of 3.27 $\AA$. When treated at temperatures up to $580^{\circ} \mathrm{C}$, melem transforms into a graphitic carbon nitride with an interplanar distance of $3.40 \AA$. Same organization has been evidenced after thermal treatment at of guanylurea dicyanamide $\left[\left(\mathrm{NH}_{2}\right) \mathrm{C}(=\mathrm{O}) \mathrm{NHC}\left(\mathrm{NH}_{2}\right)_{2}\right]\left[\mathrm{N}(\mathrm{C} \equiv \mathrm{N})_{2}\right]$ which still induces addition, cyclisation and elimination reactions [189]. In a first step, melamine is obtained at about $130^{\circ} \mathrm{C}$ and leads to a melem phase by heating at about $380^{\circ} \mathrm{C}$. Further heating around $490^{\circ} \mathrm{C}$ induces the formation of graphitic carbon nitride (d spacing still being $3.40 \AA$ ).

Lotsch and Schnick [190] have also recently investigated the thermal behaviour of three new non metal tricyanomelaminates $\left(\left(\mathrm{NH}_{4}\right)_{2}\left(\mathrm{C}_{6} \mathrm{~N}_{9} \mathrm{H}\right),\left[\mathrm{C}\left(\mathrm{NH}_{2}\right)_{3}\right]_{3}\left(\mathrm{C}_{6} \mathrm{H}_{9}\right), 2 \mathrm{H}_{2} \mathrm{O}\right.$ and $\left.\left(\mathrm{C}_{3} \mathrm{~N}_{6} \mathrm{H}_{7}\right)_{2}\left(\mathrm{C}_{6} \mathrm{~N}_{9} \mathrm{H}\right), 2.4 \mathrm{H}_{2} \mathrm{O}\right)$ prepared through metathesis reactions. Heating led to a graphitic hydrogenated carbon nitride involving the formation of the intermediate inevitable of melem compound $\mathrm{C}_{6} \mathrm{~N}_{7}\left(\mathrm{NH}_{2}\right)_{3}$ in the following temperature range 380- 
$500^{\circ} \mathrm{C}$. The structure of the melem could have been solved by single-crystal X-Ray diffraction [191]. Melem as intermediate material elaborated by polycondensation mechanism is of relevant interest in the sense that it is highly nitrogen rich, the molar $\mathrm{C}: \mathrm{N}$ ratio being 1:1.67. One should then expect that the graphitic carbon nitride obtained after further decomposition should contain great amount of nitrogen.

In this way, Gillan [143] has focused his interest on 2,4,6-triazido-1,3,5-triazine. The thermal decomposition of $\left(\mathrm{C}_{3} \mathrm{~N}_{3}\right)\left(\mathrm{N}_{3}\right)_{3}$ has been performed at $185^{\circ} \mathrm{C}$ (with slow heating) into a stainless steel reactor either under autogenous nitrogen pressure or with a previous nitrogen pressure of 6 atm. As expected, the high content of nitrogen in the organic reagent allows the formation of nitrogen-rich materials. In the first case, an orange brown powder with $\mathrm{C}_{3} \mathrm{~N}_{3.9} \mathrm{H}_{1.4} \mathrm{O}_{0.2}$ (called $\mathrm{C}_{3} \mathrm{~N}_{4}$ ) composition is obtained. In the second one, highest nitrogen pressure involves a great increase of nitrogen content in the as-obtained powder as it has the following $\mathrm{C}_{3} \mathrm{~N}_{4.7} \mathrm{H}_{1.3} \mathrm{O}_{0.4}$ (called $\mathrm{C}_{3} \mathrm{~N}_{5}$ ) composition. Both samples are amorphous and have significant $\mathrm{sp}^{2}$ carbon bonding in a conjugated doubly bonded network. The decomposition mechanism led to the formation of nitrene species that couple, attack another ring or insert into its own triazine ring, which allowed reaching high nitrogen content into carbon nitrides. In this particular case, because of this decomposition mechanism, over-stoichiometry in nitrogen can then be observed. $\mathrm{C}_{3} \mathrm{~N}_{4}$ and $\mathrm{C}_{3} \mathrm{~N}_{5}$ were also significantly stable under argon atmosphere up to $600^{\circ} \mathrm{C}$, nevertheless a slight decrease of nitrogen content in $\mathrm{C}_{3} \mathrm{~N}_{5}$ sample when temperature increased up to $600^{\circ} \mathrm{C}$ was evidenced. Here, due to highly unstable character of the triazine reagent, the kinetics of the temperature increasing is a key factor: when the organic reagent is rapidly heated up to $200^{\circ} \mathrm{C}$ into the reaction vessel, the obtained material in then nanosized graphite particles with almost no detectable 
nitrogen. These works present the interest of triazines as precursors for carbon nitride synthesis but also underline the encountered experimental difficulties due to their unstable character.

Same group in 2002 [144] has studied the rapid decomposition of the trichloromelamine $\left[\left(\mathrm{C}_{3} \mathrm{~N}_{3}\right)(\mathrm{NHCl})_{3}\right]$, this reagent still exhibiting $\left(\mathrm{C}_{3} \mathrm{~N}_{3}\right)$ skeleton. The thermal increasing was generated either with an external heating above $185^{\circ} \mathrm{C}$ or by contact with heated filament. The ideal decomposition should occur according to the following equation : $\left(\mathrm{C}_{3} \mathrm{~N}_{3}\right)(\mathrm{NHCl})_{3} \rightarrow \mathrm{C}_{3} \mathrm{~N}_{4+\mathrm{x}}+3 \mathrm{HCl}+(2-\mathrm{x}) / 2 \mathrm{~N}_{2}$ (equation 12). Whatever the thermal process involved, it has been evidenced that the decomposition of trichloromelamine is highly exothermic and leads to the formation of a poorly crystallized nitrogen-rich graphitic carbon nitride $\mathrm{C}_{3} \mathrm{~N}_{4+\mathrm{x}}$ with $0.5<\mathrm{x}<0.8$. The layers can be described as $\left(\mathrm{C}_{3} \mathrm{~N}_{3}\right)$ triazine rings bridged one to another by three-fold coordinated nitrogen which can be hydrogenated or not. Authors have evidenced that annealing of the material tends towards a loss of hydrogen and nitrogen correlated with an increasing of non hydrogenated bonding nitrogen in the graphitic planes. Miller et al. [144] have then showed that pressure was not necessary to favour high content of nitrogen in carbon nitrides, the thermal decomposition of organic precursors simply being an interesting and promising solution. In their case, the obtained material is thermally robust up to $600^{\circ} \mathrm{C}$. According to Miller et al. [144] and Gillan [143], this temperature seems to be a key step relative to the stability of layered carbon nitrides.

Komatsu [145] has focused on the melamine $\mathrm{C}_{3} \mathrm{~N}_{3}\left(\mathrm{NH}_{2}\right)_{3}$ polycondensation using a Lewis acid $\left(\mathrm{ZnCl}_{2}\right)$. Precursors were heated at $650^{\circ} \mathrm{C}$ during 1 hour into an alumina tube in presence of $\mathrm{CaCl}_{2}$ at the top, the tube being inserted into an autoclave. The asobtained graphitic material exhibits high nitrogen content (chemical analysis being: $\mathrm{C}$ : 
$37.11 \%, \mathrm{H}: 1.84 \%, \mathrm{~N}: 61.05 \%$ ) and a very good crystallinity, all peaks being indexed in an orthorhombic cell which parameters $a, b$ and $c$ are respectively $7.300 \AA, 8.467 \AA$ and $6.492 \AA$ (they do not correspond to parameters expected for orthorhombic graphitic $\mathrm{C}_{3} \mathrm{~N}_{4}$ as described by Alves et al. [50]. The structure is closely related to that predicted by Teter and Hemley [41] taking into account an additional $\left(\mathrm{C}_{3} \mathrm{~N}_{3}\right)$ vacancy surrounded by six $\mathrm{C}_{3} \mathrm{~N}_{4}$ units. In this case, the Lewis acid $\mathrm{ZnCl}_{2}$ tends to form chlorine-free $\mathrm{C}_{3} \mathrm{~N}_{4}-$ zinc complex, zinc being totally removed after washing. The carbon nitride is insoluble (acidic or basic solution), infusible and thermally stable up to $600^{\circ} \mathrm{C}$. Recently another pyrolysis treatment of melamine was described by Zhao et al. [146]. As mentioned by authors, melamine has been widely used as precursor for synthesizing carbon nitrides via different routes such as electrodeposition [192], solvothermal method [177], pyrolysis under high pressure [108]. Zhao et al. have focused on the de-ammonation polycondensation of melamine at moderate temperature $\left(300^{\circ} \mathrm{C}\right.$ then $600^{\circ} \mathrm{C}$ in atmosphere followed by $300^{\circ} \mathrm{C}$ then $650^{\circ} \mathrm{C}$ in vacuum). The resulting polycondensate material was nitrogen rich (elemental analysis indicates: $\mathrm{C}: 32.47 \%, \mathrm{~N}: 50.14 \%$ and $\mathrm{H}$ : $\left.17.39 \%, \mathrm{C}_{3} \mathrm{~N}_{4.63} \mathrm{H}_{1.61}\right)$ and adopted a turbostratic stacking, the 002 reflexion on the XRD pattern being quite sharp and consistent with an interplanar distance of $3.21 \AA$. It is of relevant interest that, despite its high hydrogen content and the probable $\left(\mathrm{C}_{3} \mathrm{~N}_{3}\right)$ vacancies in comparison with theoretical structure predicted by Teter and Hemley, this graphitic carbon nitride exhibits a high thermal stability up to $700^{\circ} \mathrm{C}$ (which is higher than other two-dimensional phases and melamine). Moreover, one should also notice that besides flake-like particles, nanowires exhibiting width and length of $300 \mathrm{~nm}$ and 200-1000 nm respectively can be obviously observed, their formation being attributed to a linear branching condensation process. Finally, it is interesting to compare this 
experiment with that of Montigaud et al. [176] (solvothermal treatment of melamine in hydrazine, $3 \mathrm{GPa}, 800-850^{\circ} \mathrm{C}$ ). In case of Zhao et al., while experiments have been performed without nitriding agent, the nitrogen content is higher which is due to softened pressure and temperature conditions and to different chemical mechanisms involved during solvothermal process or polycondensation.

Still searching for polycondensation of triazine rings process, Guo et al. [193] have mixed 1,3,5-trichlorotriazine $\mathrm{C}_{3} \mathrm{~N}_{3} \mathrm{Cl}_{3}$ with either nitriding agents such as $\mathrm{NaNH}_{2}$ and $\mathrm{NaN}_{3}$ or with potassium. The different mixtures were introduced into a solvent-free autoclave and submitted to heating at $220^{\circ} \mathrm{C}, 380^{\circ} \mathrm{C}$ and $300^{\circ} \mathrm{C}$ respectively. Schematically, two kinds of materials are obtained. On the one hand, for temperatures of $220^{\circ} \mathrm{C}$ and $300^{\circ} \mathrm{C}$ (when the organic reagent is mixed with $\mathrm{NaNH}_{2}$ and $\mathrm{K}$ respectively), graphitic carbon nitrides are obtained and characterized by $\mathrm{CN}_{1.20}$ and $\mathrm{CN}_{0.96}$ compositions, interplanar distances of $3.28 \AA$ and $3.20 \AA$ respectively $\left(\mathrm{CN}_{0.96}\right.$ being poorly crystallized) and presence of triazine $\left(\mathrm{C}_{3} \mathrm{~N}_{3}\right)$ rings into the planes. In both cases, particles exhibited a lamellar structure in clear agreement with graphitic network. In $\mathrm{CN}_{1.20}$ and $\mathrm{CN}_{0.96}$ authors proposed that triazine rings were connected one to another by nitrogen bridges (when $\mathrm{N} / \mathrm{C}>1$ ) or carbon-carbon bonds (N/C close to 1 ). On the other hand, the process involved for higher temperature $\left(380^{\circ} \mathrm{C}\right.$, in case of $\left.\mathrm{NaN}_{3}\right)$ seemed to be different: the obtained graphitic material is nitrogen-poor, with $\mathrm{CN}_{0.25}$ composition and XRD interplanar distance $\mathrm{d}$ of $3.41 \AA$. The unexpected high value of $\mathrm{d}$ can be explained by the formation of onions-like microstructure, which has been confirmed by TEM characterization. Here, it is thought that the highly exothermic explosion of $\mathrm{NaN}_{3}$ leads to the formation of pentagonal rings from six-membered triazine rings which favours the formation of spherical surfaces and onion-like particles 
by folding in all directions. Such a mechanism has ever been encountered in case of nanosized carbon spheres elaboration by formation of pentagonal and heptagonal carbon rings [194]. Then, in case of the reaction between $\mathrm{NaN}_{3}$ and trichlorotriazine, despite the use of highly nitriding agent and because of its instability leading to a great increase of temperature, moderate temperatures lead to nitrogen-poor material exhibiting original onions microstructure.

In the same way, the polycondensation of $\mathrm{C}_{3} \mathrm{~N}_{3} \mathrm{Cl}_{3}$ in presence of $\mathrm{Li}_{3} \mathrm{~N}$ at moderate temperature $\left(220^{\circ} \mathrm{C}\right)$ under nitrogen atmosphere into a PTFE vessel has been investigated by $\mathrm{Oku}$ et al. [195]. After reaction, the presence of $\mathrm{LiCl}$ as by-product seems to confirm the chemical equation: $\mathrm{C}_{3} \mathrm{~N}_{3} \mathrm{Cl}_{3}+\mathrm{Li}_{3} \mathrm{~N} \rightarrow \mathrm{C}_{3} \mathrm{~N}_{4}+3 \mathrm{LiCl}$ (equation 13). The obtained product adopts the chemical composition $\mathrm{C}_{3} \mathrm{~N}_{3.6-4.5} \mathrm{O}_{1.1-1.2} \mathrm{H}_{4.1-4.2}$. Low magnification HREM images evidence the formation of cages structures either capsules or nanotubes with several hundreds of $\mathrm{nm}$ in size that consist in turbostratic graphitic structures with $\mathrm{C}_{3} \mathrm{~N}_{2}$ composition. These nanocages carbon nitride encapsulate nanocrystalline phases with size of 10-30 nm containing carbon, oxygen and hydrogen. Same reagents have been also studied by Khabashesku et al. [196] focusing on the same chemical equation than Oku et al. [195]. Reagents were placed either into a pyrex glass ampoule or into a stainless steel reactor depending on the amount of product required, the reaction being carried out at $380^{\circ} \mathrm{C}$ during some few hours. The same reaction has also been performed in a Monel reactor at lower temperature $\left(300^{\circ} \mathrm{C}\right)$. This last process seems to be more interesting as it allows to decrease the amount of cyano groups in the carbon nitride. After washing, the obtained materials had the following composition: $\mathrm{C}_{0.37-0.42} \mathrm{~N}_{0.55-0.58} 0_{0.02-0.05} \mathrm{Cl}_{0.002-0.005}$ (with also $0.7 \mathrm{wt} \%$ of hydrogen) where average C:N ratio (1:1.33) was close not only to that observed by Oku et al. for the whole system but 
also to the theoretical value expected for $\mathrm{C}_{3} \mathrm{~N}_{4}$. In this material, triazine rings were linked either by 3 -fold nitrogen- or $\mathrm{NH}$ - bridges which indicated graphite-like $\mathrm{sp}^{2}$ bonded structure despite the amorphous character of the material. It is interesting to notice that under high pressures (8-12 GPa), authors have succeeded to induce a change towards a more organized graphitic structure. Same group has proceeded to the same chemical reaction into a steel reactor in presence of porous substrates at $500^{\circ} \mathrm{C}$ [197]. With substrates with low surface area, the dominant product is the same than that described previously [196], but a few spherical particles with average size of 20 microns are observed. Then using substrate with high surface area, the increase of nucleation sites leads to a great increase of the number of hollow spheres, their size being smaller $(30 \mathrm{~nm}-1 \mu \mathrm{m})$. These hollow spheres have been characterized as carbon nitrides (with carbon, nitrogen and oxygen contents of 31,58 and $10 \mathrm{wt} \%$ respectively) structurally related to graphitic $\mathrm{C}_{3} \mathrm{~N}_{4}$, with interlayer $\mathrm{d}$ spacing higher than that of graphitic type but very close to intershell spacing in carbon nanotubes, which is consistent with the rolling of planes. The same reaction has been carried out by refluxing the mixture of two reagents in diglyme (boiling point: $162^{\circ} \mathrm{C}$ ). In this case, hollow spheres are still elaborated (with a significant decrease of cyano groups) but they trap the solvent which leads to an increase of $\mathrm{C}: \mathrm{N}$ ratio. Whatever the process used, Zimmerman et al. observed the formation of hollow spheres, which was attributed to the existence of oligomers as mobile intermediates leading to spherical geometry by self-assembling. Then, when comparing works relative to the system $\mathrm{C}_{3} \mathrm{~N}_{3} \mathrm{Cl}_{3}-\mathrm{Li}_{3} \mathrm{~N}$ [195-197], they mainly led to nitrogen-rich carbon nitrides with graphitic organization and with comparable composition but the particles morphologies are depending on experimental conditions such as gaseous atmosphere, pressure, temperature or the presence of a 
template for example. Moreover one should here notice that same reagents used for solvothermal synthesis in benzene by Cao et al. [178] have allowed the formation of dense carbon nitrides which once more underlines the influence of different chemical mechanisms involved (via dissolution or thermal polycondensation) according to the different experimental processes.

To study the polycondensation mechanism, Gu et al. [198] have performed the reaction between cyanuric chloride and calcium cyanamide at $500-550^{\circ} \mathrm{C}$ into a stainless autoclave (after washing, further drying in vacuum at $60^{\circ} \mathrm{C}$ is necessary). Here a mixture of graphite and graphitic carbon nitride is obtained. The C:N ratio, like interplanar distance, increases versus temperature and tends towards graphite (1:0.297 at $650^{\circ} \mathrm{C}$ ). To explain the graphitic carbon nitride formation, authors proposed a mechanism based on the formation of reactive $\left[\mathrm{C}_{3} \mathrm{~N}_{3}\right]^{3+}$ and unstable $\left[\mathrm{CN}_{2}\right]^{2-}$ intermediate species which then rapidly combined to form the $\mathrm{C}_{3} \mathrm{~N}_{4}$ network. In this case, as a consequence, triazine rings were bridged by threefold coordinated nitrogen atoms.

Nevertheless, the use of $\left(\mathrm{C}_{3} \mathrm{~N}_{3}\right)$ skeleton for the elaboration of carbon nitrides seems far from necessary. On the basis of works of Shtrempler et al. concerning the thermal stability of thiosemicarbazide complexes [199], Goglio et al. [200] have investigated the thermal decomposition $\left(20<\mathrm{T}<590^{\circ} \mathrm{C}\right)$ at atmospheric pressure under argon flow of the organic precursor $\mathrm{NH}_{2} \mathrm{CSNHNH}_{3}$. In the obtained brown orange powder, the molar C:N ratio was close to theoretical value expected (1:1.4), the hydrogen content is low (1.5wt\%). The material was quite well crystallized as the XRD pattern was consistent with a graphitic structure with an interplanar distance of $3.24 \AA$. This network was in agreement with a defective lamellar $\mathrm{C}_{3} \mathrm{~N}_{4}$ structure with $\mathrm{AB}$ stacking [201]. In this 
case, it was interesting to notice that despite the absence of any structural relationship between the reagent and the required carbon nitride, $\left(\mathrm{C}_{3} \mathrm{~N}_{3}\right)$ triazine rings have been formed during the thermal decomposition and have led to a two-dimensional organization of the material at moderate temperature.

Qiu et al. [202] have used carbon tetrachloride $\left(\mathrm{CCl}_{4}\right)$ and ethylenediamine $\left(\mathrm{CH}_{2} \mathrm{NH}_{2}\right)_{2}$ as precursors. They were refluxed together at $90^{\circ} \mathrm{C}$, the obtained precursor was dried at $120^{\circ} \mathrm{C}$, ground into powder and heat treated at atmospheric pressure under a nitrogen or ammonia flow at $600^{\circ} \mathrm{C}$ during 5hours. The overall $\mathrm{C}: \mathrm{N}$ ratio in as-obtained carbon nitrides is 1:0.23 and 1:0.28 for $\mathrm{N}_{2}$ and $\mathrm{NH}_{3}$ treatments respectively. Both materials consisted of turbostratic matrix embedding crystallites with $\alpha-\mathrm{C}_{3} \mathrm{~N}_{4}$ structure that are more numerous with $\mathrm{NH}_{3}$ treatment. As ever underline for turbostratic $\mathrm{BN}$ which is favourable for cubic BN growth [203], the turbostratic carbon nitride matrix should offer suitable environments for the nucleation of $\alpha-\mathrm{C}_{3} \mathrm{~N}_{4}$ crystallites at ambient pressure. These works are of relevant interest in the sense that they suggest the stability of dense carbon nitride at ambient pressure.

Recently Groenewolt and Antonietti have performed the attractive synthesis of spherical carbon nitride nanoparticles using a template process [204]. A nanoporous silica matrix was soaked with liquid cyanamide $\left(\mathrm{CH}_{2} \mathrm{~N}_{2}\right)$, then dried. The synthesis reaction was then carried out by heating such monolith under $\mathrm{N}_{2}$ flow at $550^{\circ} \mathrm{C}$. Matrix was then removed by hydrofluoric acid treatment. Here, despite the interesting aspect of replication of inorganic matrix, a discussion about polycondensation mechanism is proposed. Thermal analysis has evidenced that the first step concerned a dimerization of $\mathrm{N} \equiv \mathrm{C}-\mathrm{NH}_{2}$ molecules towards dicyandiamide $\left[\left(\mathrm{NH}_{2}\right)_{2} \mathrm{C}=\mathrm{N}-\mathrm{C} \equiv \mathrm{N}\right]$ at $150^{\circ} \mathrm{C}$. A condensation leading to the formation of melamine occured at $240^{\circ} \mathrm{C}$, cyameluric core appearing at $390^{\circ} \mathrm{C}$, 
final graphitic network being formed at $520^{\circ} \mathrm{C}$. Then, this experiment led towards a polycondensation process in moderate conditions from a simple linear molecule as starting reagent.

All the processes based on thermal decomposition at ambient pressure often lead to the formation of two-dimensional nitrogen-rich carbon nitrides where triazine rings are mainly bridged by 3-fold nitrogen. The deviation from theoretical $\mathrm{C}: \mathrm{N}$ ratio can be explained by the formation of $\mathrm{C}_{3} \mathrm{~N}_{3}$ voids. For these reasons, the crystallinity of materials is far from excellent, turbostratic organization being often encountered. Hydrogen is generally present and bonded to bridging nitrogen (no $\mathrm{C}-\mathrm{H}$ bonds have been claimed by authors). Its presence seems not to affect the stability of materials. A temperature of $600^{\circ} \mathrm{C}$ also seems to be a key step in the stability of graphitic carbon nitride.

Thermal treatment of organic molecules appears then as a key route for the elaboration of suitable precursors for direct conversion towards dense materials.

\section{Perspectives}

Since the potential existence of low-compressibility $\mathrm{C}_{3} \mathrm{~N}_{4}$ has been claimed by Liu and Cohen on the basis of ab initio calculations [4] more than 800 papers have been focused on this challenge and deal either with bulk or thin films elaboration or characterization or theoretical approach [205]. This State of Art underlines great efforts devoted to bulk-carbon nitrides synthesis involving various chemical routes. These processes mainly differ in energy required to carry out the experiment (pressure and/or temperature conditions) and the associated kinetics aspects, in nature of reagents (either 
common or distinguished sources for carbon and nitrogen), in the presence (or absence) of a solvent, a flux or a catalyst.

Our analysis of the published results leads us to the following global conclusions concerning obtained materials:

- Graphitic carbon nitrides have been widely obtained. Despite interesting results have also been obtained with distinguished sources for $\mathrm{C}$ and $\mathrm{N}$ as precursors, reagents were mainly consisting of $\left(\mathrm{C}_{3} \mathrm{~N}_{3}\right)$ triazine skeleton (melamine, cyanuric chloride for example). It has been evidenced that the presence of these heterocycles favours under moderate conditions via polycondensation mechanism the formation of melem compound. Such molecular material when submitted to highest temperature then decomposes to form graphitic carbon nitride. Fruitful involved processes have been direct synthesis under high pressure, ball milling, solvothermal synthesis and elaboration under moderate conditions. C: $\mathrm{N}$ ratio appears quite difficult to control (as well as crystallinity), nevertheless it is possible to induce either nitrogen under- or overstoichiometry. $\mathrm{C}: \mathrm{N}$ ratios lower than 0.75 can be explained in terms of $\mathrm{C}_{3} \mathrm{~N}_{3}$ voids which does not seem to affect drastically the thermal stability of the graphitic material mainly claimed around $600^{\circ} \mathrm{C}$. Hydrogen is often encountered is synthetized 2D-carbon nitrides, whatever the involved process. Moreover, soft conditions (solvothermal process or polycondensation in moderate thermal conditions) appear as particularly attractive in the sense that they allow to reach various morphologies. The use of nitriding agents such as $\mathrm{NaN}_{3}$ or $\mathrm{Li}_{3} \mathrm{~N}$ seems also as a good solution to control the stoichiometry of materials.

- To date, direct conversion experiments do not lead to really convincing results as segregation of the system into diamond and pure nitrogen seems difficult to avoid. It is 
claimed that $20 \mathrm{GPa}$ and $2000 \mathrm{~K}$ will be necessary to avoid such decomposition. Nevertheless, few attempts have been carried out and, taking into account the great progresses relative to graphitic carbon nitrides synthesis these last years, many interesting works should be performed studying either the influence of starting crystallinity, hydrogen content or C:N stoichiometry. Moreover we strongly believe that X-Ray diffraction experiments using synchrotron radiation with diamond anvil cells equipment and laser heating are necessary to evidence unambiguously the behaviour of graphitic carbon nitrides under pressure and temperature. Special care will have to be devoted to the determination of nitrogen content after the experiment and its distribution on the whole material in case of multiphasic sample. Due to severe pressure and temperature conditions required, such studies will be mainly useful for basic research nevertheless they could be complementary of ab initio approach in the sense that they could allow to evidence unpredicted structures and/or compositions for carbon nitrides. Few attempts have been carried out concerning flux assisted conversion. Whatever, first results are clearly promising as such experiments have led to the formation of $\beta$ - and $\alpha$ $\mathrm{C}_{3} \mathrm{~N}_{4}$ simultaneously. In this case, the use of nickel alloy as flux has been particularly interesting for hydrogenated carbon nitrides conversion because of the affinity of metal for hydrogen. We strongly suggest a thermodynamic approach in the purpose to select metallic alloys (with moderate melting temperature to avoid $\mathrm{N}_{2}$ formation) able to form hydrides but neither nitrides nor carbides ; in this way hydrogenated graphitic carbon nitrides with adequate $\mathrm{C}: \mathrm{N}$ ratio would be of relevant interest as precursors as the breaking of $\mathrm{N}-\mathrm{H}$ bonds ( $\mathrm{C}-\mathrm{H}$ bonds have not been claimed in these materials) will affect the whole stability of the material into the flux and modify its solubility. 
- Finally, concerning direct synthesis of dense carbon nitrides unambiguous results are far from numerous. The high pressure direct synthesis and the shockwaves route have led to elaborate dense structures but nitrogen content still remains a problem in the sense that either these materials are nitrogen-poor or the presence of nitrogen has not been evidenced. As ever mentioned, the involvement of high pressure and temperature favours the stabilization of $\mathrm{N}_{2}$ molecule which then strongly damages carbon nitrides stoichiometry. From a general point of view, many dense structures are claimed nevertheless characterizations are often insufficient. It is interesting to notice that many unsolved and unpredicted structures have been evidenced. We think that ab initio calculation could be helpful for researching other compositions than $\mathrm{C}_{3} \mathrm{~N}_{4}$ (with lower nitrogen content) with a cubic cell or slightly distorded one. In this way, particular attention will have to be given on bulk modulus values. Mechanosynthesis, solvothermal process and moderate conditions way have favoured the stabilization of carbon nitrides crystallites (often nanometric) either with $\beta-$ or $\alpha-\mathrm{C}_{3} \mathrm{~N}_{4}$ structures embedded in amorphous matrix. Finally, the most promising results are relative to the elaboration of materials with either $\beta$ - or pseudocubic $\mathrm{C}_{3} \mathrm{~N}_{4}$ structure by high energy ball milling, nitridation being strongly activated by the presence of defects in carbon source. Here, the involve mechanisms strongly depend on the experimental protocol : $\beta$ polymorph is obtained when nitridation is performed during ball milling while pseudocubic phase appears after nitridation of ball milled carbon. The materials are claimed as single phases. However, we strongly suggest further optimized characterizations such as structural refinement, recording of EELS spectra at low temperature to avoid irradiation damages (published spectra being not in full accordance with those predicted by Paxton et al [206]). It is then obvious that hardness (or bulk 
modulus) measurements must be performed on these carbon nitrides as mechanic performances are expected competitive with those of diamond. Structural characterizations under pressure and temperature would be also of relevant interest to study the phase diagram of $\mathrm{C}_{3} \mathrm{~N}_{4}$. Whatever, ball milling appears particularly attractive to enhance reactivity of chemicals and such process could be tested on triazines in presence of nitriding agent.

To conclude, it is then noticeable that dense carbon nitrides have mainly be obtained in quite soft conditions while it was claimed that high pressures associated with temperature will be necessary. First, the large potentialities of solvothermal reactions have been largely demonstrated during these last ten years and consequently solvothermal route appears promising in the near future either for the $\mathrm{C}_{3} \mathrm{~N}_{4}$ synthesis or the carbon nitride crystal growth. In this way we propose to focus on supercritical benzene as non-polarsolvent, we think that the choice of a system such as triazinesodium azide could then be promising.

It has also been noticed that the polycondensation mechanism of triazines first leading to melem then graphitic carbon nitrides was particularly interesting. Organic chemistry will perhaps be the key of the next step in carbon nitrides history if researches are focused on three-dimensional polycondensation mechanisms of molecules containing carbon and nitrogen in suitable ratio.

This State of Art finally allows to conclude that many progresses concerning elaboration of carbon nitrides have been done which evidences that all efforts devoted to the research of potential superhard $\mathrm{C}_{3} \mathrm{~N}_{4}$ have not been fruitless. To date, many works will still be necessary to understand and control mechanisms involved during synthesis 
as they are strongly depending on parameters such as nature of reagents, nitriding agents, additive, pressure, temperature, duration.

\section{References}

[1] R. Riedel, Adv. Mater. 6 (1994) 549

[2] A. Badzian, T. Badzian, Int. J. Refract. Met. Hard Mater. 15 (1997) 3

[3] R.H. Wentorf, J. Chem. Phys. 26 (1957) 956

[4] A.Y. Liu et M.L. Cohen, Science 245 (1989) 841

[5] M.L. Cohen, Mater. Sci. Eng. A 209 (1996) 1

[6] T. Malkow, Mater. Sci. Eng. A 292 (2000) 112

[7] S. Muhl, J.M. Mendez, Diamond Relat. Mater. 8 (1999) 1809

[8] F. Z. Cui, D. J. Li, Surf. Coat. Technol. 131 (2000) 481

[9] W. Long, Y. Shun, Y. Bing, Rare Met. Mater. Eng. 31 (2002) 96

[10] E. K. Wilson, Chem. Eng. News 82 (2004) 34

[11] E. Kroke, M. Schwarz, Coord. Chem. Rev. 248 (2004) 493

[12] J. B. Hannay, Nature 22 (1880) 255

[13] H. Moissan, Comptes Rendus, 116 (1893) 218

[14] O. I. Leipunskii, Usp. Khim. 8 (1939) 1519

[15] P.W. Bridgman, J. Chem. Phys. 15 (1947) 92

[16] H. Liander, E. Lundblad, Ark. Kemi. 16 (1960) 139

[17] F. P. Bundy, H.T. Hall, H.M. Strong, R.H. Wentorf, Nature 176 (1955) 51

[18] B.V. Derjaguin, B.V. Spitsyn, USSR Author’s Certificate Nº399.134 (1956) and USSR Patent Nº399.134 (1980)

[19] J.C. Angus, Air Force Cambridge Res. Lab. Rep. 66 (1966) AD 630 
[20] J.C. Angus, H. A. Will, W.S. Stanko, J. Appl. Phys. 39 (1968) 2915

[21] S. Matsumoto, Y. Sato, M. Kamo, N. Setaka, Jpn. J. Appl. Phys. 21 (1982) L182

[22] H. O. Meyer, Am. Mineral. 70 (1985) 344

[23] R.H. Mitchell, J.H. Crocket, Miner. Deposita 6 (1971) 392

[24] R. C. De Vries, R. Roy, S. Somiya, S. Yamada, Trans. Mater. Res. Soc. Jpn 19 B (1994) 641

[25] A. Szymanski, E. Abgarowicz, A. Bakon, A. Niedbalska, R. Salacinski, J. Sentek, Diamond Relat. Mater. 4 (1995) 234

[26] Y.G. Gogotsi, K. G. Nickel, P. Kofstad, J. Mater. Chem. 5 (1995) 2313

[27] X.Z. Zhao, R. Roy, K.A. Cherian, A. Badzian, Nature 385 (1997) 513

[28] S. Yamaoka, M. D. S. Kumar, M. Akaishi, H. Kanda, Diamond Relat. Mater. 9 (2000) 1480

[29] A. G. Sokol, Y.N. Pal’yanov, G.A. Pal'yanova, A.F. Khokhryakov, Y. M.

Borzdov, Diamond Relat. Mater. 10 (2001) 2131

[30] R.C. De Vries, Nature 385 (1997) 485

[31] B. Basavalingu, K. Byrappa, M. Yoshimura, P. Madhusudan, A.S. Dayananda, J. Mater. Sci. 41 (2006) 1465

[32] J.M. Calderon-Moreno, Diamond Relat. Mater. 15 (2006) 958s

[33] O. Mishima ,N. Yamaoka ,O. Fukunaga , Jpn Patent 63 (1988) 274447

[34] O. Mishima ,K. Era ,J. Tanaka, S. Yamaoka , App. Phys. Lett. 53 (1988) 962

[35] N. Ahmad, D. Lichtman, Sens. Actuators 18 (1989) 397

[36] Y. Kakudate, M.Yoshida ,S. Usuba ,H. Yokoi, S. Fujiwara, M. Kawaguchi, K. Sato, T. Sawai, Trans. Mater. Res. Soc. Jpn. 14B (1994) 1447

[37] S. Nakano ,M. Akaishi ,T. Sasaki ,S. Yamaoka, Chem. Mater. 6 (1994) 2246 
[38] V.L. Solozhenko, D. Andrault, G. Fiquet, M. Mezouar, D.C. Rubie, Appl. Phys. Lett. 78 (2001) 1385

[39] V.L. Solozhenko, S. Dub, N. Novikov, Diamond Relat. Mater. 10 (2001) 2228

[40] Y. Guo, W.A. Goddard, Chem. Phys. Lett. 237 (1995) 72

[41] D.M. Teter, R.J. Hemley, Science 271 (1996) 53

[42] A.Y. Liu, R.M. Wentzcovitch, Phys. Rev. B 50 (1994) 10362

[43] J. Widany, F. Weich, Th. Köhler, D. Porezag, Th. Frauenheim, Diamond Relat. Mater. 5 (1996) 1031

[44] H. Yao, W.Y. Ching, Phys. Rev. B 50 (1994) 11231

[45] H. Haeuseler, J. Solid State Chem. 29 (1979) 121

[46] J. Martin-Gil, F.J. Martin-Gil, M. Sarikaya, M. Qian, M.José-Yacaman, A. Rubio, J. Appl. Phys. 81 (1997) 2555

[47] S.D. Mo, L. Ouyang, W.Y. Ching, I. Tanaka, Y. Koyama, R. Riedel, Phys. Rev. Lett. 83 (1999) 5046

[48] P. Kroll, J. Solid State Chem. 176 (2003) 530

[49] M.B. Kruger, J.H. Nguyen, Y.M. Li, W.A. Caldwell, M.H. Manghnani, R. Jeanloz, Phys. Rev B 55 (1997) 3456

[50] I. Alves, G. Demazeau, B. Tanguy, F. Weill, Solid State Commun. 109 (1999) 697

[51] J. Ortega, O.F. Sankey, Phys. Rev. B 51 (1995) 2624

[52] M. Côté, M.L. Cohen, Phys. Rev. B 55 (1997) 5684

[53] E. Betranhandy, S.F. Matar, Diamond Relat. Mater. 15 (2006) 1609

[54] R. Weihrich, S.F. Matar, E. Betranhandy, V. Eyert, Solid State Sci. 5 (2003) 701

[55] E. Sandré, C.J. Pickard, C. Colliex, Chem. Phys. Lett. 325 (2000) 53 
[56] J. J. Capponi, J. Chenavas, J. C. Joubert, Bull. Soc. Mineral. Cristallogr. 95 (1972) 412

[57] W. L. Roth, R. C. De Vries, J. Appl. Phys. 38 (1967) 951

[58] K. Landskron, W. Schnick, J. Solid State Chem. 156 (2001) 390

[59] J.B. Goodenough, J.A. Kafalas, J.M. Longo, "High Pressure Synthesis" in Chap. I "Preparative Methods in Solid State Chemistry" Ed. P. Hagenmuller, Academic Press (New York-London) (1972)

[60] G. Demazeau, High Pressure Res. 27 (2007) 1739

[61] G. Demazeau, Chap. 13 "Diamant et matériaux dérivés”, « Le Carbone dans tous ses Etats » Ed. P. Bernier S. Lefrant, Gordon and Breach Science Publishers

[62] J.L. Margave, R.G. Bautista, P.J. Ficalora, R.B. Badachhape, US Patent 3, 711, $595,(16 / 01 / 1973)$

[63] F.P. Bundy, J. Chem. Phys. 38 (1963) 631

[64] S. Naka, K. Horii, Y. Takeda, T. Hanawa, Nature 259 (1976) 38

[65] T. Irifune, A. Kurio,S. Sakamoto, T. Inoue, H. Sumiya, K. Funakoshi, Phys. Earth Planetary Int. 143 (2004) 593

[66] F.P. Bundy, R.H. Wentorf, Jr, J. Chem. Phys. 38 (1963) 1144

[67] A.M. Staver, N.V. Gubareva, A.I. Lyamkin, E.A. Petrov, Comb. Expl. Schock Waves 20 (1984) 567

[68] I. Simonen, S. Chevacharoenkul, Y. Horie, T. Akashi, H. Sawaoka, J. Mater. Sci. $24(1989) 1486$

[69] F.R. Corrigan, US Patent 4, 188-194 (02/12/1980)

[70] A.B. Sawaoka, M. Takamatsu ,T. Akashi, Adv. Mater. 6 (2004) 346

[71] F.R. Corrigan ,F.P. Bundy, J. Chem. Phys. 63 (1975) 3812 
[72] T. Soma ,A. Sawaoka ,S. Saito Mater. Res. Bull. 9 (1976) 755

[73] W.H. Gust , D.A. Young, Phys. Rev. B 15 (1977) 5012

[74] T. Sekine, J. Mater. Sci. Lett. 8 (1989) 1573

[75] C. M. Sung, M.F. Tai, Int. J. Refrac. Metal Hard Mat. 15 (1997) 237

[76] H. Kanda, “Advanced in new Diamond Science and Technology”, Ed. S. Saito, N. Fujimori, O. Fukunaga, M. Kano, K. Kobashi, M. Yoshikawa, Tokyo, p. 507

[77] S. Nakano, H. Ikawa, O. Fukunaga, Diamond Relat. Mater. 3 (1994) 75

[78] G. Biardeau, G. Demazeau, M. Pouchard, Brevet Fr. 2.597.087, 1987

[79] L. Vel, G. Demazeau, J. Etourneau, Mater. Sci. Eng. B10 (1991) 149

[80] G. Demazeau, J. Mater. Chem. 9 (1999) 15

[81] A. Rabeneau, Angew. Chem., Int. Ed. 24 (1985) 1026

[82] L.N. Demianets, Prog. Cryst. Growth Charact. Mater. 21 (1991) 299

[83] P. Reig, G. Demazeau, N. Naslain, J. Mat. Sci. 32 (1997) 4189

[84] K.P. Hong, G. Goglio, I. Presniakov, G. Demazeau, High Pressure Res. 22 (2002) 559

[85] K. P. Hong, G. Goglio, G. Demazeau, D. Y. Jung, Defect Diff. Forum 208 (2002) 251

[86] A. Wang, P. Capitain, V. Monnier, S. Matar, G. Demazeau, J. Mater.: Synth. Process. 5 (1997) 235

[87] A. Denis, G. Goglio, A. Largeteau, G. Demazeau, High Pressure Res. 22 (2002) 585

[88] C.Collado, G. Goglio, G. Demazeau, A. S. Barriere, L. Hirsch, M. Leroux, Mater. Res. Bull. 37 (2002) 841 
[89] G. Demazeau, G. Goglio, A. Denis, A. Largeteau, J. Phys. : Condens. Matter, 14 (2002) 11085

[90] Th. Dubois, G. Demazeau, Mater. Lett. 19 (1994) 38

[91] P. Deines, Geochim. Cosmochim. Acta. 44 (1980) 943

[92] S.R. Boyd, D.P. Mattey, C.T. Pillinger, H.J. Milledge, M.J. Mendelssohn, M. Seal, Earth Planet. Sci. Lett. 86 (1987) 341

[93] S.R. Boyd, C.T. Pillinger, H.J. Milledge, M.J. Seal, Earth Planet. Sci. Lett. 108 (1992) 139

[94] A. Niedbalska, A. Szymanski, High Pressure Res. 7 (1991) 188

[95] R. Roy, D. Ravichandran, P. Ravindranathan, A. Badzian, J. Mater. Res. 11 (1996) 1164

[96] N. Yamasaki, K. Yokosawa, S. Korablov, K. Tohjt, Diffus. Defect Data. Solid State Data. Part B, Solid State Phenom. 114 (2006) 271

[97] V.L. Solozhenko, V.Y. Leonidov, Zh. Fiz. Khim. 62 (1988) 3145

[98] O. Fukunaga, Diamond Relat. Mater. 9 (2000) 7

[99] H. Montigaud, B. Tanguy, G. Demazeau, S. Courjault, M. Birot, J. Dunogues, C.R. Acad. Sc. 325 (IIb) (1997) 229

[100] Demazeau, V. Gonnet, V. Solozhenko, B. Tanguy, M. Montigaud, C.R. Acad. Sc. $320(\mathrm{IIb})(1995) 419$

[101] X.P. Hao, D. L. Cui, G. X. Shi, Y.Q. Yin, X. G. Xu, J. Y. Wang, M. H. Jiang, X. W. Xu, X ; P. Li, B. Q. Sun, Chem. Mater. 13 (2001) 2457

[102] H.T. Hall, Rev. Sci. Instrum. 31 (1960) 125

[103] P. Richet, "Une courte histoire de la pression", La pression : un outil pour les sciences, Eds. J.C. Chervin, J. Peyronneau, CNRS Editions (2003) 
[104] M. Eremets, "High Pressure experimental methods", Oxford Science Publications, (Oxford, New York, Tokyo) 1996

[105] A.B. Sawaoka, Schock Waves in Materials Science, ed., Springer-Verlag (1993)

[106] C.C. Koch, Annu. Rev. Mater. Sci. 19 (1989) 121

[107] Z. Zhang, K. Leinenweber, M. Bauer, L.A.J. Garvie, P.F. McMillan, G.H. Wolf, J. Am. Chem. Soc. 123 (2001) 7788

[108] H.A. Ma, X.P. Jia, L.X. Chen, P.W. Zhu, W.L. Guo, X.B. Guo, Y.D. Wang, S.Q.

Li, G.T. Zou, G. Zhang, P. Bex, J. Phys.: Condens. Matter. 14 (2002) 11269

[109] R.C. Yu, L.C. Chen, J.L. Zhu, F.Y. Li, Z.X. Liu, Z.C. Qin, T.N. Yu, C.Q. Jin,

X.F. Duan, Z. Zhang, Mater. Sci. Eng. A 328 (2002) 104

[110] R.C. Yu, L.C. Chen, J.L. Zhu, F.Y. Li, Z.X. Liu, Z.C. Qin, T.N. Yu, C.Q. Jin, X.F. Duan, Z. Zhang, J. Phys.: Condens. Matter. 14 (2002) 11199

[111] H. Sjöström, L. Hultman, J.E. Sundgren, S.V. Hainsworth, T.F. Page, G.S.A.M.

Theunissen, J. Vac. Sci. Technol. A 14 (1996) 56

[112] M.Y. Chen, D. Li, X. Lin, V.P. Dravid, Y.W. Chung, M.S. Wong, W.D. Sproul, J. Vac. Sci. Technol. A 11 (1993) 521

[113] A. Andreyev, M. Akaishi, D. Golberg, Chem. Phys. Lett. 372 (2003) 635

[114] A. Andreyev, M. Akaishi, D. Golberg, Diamond Relat. Mater. 11-12 (2002) 1885

[115] J. H. NGuyen, R. Jeanloz, Mater. Sci. Eng. A 209 (1996) 23

[116] V.P. Novikov, V.P. Dymont, Appl. Phys. Lett. 70 (1997) 200

[117] V.P. Dymont, E.M. Nekrashevich, I.M. Starchenko, Solid State Commun. 111 (1999) 443

[118] T. Hughbanks, Y. Tian, Solid State Commun. 96 (1995) 321

[119] J.V. Badding, D.C. Nesting, Chem. Mater. 8 (1996) 535 
[120] V.P. Dymont, I. Smurov, Mater. Sci. Eng. B 82 (2001) 39

[121] M.R. Wixom, J. Am. Ceram. Soc. 73 (1990) 1973

[122] C. Collins, N. Thadhani, Z. Iqbal, Carbon 39 (2001) 1175

[123] K. Shibata, T. Sekine, Solid State Commun. 139 (2006) 501

[124] T. Komatsu, Phys. Chem. Chem. Phys. 6 (2004) 878

[125] T. Komatsu, T. Nakamura, J. Mater. Chem. 11 (2001) 474

[126] J. Liu, T. Sekine, T. Kobayashi, Solid State Commun. 137 (2006) 21

[127] J. S. Benjamin, Metall. Trans. 1 (1970) 2943

[128] J. S. Benjamin, Sci. Am. 234 (1976) 40

[129] G. H. Gessinger, Metall. Trans. A 7 (1976) 1203

[130] P. S. Gilman, W. D. Nix, Metall. Trans. A 12 (1981) 813

[131] W. L. Johnson, Prog. Mater. Sci. 30 (1986) 81

[132] R. B. Schwarz, Mater. Sci. Eng. 97 (1988) 71

[133] L. Schultz, Mater. Sci. Eng. 97 (1988) 15

[134] R. B. Schwarz, R. R. Petrich, C. K. Saw, J. Non-Cryst. Solids 76 (1985) 281

[135] C.C. Koch, O.B. Cavin, C.G. McKamey, J.O. Scarbrough, Appl. Phys. Lett. 43 (1983) 1017

[136] Y. Fahmy, T.D. Shen, D.A. Tucker, R.L. Spontak, C.C. Koch, J. Mater. Res. 14 (1999) 2488

[137] M.D. Alcalá, J.C. Sánchez-López, C. Real, A. Fernández, P. Matteazzi, Diamond Relat. Mater. 10 (2001) 1995

[138] L.W. Yin, M.S. Li, G. Luo, J. L. Sui, J.M. Wang, Chem. Phys. Lett. 369 (2003) 483 
[139] L.W. Yin, M.S. Li, Y.X. Liu, J.L. Sui, J.M. Wang, J. Phys.: Condens. Matter 15 (2003) 309

[140] L.W. Yin, Y. Bando, M.S. Li, Y.X. Liu, Y.X. Qi, Adv. Mater. 15 (2003) 1840

[141] Z.Y. Fei, Y.X. Liu, Chin. Phys. Lett. 20 (2003) 1554

[142] Z.G. Gong, M.S. Li, Chin. Phys. Lett. 20 (2003) 1540

[143] E.G. Gillan, Chem. Mater. 12 (2000) 3906

[144] D.R. Miller, J.J. Wang, E.G. Gillan, J. Mater. Chem. 12 (2002) 2463

[145] T. Komatsu, J. Mater. Chem. 11 (2001) 799

[146] Y.C. Zhao, D.L. Yu, H.W. Zhou, Y.J. Tian, O. Yanagisawa, J. Mater. Sci. 40 (2005) 2645

[147] V.L. Solozhenko, E.G. Solozhenko, P.V. Zinin, L.C. Ming, J. Chen, J.B. Parise, J. Phys. Chem. Solids 64 (2003) 1265

[148] H.Z. Zhao, X.L. Chen, C.C. Jia, T. Zhou, X.H. Qu, J. Jian, Y.P. Xu, T. Zhou, Mater. Sci. Eng. B 122 (2005) 90

[149] Y. Han, C. Gao, H. Ma, J. Luo, A. Hao, Y. Li, X. Li , J. Liu, M. Li, H. Liu, H. Xie, G. Zou, Carbon 43 (2005) 1084

[150] J.E. Lowther, Phys. Rev. B. 59 (1999) 11683

[151] L.C. Ming, P. Zinin, Y. Meng, X.R. Liu, S.M. Hong, Y. Xie, J. Appl. Phys. 99 (2006) 33520

[152] A. Zerr, G. Miehe, G. Serghiou, M. Schwarz, E. Kroke, R. Reidel, H. Fuess, P. Kroll, R. Boehler, Nature 400 (1999) 340

[153] T. Taniguchi, New Diamond Front. Carbon Technol. 14 (2004) 289

[154] D.W. He, F.X. Zhang, X.Y. Zhang, Z.C. Qin, M. Zhang, R.P. Liu, Y.F. Xu, W.K. Wang, J. Mater. Res. 13 (1998) 3458 
[155] C.Y. Zang, X.P. Jia, H.A. Ma, S.S. Li, Y. Tian, H.Y. Xiao, Chin. Phys. Lett. 23 (2006) 214

[156] A.L.D. Skury, G.S. Bobrovnitchii, S.N. Monteiro, Diamond Relat. Mater. 13 (2004) 1725

[157] D. W. He, X.J. Luo, L.Y. Din, Chin. J. Atom. Mole. Phys. 12 (1995) 49

[158] B. Baranowski, S. M. Filipek, J. Alloys Compd. 404-406 (2005) 2

[159] Z.Z. Liang, X. Jia, C.Y. Zang, P.W. Zhu, H.A. Ma, G.Z. Ren, Diamond Relat. Mater. 14 (2005) 243

[160] M. Yu, K. Li, Z. Lai, D. Cui, X. Hao, M. Jiang, Q. Wang, J. Cryst. Growth 269 (2004) 570

[161] S. Dong, X. Hao, X. Xu, D. Cui, M. Jiang, Mater. Lett. 58 (2004) 2791

[162] Y. Liu, L. Zhang, Z. Shi, H. Yuan, W. Pang, J. Solid State Chem. 158 (2001) 68

[163] P. E. Hickel, G. Demazeau, R. Arnaud, R. Chapoulie, P. Guibert, E. Vartanian, G.

Villeneuve, F. Bechtel, B. Capelle, High Pressure Res. 18 (2000) 265

[164] E. Ohshima, H. Ogino, I. Niikura, Katsumi Maeda, M. Sato, M. Ito T. Fukuda J.

Cryst. Growth 260 (2004) 166

[165] L. Yin, L. Zhang, F. Li, M. Yu, Mater. Res. Bull. 40 (2005) 2219

[166] R. Dwilinski, R. Doradzinski, J. Garczynski, L. Sierzputowski, J.M. Baranowski,

M. Kaminska, Diamond Relat. Mater. 7 (1998) 1348

[167] A.P. Purdy, Chem. Mater. 11 (1999) 1648

[168] D. R. Ketchum, J. W. Kolis, J. Cryst. Growth 222 (2001) 431

[169] A. Denis, G. Goglio, G. Demazeau, Mater. Sci. Eng. R 50 (2006) 167

[170] Y. Qian, Adv. Mater. 11 (1999) 1101

[171] S. H. Yu, J. Ceram. Soc. Jap. 109 (2001) S65 
[172] S. Ohara, T. Mousavand, M. Umetsu, S. Takami, T. Adschiri, Y. Kuroki, M. Takata, Solid State Ionics 172 (2004) 261

[173] H. Yang, P. Mercier, S. C. Wang, D. L. Akins, Chem. Phys. Lett. 416 (2005) 18

[174] S. Sharma, A. Ramanan, M. Jansen, Solid State Ionics 170 (2004) 93

[175] C. Li, X. Yang, B. Yang, Y. Yan, Y. Qian, Mater. Chem. Phys.103 (2007) 427

[176] H. Montigaud, B. Tanguy , G. Demazeau, I. Alves, M. Birot, J. Dunogues, Diamond Relat. Mater. 8 (1999) 1707

[177] H. Montigaud, B. Tanguy, G. Demazeau, I. Alves, S. Courjault, J. Mater. Sci. 35 (2000) 2547

[178] C. B. Cao, Q. Lv, H. S. Zhu, Diamond Relat. Mater. 12 (2003) 1070

[179] Y.J. Bai, B. Lü, Z.G. Liu, L. Li, D.L. Cui, X.G. Xu, Q.L. Wang, J. Cryst. Growth $247(2003) 505$

[180] Q. Fu, C.B. Cao, H.S. Zhu, Chem. Phys. Lett. 314 (1999) 223

[181] Q. Lv, C.B. Cao, C. Li, J.T. Zhang, H.S. Zhu, X. Kong, X.F. Duan, J. Mater. Chem. 13 (2003) 1241

[182] Q. Guo, Q. Yang, L. Zhu, C. Yi, S. Zhang, Y. Xie, Solid State Commu. 132 (2004) 369

[183] Q. Guo, Y. Xie, X. Wang, S. Zhang, T. Hou, S. Lv, Chem. Commun. 1 (2004) 26

[184] Q. Guo, Y. Xie, X. Wang, S. Lv, T. Hou, X. Liu, Chem. Phys. Lett. 380 (2003) 84

[185] T. Mu, J. Huang, Z. Liu, B. Han, Z. Li, Y. Wang, T. Jiang, H.X. Gao, J. Mater. Res. 19 (2004) 1736

[186] J. Li, C.B. Cao, J.W. Hao, H.L. Qiu, Y. Xu, H.S. Zhu, Diamond Relat. Mater. 15 (2006) 1553 
[187] X.P. Hao, D.L. Cui, X.G. Xu, M.Y. Yu, Y.J. Bai, Z.G. Liu, M.H. Jiang, Mater. Res. Bull. 37 (2002) 2085

[188] B. Jürgens, E. Irran, J. Senker, P. Kroll, H. Müller, W. Schnick, J. Am. Chem. Soc. 125 (2003) 10288

[189] B.V. Lotsch, W. Schnick, Chem. Mater. 17 (2005) 3976

[190] B.V. Lotsch, W. Schnick, Chem. Mater. 18 (2006) 1891

[191] A. Sattler, W. Schnick, Z. Anorg. Allg. Chem. 632 (2006) 238

[192] C. Li, C. B. Cao, H. S. Zhu, Mater. Lett. 58 (2004) 1903

[193] Q.X. Guo, Q. Yang, C.Q. Yi, L. Zhu, Y. Xie, Carbon 43 (2005) 1386

[194] Z.L. Wang, Z.C. Kang, J. Phys. Chem. 100 (1996) 17725

[195] T. Oku, M. Kawaguchi, Diamond Relat. Mater. 9 (2000) 906

[196] V.N. Khabashesku, J.L. Zimmerman, J.L. Margrave, Chem. Mater. 12 (2000) 3264

[197] J.L. Zimmerman, R. Williams., V.N. Khabashesku, J.L. Margrave, Nano Lett. 1 (2001) 731

[198] Y. Gu, L. Chen, L. Shi, J. Ma, Z. Yang, Y. Qian, Carbon 41 (2003) 2653

[199] G. I. Shtrempler, B. Murzubraimov, K. Rysmendeev, Russ. J. Inorg. Chem. 27 (1982) 442

[200] G. Goglio, D. Andrault, S. Courjault, G. Demazeau, High Pressure Res. 22 (2002) 535

[201] P. Moreau, F. Boucher, G. Goglio, D. Foy, V. Mauchamp, G. Ouvrard, Phys. Rev. B 73 (2006) 195111

[202] Y. Qiu, L. Gao, Chem. Commun. 18 (2003) 2378 
[203] Q. Li, R.Q. Zhang, L.D. Marks, W.J. Zhang, I. Bello, Diamond Relat. Mater. 11 (2002) 1416

[204] M. Groenewolt, M. Antonietti, Adv. Mater. 17 (2005) 1789

[205] R.C. De Vries, Mater. Res. Innovat. 1 (1997) 161

[206] A.T. Paxton, A. J. Craven, J.M. Gregg, D.W. McComb, J. of Microscopy 210 (2003) 35

[207] C.M. Sung, M. Sung, Mat. Chem. Phys. 43 (1996) 1

[208] Y.M. Li, M.B. Kruger, J.H. Nguyen, W.A. Caldwell, R. Jeanloz, Solid State Commun. 103 (1997) 107 


\section{Figure captions}

Figure 1: $\quad$ Predicted structures for dense $\mathrm{C}_{3} \mathrm{~N}_{4}$ polymorphs (C : full circles, $\mathrm{N}$ : open circles)

a) $\beta-\mathrm{C}_{3} \mathrm{~N}_{4}[4]$; b) $\alpha-\mathrm{C}_{3} \mathrm{~N}_{4}[40,41]$; c) Pseudocubic $\mathrm{C}_{3} \mathrm{~N}_{4}$ [42] ; d) Cubic $\mathrm{C}_{3} \mathrm{~N}_{4}$ [41]
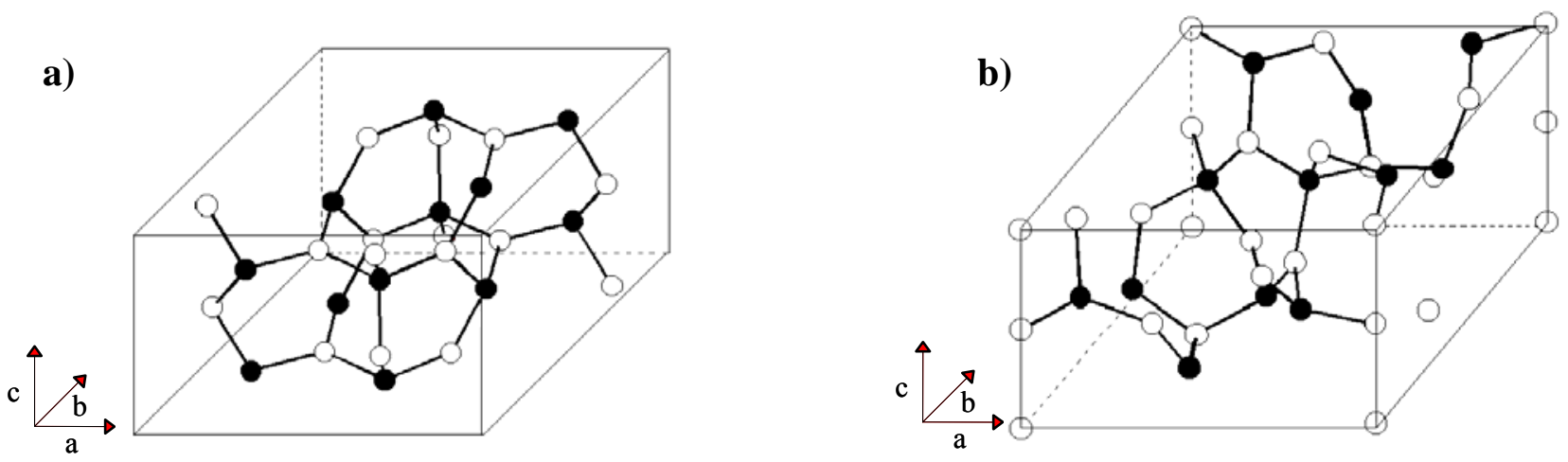

c)

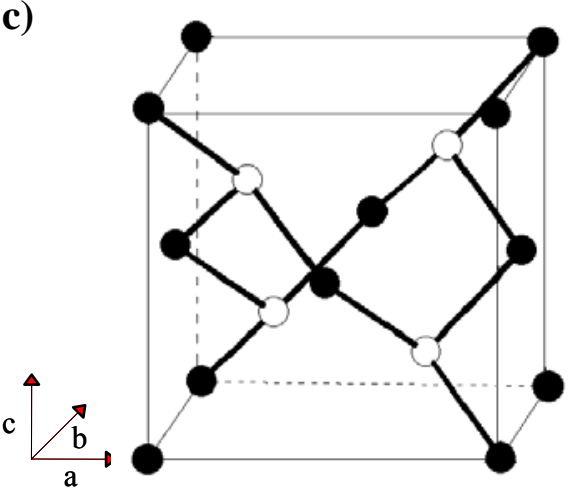

d)

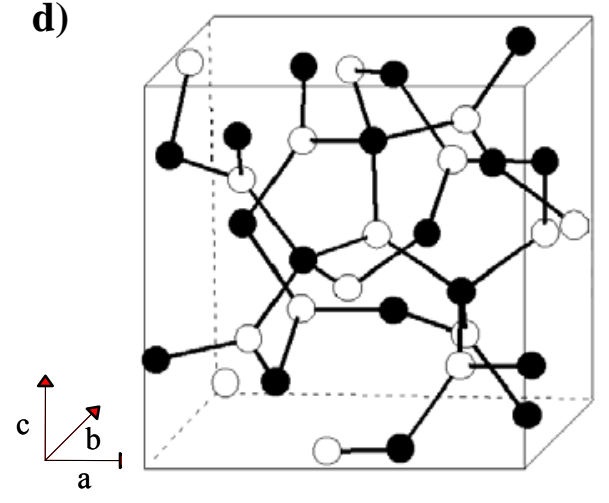


Figure 2: Graphitic planes in a) hexagonal [41] and b) orthorhombic [50 ] $\mathrm{C}_{3} \mathrm{~N}_{4}$

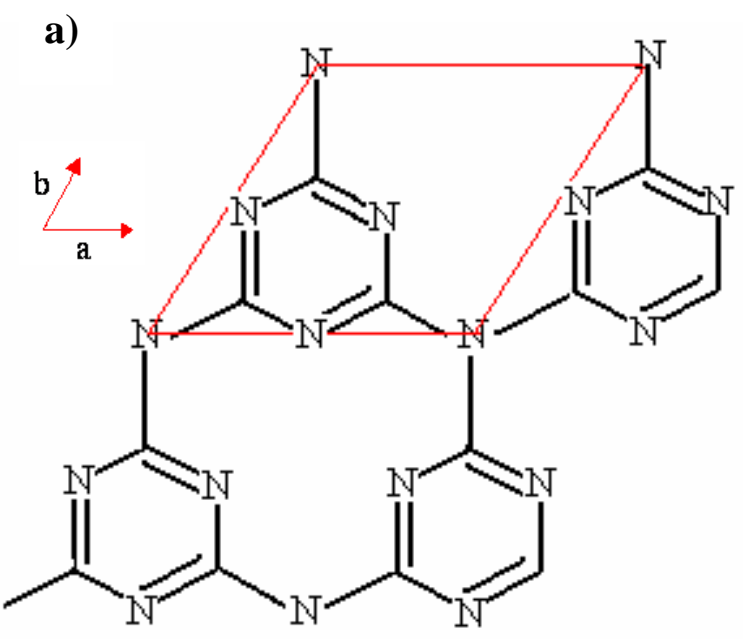

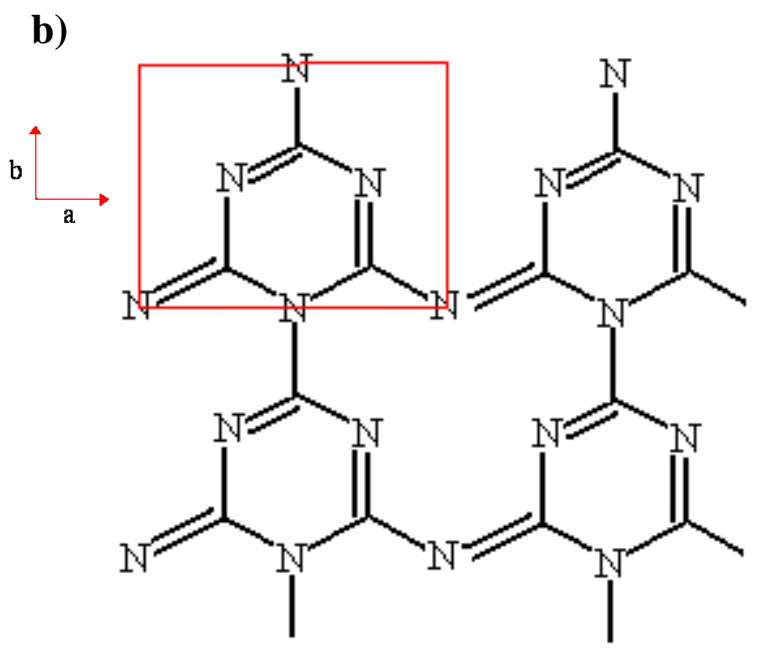


Table I - Interatomic distances (d), Bulk modulus (B) and Knoop hardness (H) of different light elements-based materials

\begin{tabular}{|c|c|c|c|c|}
\hline & $d(\dot{A})$ & $B(G P a)$ & $H\left(k g . m^{-2}\right)$ & Ref. \\
\hline Diamond & 1.54 & 443 & 8820 & {$[207]$} \\
\hline$c-B N$ & 1.58 & 367 & 4800 & {$[207]$} \\
\hline$\beta-S i_{3} N_{4}$ & 1.74 & 270 & $3470 *$ & {$[207,208]$} \\
\hline$\beta-C_{3} N_{4}$ & 1.47 & $427^{*}$ & $7300^{*}$ & {$[4,207]$} \\
\hline
\end{tabular}

* calculated value 
Table II - Predicted values of bulk modulus for $\mathrm{C}_{3} \mathrm{~N}_{4}$ polymorphs

\begin{tabular}{|c|c|c|c|c|c|c|c|c|}
\hline Ref. & {$[40]$} & {$[41]$} & [4] & [42] & {$[43]$} & {$[44]$} & [46] & [47] \\
\hline $\begin{array}{c}\text { Ab initio } \\
\text { calculation } \\
\text { method }\end{array}$ & MSFF & LDA & LDA & $\begin{array}{l}\text { MD-VCS } \\
\text { dynamics }\end{array}$ & $\begin{array}{l}\text { DFT- } \\
\text { LDA }\end{array}$ & LDA & LDA & LDA \\
\hline$\beta-C_{3} N_{4}$ & 250 & 451 & 427 & 437 & 557 & 427 & - & - \\
\hline$\alpha-C_{3} N_{4}$ & 189 & 425 & - & - & 567 & - & - & - \\
\hline $\begin{array}{l}\text { Pseudocubic } \\
C_{3} N_{4}\end{array}$ & - & 448 & - & 425 & 556 & - & 430 & - \\
\hline Cubic $C_{3} N_{4}$ & - & 496 & - & - & - & - & 480 & - \\
\hline Spinel $C_{3} N_{4}$ & - & - & - & - & - & - & - & 369 \\
\hline$g-C_{3} N_{4}$ & - & - & - & 51 & - & - & - & - \\
\hline
\end{tabular}


Table III - Direct synthesis under static high pressure

\begin{tabular}{|c|c|c|c|c|}
\hline Authors & Reagents & $\begin{array}{c}\text { Experimental } \\
\text { conditions } \\
\text { Pressure, temperature } \\
\end{array}$ & Obtained material & Ref. \\
\hline Zhang et al & $\begin{array}{l}\left(\mathrm{C}_{3} \mathrm{~N}_{3}\right)\left(\mathrm{NH}_{2}\right)_{3}+ \\
\mathrm{C}_{3} \mathrm{~N}_{3} \mathrm{Cl}_{3}\end{array}$ & $\begin{array}{l}1-1.5 \mathrm{GPa} \\
500-550^{\circ} \mathrm{C} \\
\end{array}$ & $\begin{array}{l}\mathrm{C}_{6} \mathrm{~N}_{9} \mathrm{H}_{3} \cdot \mathrm{HCl} \\
\text { Hexagonal graphitic structure } \\
\text { Excellent cristallinity }\end{array}$ & {$[107]$} \\
\hline Ma et al & $\left(\mathrm{C}_{3} \mathrm{~N}_{3}\right)\left(\mathrm{NH}_{2}\right)_{3}$ & $\begin{array}{l}5 \mathrm{GPa} \\
400-900^{\circ} \mathrm{C}\end{array}$ & $\begin{array}{l}-\mathrm{T}<500^{\circ} \mathrm{C}: \text { no significant } \\
\text { effect } \\
\text { - } \mathrm{T}>900^{\circ} \mathrm{C}: \text { amorphous carbon } \\
\text { with low } \mathrm{N} \text { content } \\
-\mathrm{T}=650^{\circ} \mathrm{C}: \text { graphitic } \mathrm{CN}_{\mathrm{x}} \\
\text { [good cristallinity], several } \\
\text { phases (melamine }+ \text { unknown), } \\
\text { good } \mathrm{C}: \mathrm{N}\end{array}$ & [108] \\
\hline Yu et al & $\mathrm{C}_{3} \mathrm{~N}_{4} \mathrm{H}_{4}$ & $\begin{array}{l}6 \mathrm{GPa} \\
1500^{\circ} \mathrm{C}\end{array}$ & $\begin{array}{l}\text { No nitrogen (graphite }+ \\
\text { diamond }+ \text { amorphous carbon) }\end{array}$ & $\begin{array}{l}{[109,} \\
110]\end{array}$ \\
\hline Andreyev et al & $\mathrm{C}_{6} \mathrm{Cl}_{6}+\mathrm{NaN}_{3}$ in excess & $\begin{array}{l}7.7 \mathrm{GPa} \\
400-500^{\circ} \mathrm{C}\end{array}$ & $\begin{array}{l}\text { Amorphous matrix containing } \\
\text { nanosized hexagonal graphitic } \\
\text { crystallites, whole } \mathrm{C}: \mathrm{N}=0.81 \\
\text { If } \mathrm{NaN}_{3} \text { not in excess : great } \\
\text { nitrogen deficit }\end{array}$ & {$[113]$} \\
\hline NGuyen et al & $\mathrm{C}_{60}+\mathrm{N}_{2}$ & $\begin{array}{l}30 \mathrm{GPa}, \\
\approx 2000^{\circ} \mathrm{C}\end{array}$ & $\begin{array}{l}\text { Dense cubic phase (quenched } \\
\text { sample) } \\
\text { Presence of Nitrogen? }\end{array}$ & [115] \\
\hline Dymont et al & Amorphous $\mathrm{C}_{\mathrm{x}} \mathrm{H}_{\mathrm{y}} \mathrm{N}_{\mathrm{z}}$ & $\begin{array}{l}7 \mathrm{GPa} \\
25-330^{\circ} \mathrm{C}\end{array}$ & $\begin{array}{l}\beta-\mathrm{C}_{4} \mathrm{~N}+\text { Graphite }+ \text { disordered } \\
\text { carbon material }\end{array}$ & $\begin{array}{l}{[117} \\
120]\end{array}$ \\
\hline
\end{tabular}


Table IV - Direct synthesis under dynamic high pressure (shockwaves experiments)

\begin{tabular}{|l|l|l|l|l|}
\hline Authors & Reagents & \multicolumn{1}{|c|}{$\begin{array}{c}\text { Experimental conditions } \\
\text { Estimated shock pressure } \\
\text { (temperature) }\end{array}$} & \multicolumn{1}{|c|}{ Obtained material } & Ref. \\
\hline Wixom & $\begin{array}{l}\text { Amorphous } \\
\text { hydrogenated } \\
\text { carbon nitrides }\end{array}$ & $60-250 \mathrm{GPa}$ & diamond & {$[121]$} \\
\hline Collins et al & $\begin{array}{l}\mathrm{NaN}(\mathrm{CN})_{2}+\mathrm{CI}_{4} \\
+\mathrm{NaN}_{3}\end{array}$ & $20-25 \mathrm{GPa}$ & $\begin{array}{l}\text { Carbon nitride } \\
\text { nanocrystallites embedded } \\
\text { in amorphous matrix with } \\
\text { sp bonding (cubic } \\
\text { symmetry, low } \mathrm{N} \text { content). }\end{array}$ & {$[122]$} \\
\hline Shibata et al & $\begin{array}{l}\mathrm{NaN}(\mathrm{CN})_{2}+\mathrm{CI}_{4} \\
\text { or } \mathrm{CBr}_{4}\end{array}$ & $13-45 \mathrm{GPa}$ & $\begin{array}{l}\text { Poorly crystallized } \\
\text { graphitic carbon nitride }(\mathrm{N} \\
\text { content lowest for higher } \\
\text { pressures })\end{array}$ & {$[123]$} \\
\hline Komatsu & $\begin{array}{l}\text { Graphitic } \mathrm{C}_{3} \mathrm{~N}_{2} \\
\text { Liu et al }\end{array}$ & $\begin{array}{l}\text { Graphitic carbon } \\
\text { nitride }(1) \\
\text { or } \mathrm{C}_{2} \mathrm{~N}_{4} \mathrm{H}_{4}(2)\end{array}$ & $\begin{array}{l}42-44 \mathrm{GPa}\left(2700^{\circ} \mathrm{C}\right) \\
\text { Cubic heterodiamond } \mathrm{C}_{2} \mathrm{~N}\end{array}$ & {$\left[12200-2400^{\circ} \mathrm{C}\right)(1)$} \\
\hline
\end{tabular}


Table V - Direct synthesis via mechanosynthesis experiments

\begin{tabular}{|c|c|c|c|c|}
\hline Authors & Reagents & $\begin{array}{l}\text { Experimental } \\
\text { conditions }\end{array}$ & Obtained material & Ref. \\
\hline Fahmy et al & Graphite $+\mathrm{NH}_{3}$ & $\begin{array}{l}\text { high energy ball } \\
\text { milling }\end{array}$ & $\begin{array}{l}\beta-\mathrm{C}_{3} \mathrm{~N}_{4} \text { embedded in } \\
\text { amorphous carbon }\end{array}$ & {$[136]$} \\
\hline Alcala et al & Graphite $+\mathrm{N}_{2}$ & $\begin{array}{l}\text { high energy ball } \\
\text { milling }\end{array}$ & $\begin{array}{l}\text { amorphization of graphite, } \\
\text { weak nitridation }\end{array}$ & [137] \\
\hline Yin et al & $\begin{array}{l}\text { Nanosized graphite }+ \\
\mathrm{NH}_{3}\end{array}$ & $\begin{array}{l}\text { high energy ball } \\
\text { milling }\end{array}$ & $\begin{array}{l}\text { nanosized } \beta-\mathrm{C}_{3} \mathrm{~N}_{4} \text { embedded } \\
\text { in amorphous carbon }\end{array}$ & [138] \\
\hline Yin et al & $\begin{array}{l}\text { Ball milled graphite } \\
+\mathrm{NH}_{3}\end{array}$ & $\begin{array}{l}\text { high energy ball } \\
\text { milling }\end{array}$ & $\beta-\mathrm{C}_{3} \mathrm{~N}_{4}$ & [139] \\
\hline Yin et al & $\begin{array}{l}\text { Ball milled graphite } \\
+\mathrm{NH}_{3}\end{array}$ & $\begin{array}{l}\text { high energy ball } \\
\text { milling followed by } \\
\text { treatment under } \mathrm{NH}_{3} \\
\text { flow at } 350-450^{\circ} \mathrm{C}\end{array}$ & $\beta-\mathrm{C}_{3} \mathrm{~N}_{4}$ nanorods & [140] \\
\hline Fei et al & $\begin{array}{l}\text { Ball milled graphite } \\
+\mathrm{NH}_{3} \text { flow }\end{array}$ & $\begin{array}{l}\text { Thermal treatment at } \\
1100^{\circ} \mathrm{C} \text { under } \mathrm{NH}_{3} \\
\text { flow of ball milled } \\
\text { graphite }\end{array}$ & $\begin{array}{l}\text { Graphitic } \mathrm{C}_{3} \mathrm{~N}_{4} \text {, excellent } \\
\text { crystallinity }\end{array}$ & [141] \\
\hline Gong et al & $\begin{array}{l}\text { Ball milled graphite } \\
+\mathrm{NH}_{3} \text { flow }\end{array}$ & $\begin{array}{l}\text {-Thermal treatment at } \\
1050^{\circ} \mathrm{C} \text { under } \mathrm{NH}_{3} \\
\text { flow of ball milled } \\
\text { graphite (1). } \\
\text {-Thermal treatment of } \\
\mathrm{g}-\mathrm{C}_{3} \mathrm{~N}_{4} \text { obtained in } \\
(1) \text { at } 1350^{\circ} \mathrm{C} \text { under } \\
\mathrm{NH}_{3} \text { flow (2) }\end{array}$ & $\begin{array}{l}\text { (1) Graphitic } \mathrm{C}_{3} \mathrm{~N}_{4} \text {, excellent } \\
\text { crystallinity } \\
\text { (2) pseudocubic } \mathrm{C}_{3} \mathrm{~N}_{4}\end{array}$ & [142] \\
\hline Zhao et al & $\mathrm{C}_{3} \mathrm{~N}_{3} \mathrm{Cl}_{3}+\mathrm{Li}_{3} \mathrm{~N}$ & $\begin{array}{l}\text { high energy ball } \\
\text { milling }\end{array}$ & Graphitic carbon nitride & [148] \\
\hline
\end{tabular}


Table VI - Direct conversion experiments

\begin{tabular}{|c|c|c|c|c|}
\hline Authors & Reagents & $\begin{array}{c}\text { Experimental } \\
\text { conditions } \\
\text { Pressure, temperature }\end{array}$ & Obtained material & Ref. \\
\hline Han et al & $\begin{array}{l}\text { Graphitic carbon } \\
\text { nitride }\end{array}$ & $\begin{array}{l}\text { Up to } 30 \mathrm{GPa}, \\
\text { room temperature or } \\
-196^{\circ} \mathrm{C}\end{array}$ & $\begin{array}{l}3 \text { abnormal changes in the } \\
\text { curve resistivity }=(\mathrm{P}) \text { at } \\
20^{\circ} \mathrm{C}\end{array}$ & {$[149]$} \\
\hline Solozhenko et al & $\begin{array}{l}\text { Turbostratic carbon } \\
\text { nitride }\end{array}$ & $\begin{array}{l}\mathrm{Up} \text { to } 17.8 \mathrm{GPa} \\
\mathrm{Up} \text { to } 1580^{\circ} \mathrm{C}\end{array}$ & Graphite/diamond $+\mathrm{N}_{2}$ & {$[147]$} \\
\hline Ming et al & $\begin{array}{l}\text { Graphitic carbon } \\
\text { nitride }\end{array}$ & $\begin{array}{l}\text { Up to } 38 \mathrm{GPa} \\
\mathrm{Up} \text { to } 2700^{\circ} \mathrm{C}\end{array}$ & $\begin{array}{l}\text { Unsolved structure before } \\
\text { quenching } \\
\text { Cubic phase }+ \text { diamond }+ \\
\text { graphitic phase }\end{array}$ & {$[151]$} \\
\hline
\end{tabular}


Table VII - Flux assisted conversion experiments

\begin{tabular}{|l|l|l|l|l|}
\hline \multicolumn{1}{|c|}{ Authors } & \multicolumn{1}{|c|}{ Reagents } & $\begin{array}{l}\text { Experimental conditions } \\
\text { Pressure, temperature, duration }\end{array}$ & \multicolumn{1}{|c|}{ Obtained material } & Ref. \\
\hline He et al & $\begin{array}{l}\mathrm{C}_{3} \mathrm{~N}_{4} \mathrm{H}_{4}+\mathrm{NiMnCo} \\
(\text { (catalyst") }\end{array}$ & $7 \mathrm{GPa}, 1400^{\circ} \mathrm{C}, 10 \mathrm{~min}$ & $\alpha-\mathrm{C}_{3} \mathrm{~N}_{4}+\beta-\mathrm{C}_{3} \mathrm{~N}_{4}$ & {$[154]$} \\
\hline Yu et al & $\begin{array}{l}\mathrm{C}_{3} \mathrm{~N}_{4} \mathrm{H}_{4}+\mathrm{NiMnCo} \\
(" c a t a l y s t ")\end{array}$ & $6 \mathrm{GPa}, 1500^{\circ} \mathrm{C}, 2.5 \mathrm{~min}$ & $\begin{array}{l}\text { Carbon polymorphs, no } \\
\text { nitrogen in the obtained } \\
\text { material }\end{array}$ & {$[110]$} \\
\hline
\end{tabular}


Table VIII- Solvothermal synthesis experiments

\begin{tabular}{|c|c|c|c|c|}
\hline Authors & Reagents & $\begin{array}{c}\text { Experimental } \\
\text { conditions } \\
\text { Pressure, } \\
\text { temperature } \\
\end{array}$ & Obtained material & Ref. \\
\hline Montigaud et al & $\begin{array}{l}\left(\mathrm{C}_{3} \mathrm{~N}_{3}\right)\left(\mathrm{NH}_{2}\right)_{3}+\mathrm{C}_{3} \mathrm{~N}_{3} \mathrm{Cl}_{3} \\
\text { Ethyl-di-isopropylamine } \\
\text { as solvent }\end{array}$ & $\begin{array}{l}140 \mathrm{MPa} \\
250^{\circ} \mathrm{C}\end{array}$ & $\begin{array}{l}\text { Graphitic carbon nitride poorly } \\
\text { crystallized } \\
\mathrm{C}: \mathrm{N}=0.78\end{array}$ & [99] \\
\hline Li et al & $\begin{array}{l}\left(\mathrm{C}_{3} \mathrm{~N}_{3}\right)\left(\mathrm{NH}_{2}\right)_{3}+\mathrm{C}_{3} \mathrm{~N}_{3} \mathrm{Cl}_{3} \\
+\mathrm{Ni} \\
\text { (1)benzene as solvent } \\
\text { (2) no solvent }\end{array}$ & $\begin{array}{l}\text { Autogenous } \\
\text { pressure } \\
400^{\circ} \mathrm{C} \text { in } \\
\text { autoclave in } \\
\text { both cases }\end{array}$ & $\begin{array}{l}\text { Nitrogen-rich graphitic carbon } \\
\text { nitrides hollow spheres (10-40 } \\
\mathrm{nm}) \\
\mathrm{C}: \mathrm{N}=0.625\end{array}$ & {$[175]$} \\
\hline Montigaud et al & $\begin{array}{l}\left(\mathrm{C}_{3} \mathrm{~N}_{3}\right)\left(\mathrm{NH}_{2}\right)_{3} \\
\text { Hydrazine as solvent }\end{array}$ & $\begin{array}{l}\mathrm{GPa}, \\
800-850^{\circ} \mathrm{C}\end{array}$ & $\begin{array}{l}\text { Graphitic } \mathrm{C}_{3} \mathrm{~N}_{3.36} \mathrm{O}_{0.14} \mathrm{H}_{1.24} \text { well } \\
\text { crystallized }\end{array}$ & $\begin{array}{l}176, \\
177]\end{array}$ \\
\hline Cao et al & $\begin{array}{l}\mathrm{CCl}_{4}+\mathrm{NH}_{3} \text { (in presence } \\
\text { of iron) }\end{array}$ & $\begin{array}{l}\mathrm{P} \text { above } \mathrm{MPa} \\
300-500^{\circ} \mathrm{C}\end{array}$ & $\begin{array}{l}\text { Poorly crystallized materials } \\
\text { with } \mathrm{C}-\mathrm{N} \text { bonding, } \mathrm{N} \text { content } \\
\text { increases with temperature }\end{array}$ & {$[178]$} \\
\hline Bai et al & $\begin{array}{l}\mathrm{CCl}_{4}+\mathrm{NH}_{4} \mathrm{Cl} \\
\left(\mathrm{NH}_{3} \text { generated in situ }\right) \\
\end{array}$ & $\begin{array}{l}\text { Autogenous } \mathrm{P} \\
400^{\circ} \mathrm{C} \\
\end{array}$ & $\begin{array}{l}\text { Well crystallized graphitic } \\
\mathrm{C}_{3} \mathrm{~N}_{4}\end{array}$ & {$[179]$} \\
\hline Fu et al & $\begin{array}{l}\mathrm{C}_{3} \mathrm{~N}_{3} \mathrm{Cl}_{3}+\mathrm{Li}_{3} \mathrm{~N} \\
\text { (benzene as solvent) }\end{array}$ & $5 \mathrm{MPa}, 350^{\circ} \mathrm{C}$ & $\begin{array}{l}\text { Carbon nitride with } \beta-\mathrm{C}_{3} \mathrm{~N}_{4} \\
\text { structure embedded in } \\
\text { amorphous powder } \\
\text { Loss of nitrogen }\end{array}$ & {$[180]$} \\
\hline Cao et al & $\begin{array}{l}\mathrm{C}_{3} \mathrm{~N}_{3} \mathrm{Cl}_{3}+\mathrm{Li}_{3} \mathrm{~N} \\
\text { (benzene as solvent) }\end{array}$ & $\begin{array}{l}3-15 \mathrm{MPa} \\
200-500^{\circ} \mathrm{C}\end{array}$ & $\begin{array}{l}\text { - if } 300<\mathrm{T}<400^{\circ} \mathrm{C}: \text { mixture of } \\
\text { phases with } \alpha \text { - and } \beta-\mathrm{C}_{3} \mathrm{~N}_{4} \\
\text { structures; presence of } \\
\text { amorphous matrix. } \\
\text { - if } \mathrm{T}<300^{\circ} \mathrm{C} \text { : amorphous } \\
\text { system }\end{array}$ & $\begin{array}{l}178, \\
181]\end{array}$ \\
\hline Guo et al & $\begin{array}{l}\mathrm{C}_{3} \mathrm{~N}_{3} \mathrm{Cl}_{3}+\mathrm{NH}_{4} \mathrm{Cl} \text { in } \\
\text { presence of iron } \\
\text { (benzene as solvent) }\end{array}$ & $\begin{array}{l}\text { Autogenous } \mathrm{P} \\
300^{\circ} \mathrm{C}\end{array}$ & $\begin{array}{l}\text { Graphitic polymeric } \\
{\left[\left(\mathrm{C}_{3} \mathrm{~N}_{3}\right)_{2}\left(\mathrm{NH}_{3}\right)\right]_{\mathrm{n}} \text { network }}\end{array}$ & [182] \\
\hline Guo et al & $\begin{array}{l}\mathrm{C}_{3} \mathrm{~N}_{3} \mathrm{Cl}_{3}+\mathrm{NaN}_{3} \\
\text { (benzene as solvent) }\end{array}$ & $\begin{array}{l}\text { Autogenous } \mathrm{P} \\
220^{\circ} \mathrm{C} \\
\end{array}$ & $\begin{array}{l}\text { Graphitic carbon nitride } \\
\text { nanotubes with } \mathrm{C}: \mathrm{N}=0.8\end{array}$ & {$[183]$} \\
\hline Guo et al & $\begin{array}{l}\mathrm{C}_{3} \mathrm{~N}_{3} \mathrm{Cl}_{3}+\mathrm{NaNH}_{2} \\
\text { (benzene as solvent) }\end{array}$ & $\begin{array}{l}\text { Autogenous P } \\
180-220^{\circ} \mathrm{C}\end{array}$ & $\begin{array}{l}\text { Graphitic carbon nitride } \\
\text { nanocrystallites with } \mathrm{C}: \mathrm{N}= \\
0.72\end{array}$ & {$[184]$} \\
\hline Mu et al & $\begin{array}{l}\mathrm{C}_{3} \mathrm{~N}_{3} \mathrm{Cl}_{3}+\mathrm{Na} \\
\text { (cyclohexane as solvent) }\end{array}$ & $\begin{array}{l}\text { Autogenous } \mathrm{P} \\
250^{\circ} \mathrm{C}\end{array}$ & $\begin{array}{l}\text { Polymeric carbon nitride } \\
\text { powder with } \mathrm{C}: \mathrm{N}=1: 1, \\
\text { spherical particles }\end{array}$ & {$[185]$} \\
\hline Li et al & $\begin{array}{l}\mathrm{C}_{3} \mathrm{~N}_{3} \mathrm{Cl}_{3}+\mathrm{Na} \\
\text { With (1) or without } \mathrm{NiCl}_{2} \\
\text { (2) } \\
\text { (cyclohexane as solvent) }\end{array}$ & $\begin{array}{l}1.8-4.5 \mathrm{Mpa} \\
230-290^{\circ} \mathrm{C}\end{array}$ & $\begin{array}{l}\text { Carbon nitride nanotube } \\
\text { bundles (1) } \\
\text { Carbon nitride nanoribbons (2) }\end{array}$ & {$[186]$} \\
\hline
\end{tabular}


Table IX - Synthesis under moderate conditions

\begin{tabular}{|c|c|c|c|c|}
\hline Authors & Reagents & $\begin{array}{l}\text { Experimental conditions } \\
\text { temperature }\end{array}$ & Obtained material & Ref. \\
\hline Jürgens et al & $\begin{array}{l}\text { Melamine or } \\
\text { dicyandiamide or } \\
\text { ammonium } \\
\text { dicyanamide or } \\
\text { cyanamide }\end{array}$ & $\begin{array}{l}\text { Heating up to } 450^{\circ} \mathrm{C}(1) \\
\text { Heating of melem at } \\
580^{\circ} \mathrm{C}(2)\end{array}$ & $\begin{array}{l}\text { - Melem (parallel layers of } \\
\mathrm{C}_{6} \mathrm{~N}_{7}\left(\mathrm{NH}_{2}\right)_{3} \text {, nearly planar } \\
\text { molecule) }(1) \\
\text { - Graphitic carbon nitride (2) }\end{array}$ & {$[188]$} \\
\hline Lotsch et al & $\begin{array}{l}\text { Guanylurea } \\
\text { dicyanamide }\end{array}$ & $\begin{array}{l}\text { Heating at } 380^{\circ} \mathrm{C} \mathrm{(1)} \\
\text { Heating at } 490^{\circ} \mathrm{C} \mathrm{(2)}\end{array}$ & $\begin{array}{l}- \text {-Melem } \mathrm{C}_{6} \mathrm{~N}_{7}\left(\mathrm{NH}_{2}\right)_{3}(1) \\
\text {-Graphitic carbon nitride (2) }\end{array}$ & [189] \\
\hline Lotsch et al & tricyanomelaminates & Heating at $380-500^{\circ} \mathrm{C}$ & $\begin{array}{l}\text { Melem then graphitic } \\
\text { hydrogenated carbon nitride }\end{array}$ & [190] \\
\hline Gillan & $\left(\mathrm{C}_{3} \mathrm{~N}_{3}\right)\left(\mathrm{N}_{3}\right)_{3}$ & $\begin{array}{l}180^{\circ} \mathrm{C} \text { (slow heating), } \\
\text { reaction vessel } \\
\text { Autogenous nitrogen } \\
\text { pressure (1) or starting } \\
\text { pressure of } 6 \text { atm (2) }\end{array}$ & $\begin{array}{l}\text {-Amorphous } \mathrm{C}_{3} \mathrm{~N}_{3.9} \mathrm{H}_{1.4} \mathrm{O}_{0.2} \\
\text { (1) } \\
\text {-Amorphous } \mathrm{C}_{3} \mathrm{~N}_{4.7} \mathrm{H}_{1.3} \mathrm{O}_{0.4} \\
\text { (2) }\end{array}$ & {$[143]$} \\
\hline Miller et al & $\left(\mathrm{C}_{3} \mathrm{~N}_{3}\right)(\mathrm{NHCl})_{3}$ & $\begin{array}{l}\text { External heating above } \\
185^{\circ} \mathrm{C} \text { or heated filament }\end{array}$ & $\begin{array}{l}\text { Poorly crystallized nitrogen- } \\
\text { rich carbon nitride }\end{array}$ & [144] \\
\hline Komatsu & $\begin{array}{l}\left(\mathrm{C}_{3} \mathrm{~N}_{3}\right)\left(\mathrm{NH}_{2}\right)_{3} \text { in } \\
\text { presence of } \mathrm{ZnCl}{ }_{2}\end{array}$ & $650^{\circ} \mathrm{C}$, autoclave & $\begin{array}{l}\text { Well-crystallized graphitic } \\
\text { nitrogen rich carbon nitride }\end{array}$ & [145] \\
\hline Zhao et al & $\left(\mathrm{C}_{3} \mathrm{~N}_{3}\right)\left(\mathrm{NH}_{2}\right)_{3}$ & $\begin{array}{l}300^{\circ} \mathrm{C} \text { then } 600^{\circ} \mathrm{C} \text { in } \\
\text { atmosphere followed by } \\
300^{\circ} \mathrm{C} \text { then } 650^{\circ} \mathrm{C} \text { in } \\
\text { vacuum }\end{array}$ & $\begin{array}{l}\text { Turbostratic graphitic } \\
\text { nitrogen rich carbon nitride }\end{array}$ & {$[146]$} \\
\hline Guo et al & $\begin{array}{l}\mathrm{C}_{3} \mathrm{~N}_{3} \mathrm{Cl}_{3}+\mathrm{NaNH}_{2} \\
\text { (1) or K (2) or } \mathrm{NaN}_{3} \\
\text { (3) }\end{array}$ & $\begin{array}{l}(1) 220^{\circ} \mathrm{C},(2) 300^{\circ} \mathrm{C},(3) \\
380^{\circ} \mathrm{C} \\
\text { Solvent-free autoclave }\end{array}$ & $\begin{array}{l}\text { Graphitic carbon nitrides : } \\
\mathrm{CN}_{1.20} \text { lamellar structure (1), } \\
\mathrm{CN}_{0.96} \text { lamellar structure (2), } \\
\mathrm{CN}_{0.25} \text { onion-like } \\
\text { microstructure (3) }\end{array}$ & [193] \\
\hline Oku et al & $\mathrm{C}_{3} \mathrm{~N}_{3} \mathrm{Cl}_{3}+\mathrm{Li}_{3} \mathrm{~N}$ & $\begin{array}{l}220^{\circ} \mathrm{C}, \mathrm{N}_{2} \text { atmosphere, } \\
\text { PTFE vessel }\end{array}$ & $\begin{array}{l}\text { Nanocrystalline phases } \\
\text { containing } \mathrm{C}, \mathrm{O} \text { and } \mathrm{H} \\
\text { encapsulated in carbon } \\
\text { nitride nanocages }\end{array}$ & [195] \\
\hline $\begin{array}{l}\text { Khabashesku } \\
\text { et al }\end{array}$ & $\mathrm{C}_{3} \mathrm{~N}_{3} \mathrm{Cl}_{3}+\mathrm{Li}_{3} \mathrm{~N}$ & $\begin{array}{l}380^{\circ} \mathrm{C} \text {, Pyrex glass } \\
\text { ampoule or stainless steel } \\
\text { reactor or } 300^{\circ} \mathrm{C} \text { in Monel } \\
\text { reactor }\end{array}$ & $\begin{array}{l}\text { Amorphous nitrogen-rich } \\
\text { carbon nitride }\end{array}$ & [196] \\
\hline $\begin{array}{l}\text { Zimmerman } \\
\text { et al }\end{array}$ & $\begin{array}{l}\mathrm{C}_{3} \mathrm{~N}_{3} \mathrm{Cl}_{3}+\mathrm{Li}_{3} \mathrm{~N} \text { in } \\
\text { presence of porous } \\
\text { substrate }\end{array}$ & $500^{\circ} \mathrm{C}$, steel reactor & $\begin{array}{l}\text { Carbon nitride hollow } \\
\text { spheres }\end{array}$ & [197] \\
\hline Gu et al & $\mathrm{C}_{3} \mathrm{~N}_{3} \mathrm{Cl}_{3}+\mathrm{CaCN}_{2}$ & $\begin{array}{l}500-550^{\circ} \mathrm{C} \text {, stainless } \\
\text { autoclave } \\
\text { Drying in vacuum at } 60^{\circ} \mathrm{C}\end{array}$ & $\begin{array}{l}\text { Graphitic carbon nitride }+ \\
\text { graphite }\end{array}$ & [198] \\
\hline Goglio et al & $\begin{array}{l}\text { Thiosemicarbazide } \\
\mathrm{NH}_{2} \mathrm{CSNHNH}_{3} \\
\end{array}$ & $590^{\circ} \mathrm{C}$, argon flow & $\begin{array}{l}\text { Graphitic nitrogen-rich } \\
\text { carbon nitride }\end{array}$ & [200] \\
\hline Qiu et al & $\mathrm{CCl}_{4}+\left(\mathrm{CH}_{2} \mathrm{NH}_{2}\right)_{2}$ & $\begin{array}{l}\text { Reflux at } 90^{\circ} \mathrm{C} \text {, drying, } \\
\text { thermal treatment under } \\
\mathrm{N}_{2} \text { or } \mathrm{NH}_{3} \text { flow at } 600^{\circ} \mathrm{C}\end{array}$ & $\begin{array}{l}\text { Crystallites with } \alpha-C_{3} \mathrm{~N}_{4} \\
\text { structure embedded in } \\
\text { turbostratic carbon nitride } \\
\text { matrix (low N content) }\end{array}$ & {$[202]$} \\
\hline $\begin{array}{l}\text { Groenewolt } \\
\text { et al }\end{array}$ & $\begin{array}{l}\mathrm{CH}_{2} \mathrm{~N}_{2} \\
\text { Template process } \\
\text { with silica matrix }\end{array}$ & $\begin{array}{l}\text { Soaking of silica matrix } \\
\text { by } \mathrm{CH}_{2} \mathrm{~N}_{2} \text {, then heating of } \\
\text { the monolith under } \mathrm{N}_{2} \text { at } \\
550^{\circ} \mathrm{C} \text {. }\end{array}$ & $\begin{array}{l}\text { Graphitic carbon nitride } \\
\text { nanospheres }\end{array}$ & {$[204]$} \\
\hline
\end{tabular}

